\title{
Occupational Radiation Exposure at Agreement State-Licensed Materials Facilities, 1997-2010
}

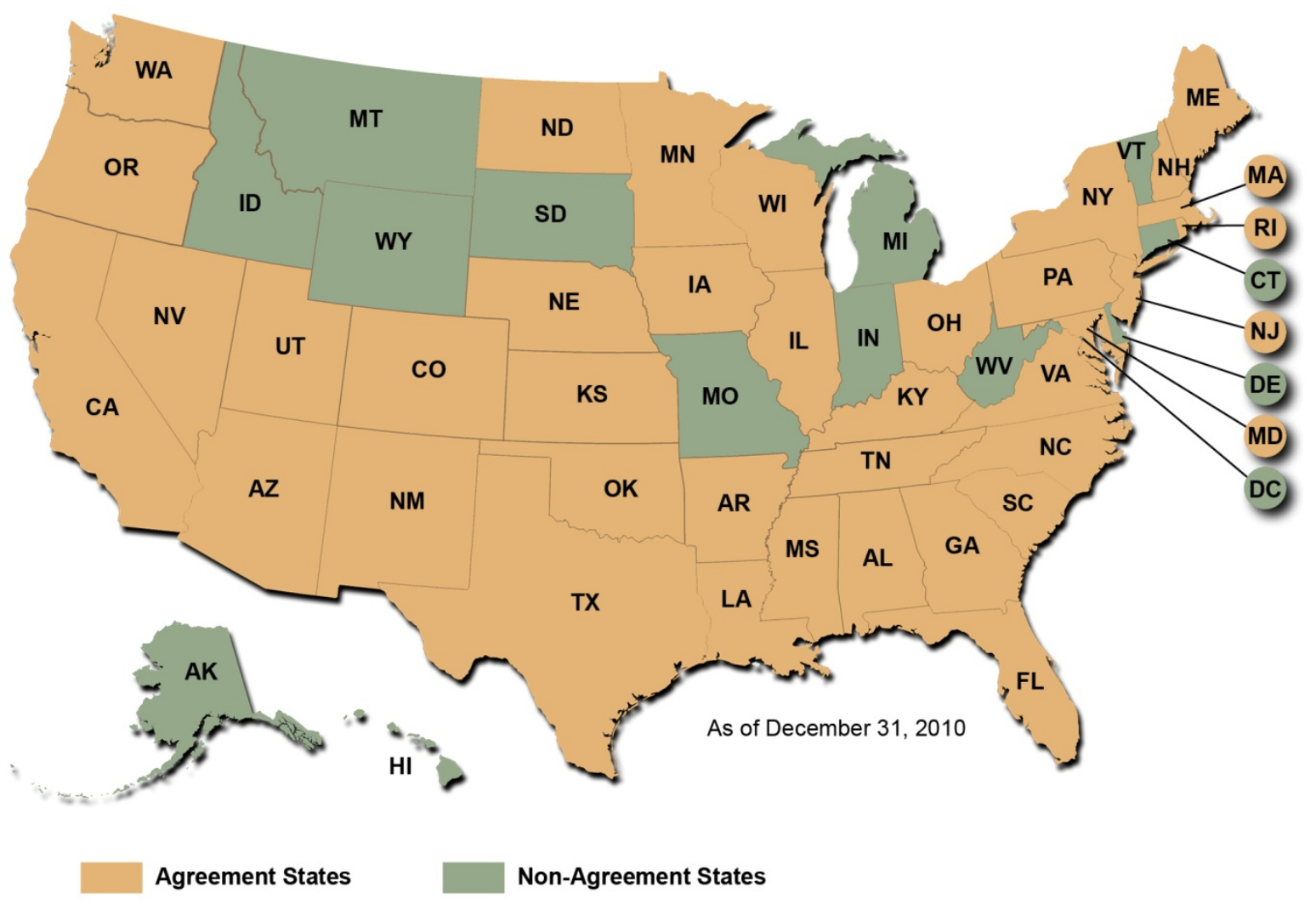





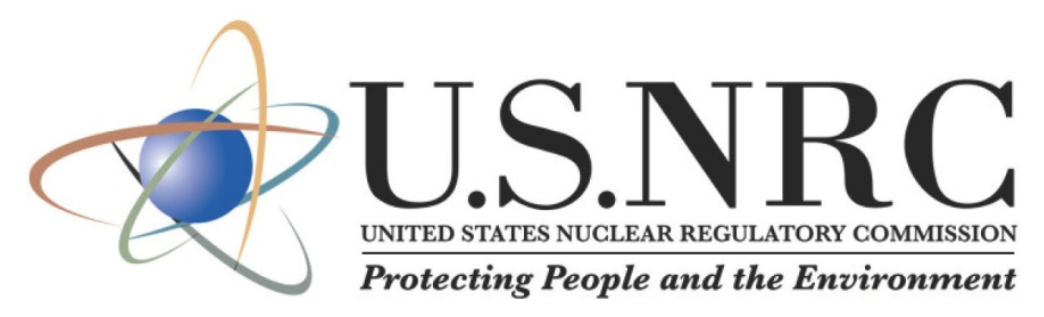

\section{Occupational Radiation Exposure at Agreement State-Licensed Materials Facilities, 1997-2010}

Manuscript Completed: April 2012

Date Published: July 2012

Prepared by:
D.E. Lewis
D.A. Hagemeyer
Y.U. McCormick*

*Oak Ridge Associated Universities 100 ORAU Way Oak Ridge, TN 37830 



\section{EDITOR'S NOTE}

Staff in the U.S. Nuclear Regulatory Commission Offices of Federal and State Materials and Environmental Management Programs and Nuclear Regulatory Research assisted in the preparation of this report, serving as technical reviewers. In addition, members from the Conference of Radiation Control Program Directors, Inc. and the Organization of Agreement States provided technical comments on this report.

Comments should be directed to:

Doris E. Lewis

REIRS Project Manager

Office of Nuclear Regulatory Research

U.S. Nuclear Regulatory Commission

Washington, DC 20555

Phone: 301-251-7559

E-mail Address: Doris.Lewis@nrc.gov

\section{Paperwork Reduction Act Statement}

This NUREG contains and references information collection requirements that are subject to the Paperwork Reduction Act of 1995 (44 U.S.C. 3501 et seq.). These information collections were approved by the Office of Management and Budget, approval number 3150-0014.

\section{Public Protection Notification}

The NRC may not conduct or sponsor, and a person is not required to respond to, a request for information or an information collection requirement unless the requesting document displays a currently valid OMB control number. 



\section{TABLE OF CONTENTS}

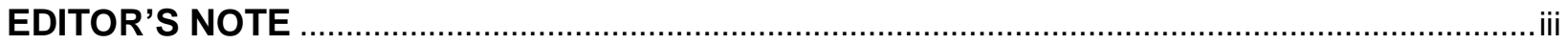

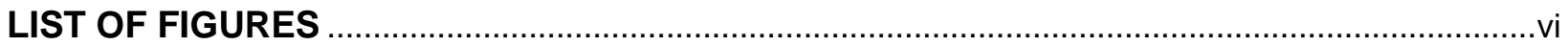

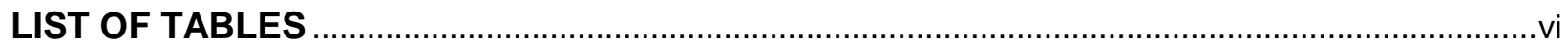

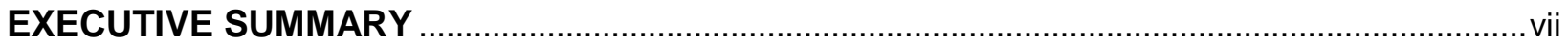

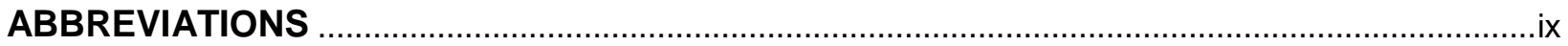

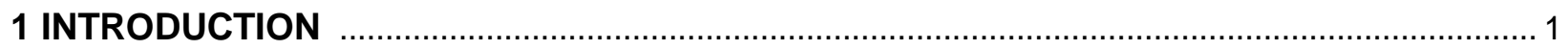

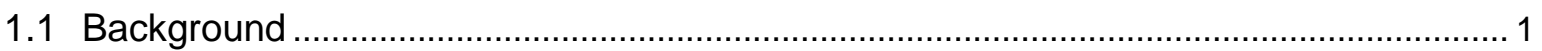

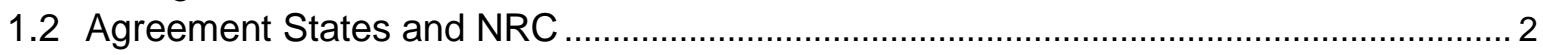

1.3 Agreement State Compatibility with NRC Regulations .............................................. 2

2 LIMITATIONS OF THE DATA

3 ANNUAL PERSONNEL MONITORING REPORTS …....................................................... 7

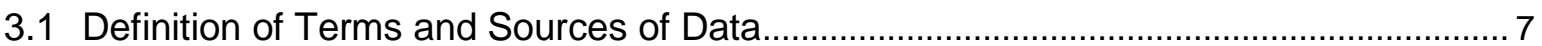

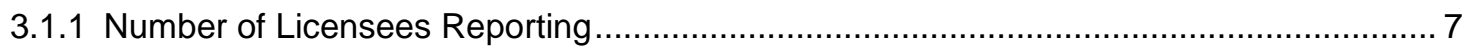

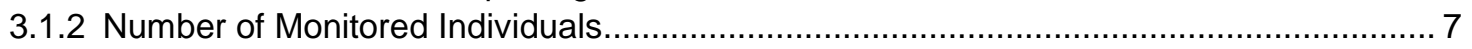

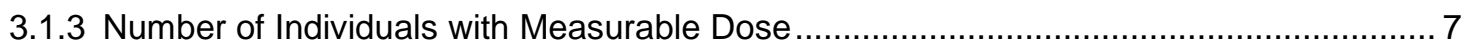

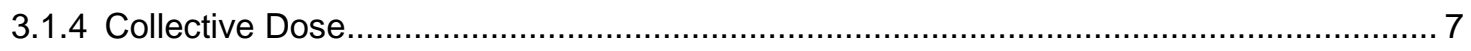

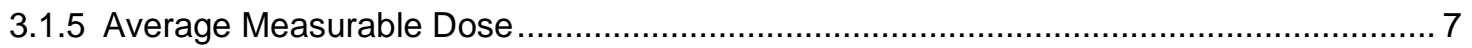

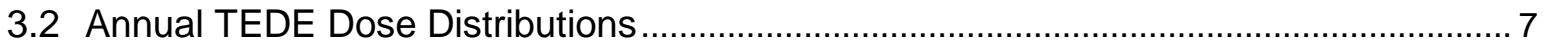

3.3 Summary of Occupational Dose Data by License Category ....................................... 12

3.3.1 Industrial Radiography Licenses, Fixed Locations, and Temporary Job Sites ............... 12

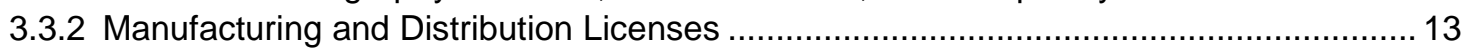

3.3.3 Waste Disposal Burial and Service Processing and/or Repackaging ........................... 15

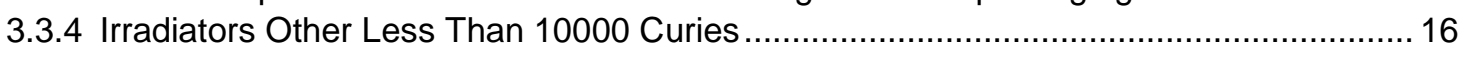

3.3.5 Well Logging Byproduct and/or Special Nuclear Material (SNM) Sealed

Sources Only and Measuring Systems Portable Gauges .......................................... 17

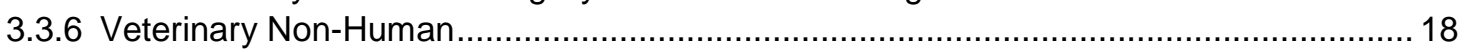

3.3.7 Instrument Calibration Service Only - Source $>100$ Curies/Other Services................... 18

4 EXPOSURES TO PERSONNEL IN EXCESS OF REGULATORY LIMITS .......................... 21

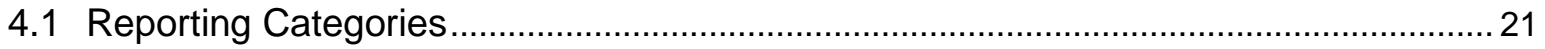

4.2 Summary of Occupational Radiation Doses in Excess of NRC Regulatory Limits ...... 22

4.3 Summary of Annual Dose Distributions for Certain Agreement State Licensees ........ 23

4.4 Maximum Occupational Radiation Doses Below NRC Regulatory Limits .................... 25

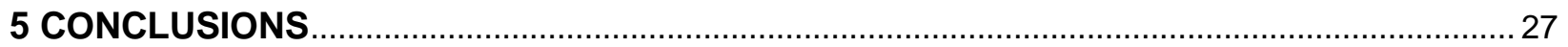

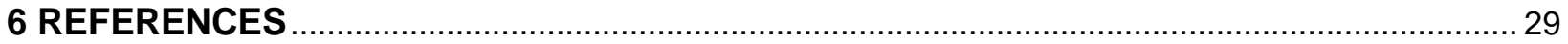

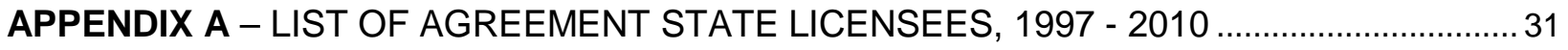




\section{LIST OF FIGURES}

Figure 3.1 Annual Values for Industrial Radiography Licensees, 1997-2010 ........................ 12

Figure 3.2 Annual Values for Manufacturing \& Distribution and Nuclear Pharmacies, 1998-2010

Figure 3.3 Annual Values for Waste Disposal Burial and Service Processing and/or Repackaging, 1997-2010 15

Figure 3.4 Annual Values for Irradiators Other Less than 10000 Curies, 1997-2010 16

Figure 3.5 Annual Values for Well Logging Measuring Systems, 1997-2010 17

Figure 3.6 Annual Values for Instrument Calibration and Other Services, 1997-2010 19

\section{LIST OF TABLES}

Table 3.1 Annual Exposure Information, 1997-2010 ............................................................ 8

Table 3.2 Summary Distribution of Collective TEDE by License Category, 1997-2010 ........... 11

Table 3.3 Annual Exposure Information for Industrial Radiographers, 2008-2010 _................ 13

Table 3.4 Annual Exposure Information for Manufacturing and Distribution, 2008-2010......... 14

Table 3.5 Annual Exposure Information for Waste Disposal Burial and Service Processing

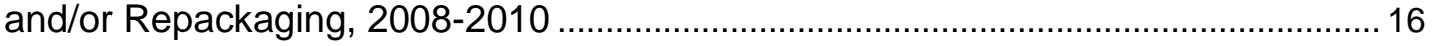

Table 3.6 Annual Exposure Information for Irradiators Other Less Than 10000 Curies, 2008-2010.

Table 3.7 Annual Exposure Information for Well Logging Byproduct and/or SNM Sealed Sources Only and Measuring Systems Portable Gauges, 2008-2010 18

Table 3.8 Annual Exposure Information for Veterinary Non-Human, Instrument Calibration Service, Other Services, 2008-2010

Table 4.1 Summary of Annual Distributions for Certain Agreement State Licensees, 1997-2010

Table 4.2 Maximum Occupational Exposures for Each Exposure Category, 1997-2010 26 


\section{EXECUTIVE SUMMARY}

On December 18, 2008, the U.S. Nuclear Regulatory Commission (NRC) staff provided a Policy Issue Notation Vote Paper, SECY-08-0197 (ADAMS Accession No. ML083360582), to the Commission which presented the regulatory and technical options of moving, or not moving, towards a greater degree of alignment of the NRC radiation protection regulatory framework with the International Commission on Radiological Protection (ICRP) Publication 103. In a Staff Requirements Memorandum dated April 2, 2009, SRM-SECY-08-0197 (ML090920103), the Commission approved the staff's recommendation to immediately begin engagement with stakeholders and interested parties to initiate development of the technical basis for possible revision of the NRC's radiation protection regulations, as appropriate and where scientifically justified. As part of the outreach to stakeholders and interested parties, NRC staff noted the need to expand the current occupational radiation dose information contained in the Radiation Exposure Information and Reporting System (REIRS) database.

Seven categories of NRC licensees are required to annually report on individual occupational exposure in accordance with Title 10 of the Code of Federal Regulations, Section 20.2206 (10 CFR 20.2206, "Reports of Individual Monitoring"). Specifically, these categories include commercial nuclear power reactors; industrial radiographers; fuel processors (including uranium enrichment facilities), fabricators, and reprocessors; manufacturing and distribution of byproduct material; independent spent fuel storage installations; facilities for land disposal of low-level waste; and geologic repositories for high-level waste. Because NRC has not licensed any geologic repositories for high-level waste and no NRC-licensed low-level waste disposal facilities are currently in operation, only five categories of NRC licensees report occupational radiation dose information to the REIRS database. Annually, approximately 170,000 reports on individual occupational radiation exposure are reported by NRC licensees.

The NRC's Statement on Adequacy and Compatibility of Agreement State Programs and Management Directive 5.9, "Adequacy and Compatibility of Agreement State Programs" (ML041770094) identifies the criteria that the NRC uses to determine those program elements that should be adopted by an Agreement State to maintain an adequate and compatible program. Although 10 CFR 20.2206 specifies certain categories of NRC licensees to report on individual occupational radiation exposure data, this requirement for Agreement States and their licensees is designated as a Compatibility Category D provision. Agreement States are not required to adopt Compatibility Category $\mathrm{D}$ provisions and reporting occupational radiation dose information is strictly voluntary on the part of the Agreement State Radiation Control Program. However, some Agreement State licensees voluntarily report their occupational radiation dose information to the NRC. Annually, approximately 3,500 reports on individual occupational radiation exposure are reported by Agreement State licensees and included in the REIRS database.

To expand the Agreement State occupational radiation dose information contained in the REIRS database, on August 6, 2010 NRC sent a letter (ML102100390) to Agreement State Radiation Control Programs. This letter requested occupational radiation dose information from industrial 
radiography and nuclear pharmacy licensees, from the 2000 through 2009 monitoring years. These Agreement State licensee categories were asked to submit their data to help expand the current data from NRC licensees in these two licensee categories. This information can be used by NRC staff to inform decisions regarding potential changes to the agency's current annual occupational dose limit of 5 rem to coincide with the ICRP 103 recommendation of a 2 rem annual limit.

While the NRC letter requested dose data from the 2000 through 2009 monitoring years, NRC staff recognized the need to conduct a comprehensive analysis of the Agreement State occupational radiation dose data contained in the REIRS database. This analysis would provide NRC staff with information regarding occupational dose trends among Agreement State licensees for comparison between NRC licensees within the same licensee categories. This report summarizes the Agreement State occupational radiation exposure data maintained in the REIRS database from 1997 through 2010. The information contained in this report was compiled from the annual reports submitted by nine Agreement State licensee categories. These Agreement State licensee categories are industrial radiographers; manufacturers and distributors of byproduct material; waste disposal service processing and/or repackaging; irradiators; well logging companies; sealed source facilities; measuring systems and portable gauge facilities; calibration services; and veterinary (non-human) facilities. The annual reports submitted by these licensees consist of radiation exposure records for each monitored individual. These records were analyzed for trends and are presented in this report in terms of the collective dose and the dose distribution among the monitored individuals.

From 1997 through 2010, annual reports were received from a total of 312 Agreement State licensees. Compilations of the reports submitted by the 312 Agreement State licensees indicated that 40,622 individuals were monitored, 31,704 of whom received a measurable dose (Table 3.1). The collective dose incurred by these individuals was 5,908 person-rem. The average measurable dose per individual for all Agreement State licensees calculated from the reported data was $0.19 \mathrm{rem}$. The average measurable dose is defined as the total collective dose equivalent (TEDE) divided by the number of individuals receiving a measurable dose. 


\section{ABBREVIATIONS}

AEA Atomic Energy Act

ALARA as low as reasonably achievable

CDE committed dose equivalent

CEDE committed effective dose equivalent

CRCPD Conference of Radiation Control Program Directors, Inc.

CSU chemistry synthesis unit

DDE deep dose equivalent

FSME Office of Federal and State Materials and Environmental Management Programs

ICRP International Commission on Radiological Protection

LDE lens dose equivalent

M\&D Manufacturing and Distribution

$\mathrm{mSv} \quad$ millisievert

ND non-detectable

NMED Nuclear Material Events Database

NRC U.S. Nuclear Regulatory Commission

OAS Organization of Agreement States

REIRS Radiation Exposure Information and Reporting System

RES Office of Nuclear Regulatory Research

SDE-ME shallow dose equivalent to the maximally exposed extremity

SDE-WB shallow dose equivalent to the whole body

SI international system of units

SNM special nuclear material

SRM Staff Requirements Memorandum

Sv unit of sievert

TEDE total effective dose equivalent

TODE total organ dose equivalent 



\section{INTRODUCTION}

\subsection{Background}

On December 18, 2008, the U.S. Nuclear Regulatory Commission (NRC) staff provided a Policy Issue Notation Vote Paper, SECY-08-0197 [Ref. 1], to the Commission which presented the regulatory and technical options of moving, or not moving, towards a greater degree of alignment of the NRC radiation protection regulatory framework with the International Commission on Radiological Protection Publication 103 [Ref. 2]. In a Staff Requirements Memorandum (SRM) dated April 2, 2009, SRM-SEC-08-0197 [Ref. 3], the Commission approved the NRC staff's recommended option to immediately begin engagement with stakeholders and interested parties. NRC staff noted the need to expand the current occupational radiation dose information contained in the Radiation Exposure Information and Reporting System (REIRS) database.

The NRC manages the REIRS database which maintains the occupational radiation dose information from specific categories of NRC licensees. Seven categories of NRC licensees are required to report annually on individual exposure in accordance with Title 10 of the Code of Federal Regulations, Section 20.2206 (10 CFR 20.2206, "Reports of Individual Monitoring"). Specifically, these categories include commercial nuclear power reactors; industrial radiographers; fuel processors (including uranium enrichment facilities), fabricators, and reprocessors; manufacturing and distribution of byproduct material; independent spent fuel storage installations; facilities for land disposal of low-level waste; and geologic repositories for high-level waste. Because NRC has not licensed any geologic repositories for high-level waste and no NRC-licensed low-level waste disposal facilities are currently in operation, NRC does not receive occupational radiation dose information from these two licensee categories.

To expand the Agreement State occupational radiation dose information contained in the REIRS database, NRC sent a letter (ML10210039) to Agreement State Radiation Control Programs [Ref. 4]. This letter requested occupational radiation dose information from industrial radiography and nuclear pharmacy licensees, for the 2000 through 2010 monitoring years. These Agreement State licensees were asked to submit their data to help expand the current data from NRC licensees in these two licensee categories. Currently, the REIRS database contains 100,535 records from industrial radiography and nuclear pharmacy licensees from 1997 through 2010. Nearly 39\% or 38,857 are dose records from Agreement State licensees within these categories. However, twice as many industrial radiography and nuclear pharmacy licensees are licensed and regulated by Agreement States.

The purpose of this report is to examine occupational radiation exposures received under Agreement State licensees. As such, this report reflects the occupational radiation exposure data contained in the REIRS database, for 1997 through 2010, from Agreement State-licensed materials facilities. 


\subsection{Agreement States and NRC}

Agreement States are those States that have entered into formal agreements with the NRC, pursuant to subsection 274b of the Atomic Energy Act (AEA) [Ref. 5,6], to regulate certain quantities of byproduct, source, and special nuclear material at facilities located within their borders. Agreement States issue radioactive material licenses, promulgate regulations, and enforce those regulations under the authority of each individual State's laws. Agreement States exercise their licensing and enforcement actions under direction of the governors in a manner that is adequate to protect public health and safety and compatible with the programs of the NRC. As of 2010, 36 States have signed formal agreements with the NRC [Ref. 7].

NRC assistance to States entering into agreements includes review of requests from States for $274 \mathrm{~b}$ Agreements, or amendments to existing agreements, and meetings with States to discuss and resolve NRC review comments. NRC has the responsibility to periodically assess the Agreement State radioactive materials licensing and inspection programs through the Integrated Material Performance Evaluation Program (IMPEP) process with participation by the Organization of Agreement States (OAS) [Ref. 8]. Additionally, NRC provides early and substantive involvement of States in NRC rulemaking and other regulatory efforts; conducts training courses and workshops; evaluates technical licensing and inspection issues from Agreement States; and evaluates State rule changes.

The OAS is a nonprofit, voluntary, scientific, and professional society incorporated in the District of Columbia. The membership of OAS consists of state radiation control program directors and staff from the 36 Agreement States who are responsible for implementation of their respective Agreement State programs. The purpose of the OAS is to provide a mechanism for these Agreement States to work with each other and with the NRC on regulatory issues associated with their respective agreements.

The Conference of Radiation Control Program Directors, Inc. (CRCPD) [Ref. 9] is a 501(c)(3) non-profit, non-governmental professional organization dedicated to radiation protection. CRCPD's membership primarily consists of radiation professionals in State and local government that regulate the use of radiation sources. The purpose and goal of the CRCPD is to assist its members in their efforts to protect the public, radiation workers, and patients from unnecessary radiation exposure. CRCPD provides a forum for centralized communication on radiation protection matters between the States, Federal Government, and between individual States.

\subsection{Agreement State Compatibility with NRC Regulations}

The NRC's Statement on Adequacy and Compatibility of Agreement State Programs identifies the criteria that the NRC uses to determine those program elements that should be adopted by an Agreement State to maintain an adequate and compatible program. [Ref. 10] "An Agreement State radiation control program is compatible with the NRC's regulatory program when the State program does not create conflicts, duplications, gaps, or other conditions that jeopardize an orderly pattern in the regulation of agreement material (source, byproduct, and small quantities 
of special nuclear material as identified by Section 274b. of the Atomic Energy Act, as amended) on a nationwide basis." [Ref. 10]

An Agreement State radiation control program is adequate to protect public health and safety if administration of the program provides reasonable assurance of protection of public health and safety in regulating the use of agreement material. Accordingly, NRC program elements are established in four compatibility categories.

- Compatibility Category A

NRC program elements in Category $A$ are those that are basic radiation protection standards and scientific terms and definitions that are necessary to understand radiation protection concepts. The program elements adopted by an Agreement State should be essentially identical to those of NRC to provide uniformity in the regulation of agreement material on a nationwide basis.

- Compatibility Category B

NRC program elements in Category B are those that apply to activities that have direct and significant transboundary implications. An Agreement State should adopt program elements essentially identical to those of NRC.

- Compatibility Category C

NRC program elements in Category $C$ are those that do not meet the criteria of Category A or B but the essential objectives of which an Agreement State should adopt to avoid conflict, duplication, gaps, or other conditions that would jeopardize an orderly pattern in the regulation of agreement material on a nationwide basis. An Agreement State should adopt the essential objectives of the NRC program elements.

- Compatibility Category D

NRC program elements in Category $D$ are those that do not meet any of the criteria of Category A, B, or C, above and, thus, do not need to be adopted by Agreement States for purposes of compatibility.

The requirements to report occupational radiation dose information from specific categories of licensees and participation in the NRC's REIRS database for Agreement States are designated as Compatibility Category D provisions. Because Agreement States are not required to adopt Compatibility Category D provisions, the collection and reporting of this information to the NRC is strictly voluntary on the part of the Agreement State Radiation Control Program. 



\section{LIMITATIONS OF THE DATA}

This report summarizes the Agreement State occupational radiation exposure data maintained in the REIRS database from 1997 through 2010. Nearly seven times as many facilities are licensed and regulated by Agreement States than are licensed and regulated by NRC. There are approximately 20,000 Agreement State licensees compared with almost 3,000 NRC licensees.

From 1997 through 2009, 3,131 radiation exposure records were received by the REIRS program from Agreement State licensees. As a result of the August 6, 2010 NRC Letter, another 37,491 radiation dose records were received between 2010 and 2011 . The total number of Agreement State records account for less than 1\% of all records contained in the REIRS database. Occupational radiation exposure records from the following Agreement State licensee categories are in the REIRS database: industrial radiographers, manufacturers and distributors of byproduct material, waste disposal burial and service processing and/or repackaging, irradiators, well logging byproduct and/or sealed source facilities, measuring systems and portable gauge facilities, calibration services, veterinary (non-human) facilities, and other services.

The Agreement State occupational radiation dose records contained in the REIRS database can be used by NRC staff to make informed decisions regarding potential changes to the agency's current annual occupational limit of 5 rem to align with the ICRP 103 recommendation of an annual limit of $2 \mathrm{rem}$. Although the Agreement State licensee data in the REIRS database account for less than $1 \%$ of the data, an analysis can be conducted regarding the potential impact of such a regulatory change. Section 4 contains additional details regarding the potential impacts of changing the current annual occupational limit from 5 rem to 2 rem.

All of the figures compiled in this report relating to exposures and occupational doses are based on the results and interpretations of the readings of various types of radiation-monitoring devices employed by each licensee. This information, obtained from routine radiation-monitoring programs, is sufficient to characterize the radiation exposure incident to individuals' work and is used in evaluating the radiation protection program.

Monitoring requirements specified in 10 CFR 20.1502 require licensees to monitor individuals who receive or are likely to receive, in 1 year, a dose in excess of $10 \%$ of the applicable limits. For adults, the annual occupational limit is $5 \mathrm{rem}$, so $0.5 \mathrm{rem}$ per year is the level above which monitoring is required. Separate dose limits have been established for minors, declared pregnant individuals, and members of the public. Monitoring is also required for any individual entering a high or very high radiation area. Depending on the administrative policy of each licensee, persons such as visitors and clerical individuals may also be provided with monitoring devices, even though the probability of their exposure to measurable levels of radiation is extremely small. It is worth noting that this report does not include compilations of nonoccupational exposure, such as exposure received by medical patients from X-rays, fluoroscopy, or accelerators, which is outside NRC regulatory jurisdiction. 
Many licensees elect to report the doses for every individual for whom they provided monitoring. This practice increases the number of individuals that are considered to be exposed to radiation. In an effort to account for this increase, the number of individuals reported as having "no measurable dose" ${ }^{1}$ has been subtracted from the total number of individuals monitored in order to calculate an average dose per individual receiving a measurable dose, as well as the average dose per monitored individual.

When examining the annual statistical data, it is important to note that all of the personnel included in the report may not have been monitored throughout the entire year. Many licensees, such as industrial radiographers and nuclear pharmacies, may monitor numerous individuals for periods much less than a year. The average doses calculated from these data, therefore, are less than the average dose that an individual involved in that activity for the full year would receive. Licensees are not required to report the specific period of monitoring within the year. Many licensees report dose records for January 1 through December 31, regardless of the actual dates of monitoring. If an individual visits for only 1 day, but visits three times during the year, it is often reported as if the individual was there all year. NRC encourages reporting of the actual monitoring dates, but it is not a regulatory requirement.

All dose equivalent values in this report are given in units of rem in accordance with the general provisions for records in 10 CFR 20.2101(a). In order to convert rem into the International System of Units (SI) unit of sieverts (Sv), readers should divide the value in rem by 100 . Therefore, 1 rem = $0.01 \mathrm{~Sv}$. In order to convert rem into millisieverts $(\mathrm{mSv})$, readers should multiply the value in rem by 10 .

\footnotetext{
${ }^{1}$ The number of workers with measurable dose includes any individual with a dose greater than zero rem and does not include doses reported as "not detectable."
} 


\section{ANNUAL PERSONNEL MONITORING REPORTS}

\subsection{Definition of Terms and Sources of Data}

Although Agreement State licensees are not required to submit exposure reports to NRC, some Agreement State licensees annually submit this data voluntarily. In addition to this voluntary submission, some Agreement State licensees also responded to the NRC Letter. The NRC Letter was a one-time request for certain categories of Agreement State licensees to submit their exposure data. As of June 2011, the NRC's REIRS database contains 40,622 occupational radiation exposure reports from Agreement State licensees. Table 3.1 summarizes the annual data that have been submitted from 1997 through 2010.

\subsubsection{Number of Licensees Reporting}

The number of licensees refers to the number of Agreement State licensees that filed occupational radiation exposure reports voluntarily for each year and in response to the NRC Letter. Appendix A contains additional detailed information on Agreement State licensees that have submitted information.

\subsubsection{Number of Monitored Individuals}

The number of monitored individuals refers to the total number of individuals that Agreement State licensees reported as being monitored for exposure to external and internal radiation during each respective year. The total number of individuals was determined from the number of unique personal identification numbers submitted per licensee.

\subsubsection{Number of Individuals with Measurable Dose}

The number of individuals with measurable dose includes any individual with a TEDE greater than zero rem.

\subsubsection{Collective Dose}

The concept of collective dose is used in this report to denote the summation of the TEDE received by all monitored individuals and is reported in units of person-rem. The collective dose is calculated by summing the TEDE for all monitored individuals. The phrase "collective dose" is used throughout this report to mean the collective TEDE, unless otherwise specified.

\subsubsection{Average Measurable Dose}

The average measurable dose is obtained by dividing the collective TEDE by the number of monitored individuals with measurable dose. This is the average most commonly used in this and other reports when examining trends and comparing doses received by individuals in various segments of the nuclear industry. It excludes individuals receiving zero or no detectable dose, many of whom were monitored for convenience or identification purposes.

\subsection{Annual TEDE Dose Distributions}

Table 3.2 provides a statistical compilation of the occupational dose reports by categories of licensees (see Section 3.4 for a description of each licensee category). The dose distributions are generated by summing the TEDE for each individual and counting the number of individuals in each dose range. In nearly every licensee category, a large number of individuals receive doses that are less than measurable, and very few doses exceed 4 rem. 
Based on the 312 licensees that voluntarily submitted radiation dose data for the past 14 years, nearly $22 \%(8,918)$ of the individuals monitored received no measurable dose and $0.7 \%(304)$ of the individuals monitored exceeded 2 rem.

TABLE 3.1

Annual Exposure Information

$1997-2010$

\begin{tabular}{|c|c|c|c|c|c|c|}
\hline $\begin{array}{l}\text { NRC License } \\
\text { Category and } \\
\text { Program Code }\end{array}$ & Year & $\begin{array}{l}\text { Number of } \\
\text { Licensees }\end{array}$ & $\begin{array}{l}\text { Number of } \\
\text { Monitored } \\
\text { Individuals }\end{array}$ & $\begin{array}{l}\text { Number of } \\
\text { Individuals with } \\
\text { Measurable Dose }\end{array}$ & $\begin{array}{l}\text { Collective Dose } \\
\text { (person-rem) }\end{array}$ & $\begin{array}{c}\text { Average } \\
\text { Measurable } \\
\text { Dose (rem) }\end{array}$ \\
\hline \multirow{2}{*}{$\begin{array}{c}\text { Industrial } \\
\text { Radiography }\end{array}$} & 1997 & 2 & 36 & 12 & 0.310 & 0.026 \\
\hline & 1998 & 2 & 42 & 33 & 4.189 & 0.127 \\
\hline \multirow{12}{*}{$\begin{array}{l}03310 \\
03320\end{array}$} & 1999 & 1 & 9 & 7 & 1.585 & 0.226 \\
\hline & 2000 & 12 & 192 & 160 & 65.722 & 0.411 \\
\hline & 2001 & 9 & 105 & 84 & 27.289 & 0.325 \\
\hline & 2002 & 14 & 158 & 122 & 35.098 & 0.288 \\
\hline & 2003 & 25 & 282 & 226 & 109.971 & 0.487 \\
\hline & 2004 & 24 & 352 & 289 & 159.914 & 0.553 \\
\hline & 2005 & 26 & 466 & 392 & 247.134 & 0.630 \\
\hline & 2006 & 44 & 1,195 & 1,030 & 612.518 & 0.595 \\
\hline & 2007 & 44 & 1,477 & 1,313 & 738.452 & 0.562 \\
\hline & 2008 & 31 & 870 & 748 & 387.942 & 0.519 \\
\hline & 2009 & 39 & 966 & 723 & 344.975 & 0.477 \\
\hline & 2010 & 41 & 1,045 & 824 & 330.055 & 0.401 \\
\hline \multicolumn{2}{|c|}{ Overall Total } & 314 & 7,195 & 5,963 & $3,065.154$ & 0.514 \\
\hline \multirow{3}{*}{$\begin{array}{c}\text { Manufacturing } \\
\text { and } \\
\text { Distribution }\end{array}$} & 1997 & \multicolumn{5}{|c|}{ No Data Reported } \\
\hline & 1998 & 2 & 48 & 12 & 1.364 & 0.114 \\
\hline & 1999 & 3 & 60 & 16 & 0.204 & 0.013 \\
\hline \multirow{11}{*}{$\begin{array}{l}02500 \\
03214\end{array}$} & 2000 & 4 & 87 & 29 & 5.320 & 0.183 \\
\hline & 2001 & 7 & 121 & 59 & 6.520 & 0.111 \\
\hline & 2002 & 125 & 2,583 & 1,422 & 42.922 & 0.030 \\
\hline & 2003 & 149 & 3,775 & 3,044 & 328.092 & 0.108 \\
\hline & 2004 & 162 & 4,073 & 3,335 & 321.149 & 0.096 \\
\hline & 2005 & 158 & 4,165 & 3,248 & 322.476 & 0.099 \\
\hline & 2006 & 158 & 4,192 & 3,352 & 360.798 & 0.108 \\
\hline & 2007 & 159 & 4,179 & 3,331 & 349.877 & 0.105 \\
\hline & 2008 & 156 & 4,207 & 3,279 & 319.200 & 0.097 \\
\hline & 2009 & 173 & 4,149 & 3,299 & 342.289 & 0.104 \\
\hline & 2010 & 21 & 550 & 333 & 40.992 & 0.123 \\
\hline \multicolumn{2}{|c|}{ Overall Total } & 1,277 & 32,189 & 24,759 & $2,441.203$ & 0.099 \\
\hline \multirow{4}{*}{$\begin{array}{c}\text { Waste Disposal } \\
\text { Burial and Service } \\
\text { Processing and/or } \\
\text { Repackaging }\end{array}$} & 1997 & 1 & 5 & 3 & 1.508 & 0.503 \\
\hline & 1998 & 2 & 33 & 17 & 1.954 & 0.115 \\
\hline & 1999 & 2 & 42 & 29 & 2.869 & 0.099 \\
\hline & 2000 & 1 & 5 & 4 & 0.874 & 0.219 \\
\hline & 2001 & 1 & 5 & 4 & 0.948 & 0.237 \\
\hline \multirow{9}{*}{03234} & 2002 & 2 & 19 & 13 & 1.304 & 0.100 \\
\hline & 2003 & 2 & 17 & 10 & 1.485 & 0.149 \\
\hline & 2004 & \multicolumn{5}{|c|}{ No Data Reported } \\
\hline & 2005 & 1 & 5 & 5 & 3.120 & 0.624 \\
\hline & 2006 & 1 & 5 & 5 & 2.601 & 0.520 \\
\hline & 2007 & 2 & 13 & 7 & 2.263 & 0.323 \\
\hline & 2008 & 1 & 5 & 5 & 1.717 & 0.343 \\
\hline & 2009 & 1 & 3 & 2 & 1.712 & 0.856 \\
\hline & 2010 & 1 & 3 & 3 & 2.681 & 0.894 \\
\hline \multicolumn{2}{|c|}{ Overall Total } & 18 & 160 & 107 & 25.036 & 0.234 \\
\hline
\end{tabular}


TABLE 3.1

Annual Exposure Information (continued)

$1997-2010$

\begin{tabular}{|c|c|c|c|c|c|c|}
\hline $\begin{array}{l}\text { NRC License } \\
\text { Category and } \\
\text { Program Code }\end{array}$ & Year & $\begin{array}{l}\text { Number of } \\
\text { Licensees }\end{array}$ & $\begin{array}{l}\text { Number of } \\
\text { Monitored } \\
\text { Individuals }\end{array}$ & $\begin{array}{c}\text { Number of } \\
\text { Individuals with } \\
\text { Measurable Dose }\end{array}$ & $\begin{array}{c}\text { Collective Dose } \\
\text { (person-rem) }\end{array}$ & $\begin{array}{c}\text { Average } \\
\text { Measurable } \\
\text { Dose (rem) }\end{array}$ \\
\hline \multirow{12}{*}{$\begin{array}{c}\text { Irradiators Other } \\
\text { Less Than } 10000 \\
\text { Curies } \\
03511\end{array}$} & 1997-1999 & \multicolumn{5}{|c|}{ No Data Reported } \\
\hline & 2000 & 1 & 10 & 5 & 2.335 & 0.467 \\
\hline & 2001 & 1 & 11 & 6 & 3.790 & 0.632 \\
\hline & 2002 & 1 & 12 & 6 & 3.190 & 0.532 \\
\hline & 2003 & 1 & 13 & 4 & 3.989 & 0.997 \\
\hline & 2004 & 1 & 12 & 4 & 2.291 & 0.573 \\
\hline & 2005 & 1 & 9 & 4 & 2.232 & 0.558 \\
\hline & 2006 & 1 & 11 & 5 & 2.474 & 0.495 \\
\hline & 2007 & 1 & 10 & 4 & 2.357 & 0.589 \\
\hline & 2008 & 1 & 10 & 4 & 2.575 & 0.644 \\
\hline & 2009 & 1 & 10 & 4 & 2.113 & 0.528 \\
\hline & 2010 & \multicolumn{5}{|c|}{ No Data Reported } \\
\hline \multicolumn{2}{|c|}{ Overall Total } & 10 & 108 & 46 & 27.346 & 0.594 \\
\hline \multirow{12}{*}{$\begin{array}{l}\text { Well Logging } \\
\text { Byproduct and/or } \\
\text { SNM Sealed } \\
\text { Sources Only } \\
03111\end{array}$} & 1997-1999 & \multicolumn{5}{|c|}{ No Data Reported } \\
\hline & 2000 & 1 & 68 & 62 & 23.724 & 0.383 \\
\hline & 2001 & 1 & 83 & 82 & 38.305 & 0.467 \\
\hline & 2002 & 1 & 69 & 66 & 32.331 & 0.490 \\
\hline & 2003 & 1 & 60 & 58 & 28.011 & 0.483 \\
\hline & 2004 & 1 & 60 & 58 & 25.012 & 0.431 \\
\hline & 2005 & 1 & 65 & 58 & 25.165 & 0.434 \\
\hline & 2006 & 1 & 68 & 63 & 27.714 & 0.440 \\
\hline & 2007 & 1 & 68 & 61 & 26.623 & 0.436 \\
\hline & 2008 & 1 & 70 & 65 & 34.384 & 0.529 \\
\hline & 2009 & 1 & 68 & 65 & 30.503 & 0.469 \\
\hline & 2010 & 1 & 68 & 56 & 27.050 & 0.483 \\
\hline \multicolumn{2}{|c|}{ Overall Total } & 11 & 747 & 694 & 318.822 & 0.459 \\
\hline \multirow{12}{*}{$\begin{array}{c}\text { Measuring } \\
\text { Systems Portable } \\
\text { Gauges } \\
\mathbf{0 3 1 2 1}\end{array}$} & 1997-1999 & \multicolumn{5}{|c|}{ No Data Reported } \\
\hline & 2000 & 1 & 20 & 18 & 4.733 & 0.263 \\
\hline & 2001 & 1 & 16 & 15 & 3.145 & 0.210 \\
\hline & 2002 & 1 & 12 & 11 & 2.795 & 0.254 \\
\hline & 2003 & 1 & 13 & 12 & 3.242 & 0.270 \\
\hline & 2004 & 1 & 14 & 11 & 2.418 & 0.220 \\
\hline & 2005 & 1 & 14 & 13 & 1.656 & 0.127 \\
\hline & 2006 & 1 & 16 & 16 & 4.552 & 0.285 \\
\hline & 2007 & 1 & 11 & 9 & 1.831 & 0.203 \\
\hline & 2008 & 1 & 12 & 12 & 1.595 & 0.133 \\
\hline & 2009 & \multicolumn{5}{|c|}{ No Data Reported } \\
\hline & 2010 & 1 & 15 & 11 & 3.900 & 0.355 \\
\hline & erall Total & 10 & 143 & 128 & 29.867 & 0.233 \\
\hline
\end{tabular}


TABLE 3.1

Annual Exposure Information (continued)

1997-2010
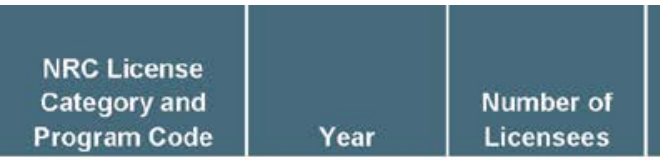

Number of
Monitored
Individuals

Number of

Individuals with

Measurable Dose

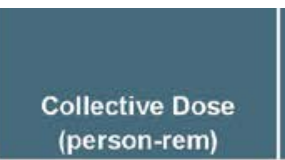

Average

Measurable

Veterinary Non-Human 1997-2009 02400

\begin{tabular}{|c|c|}
2010 \\
Overall Total
\end{tabular}

Instrument Calibration Service 1997-2008 Only - Source > 100 Curies/Other Services 03222 03225

\begin{tabular}{|c|c|}
\hline 2008 & 1 \\
\hline 2009 & 2 \\
\hline 2010 & 2 \\
\hline Overall Total & 5 \\
\hline GRAND TOTALS & 1,646 \\
\hline
\end{tabular}

\begin{tabular}{|c|}
\hline \\
4 \\
4 \\
4 \\
\hline
\end{tabular}

No Data Reported

0
0
No Data Reported
3
2
2
7
31,704

0.000
0.000

0.000
0.414
0.247
0.661
$5,908.089$

0.000

0.207

0.124

40,622

31,704

0.094

0.186 


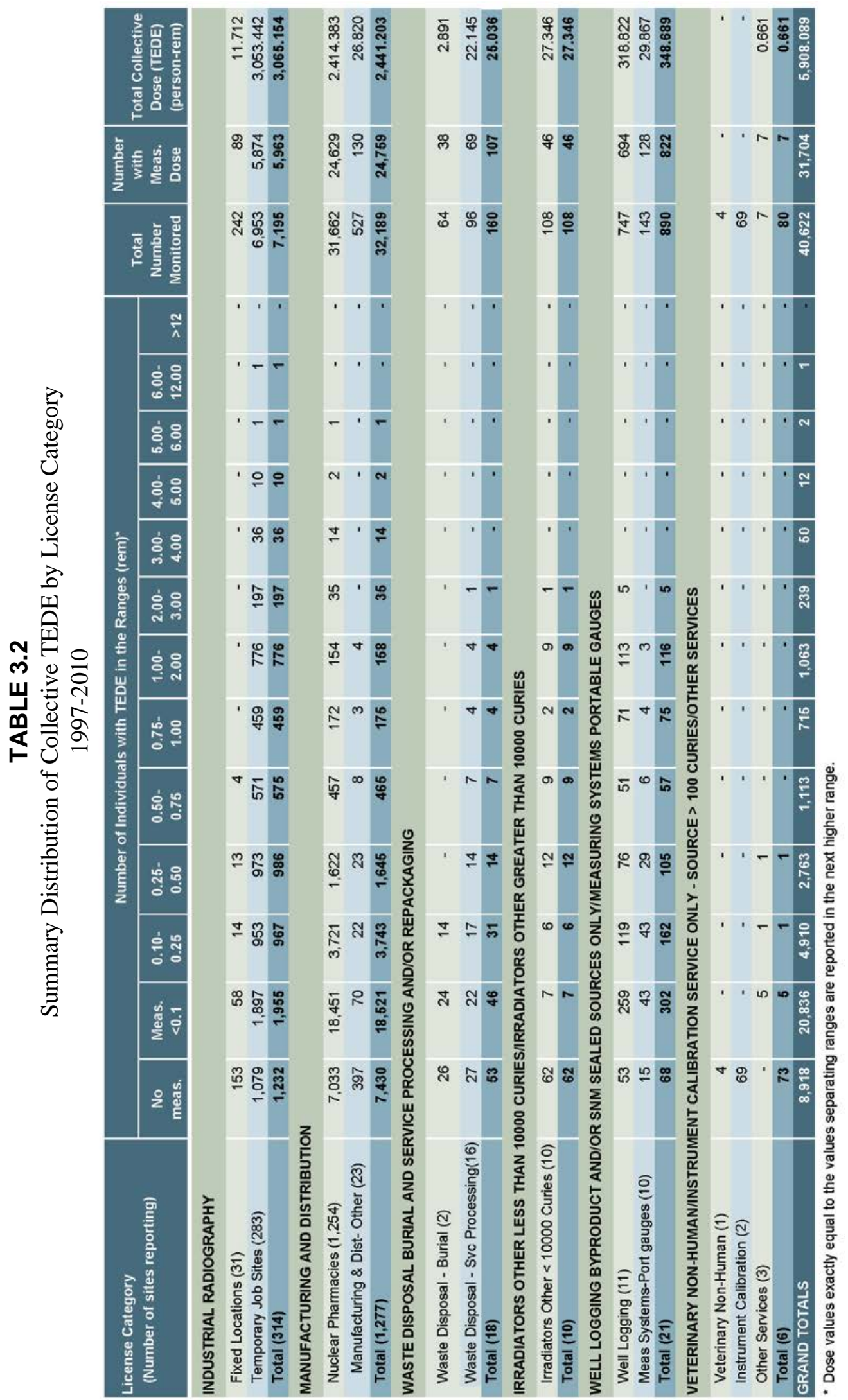




\subsection{Summary of Occupational Dose Data by License Category}

\subsubsection{Industrial Radiography Licenses, Fixed Locations, and Temporary Job Sites}

Industrial radiography licenses are issued to allow the use of sealed radioactive materials, usually in exposure devices or cameras, that primarily emit gamma rays for nondestructive testing of pipeline weld joints, steel structures, boilers, aircraft and ship parts, and other highstress alloy parts. Some firms are licensed to conduct such activities in one location, usually in a permanent facility designed and shielded for radiography; others perform radiography at temporary job sites in the field. The radioisotopes most commonly used are cobalt-60 and iridium-192. Table 3.1 lists the number of licensees that submitted annually from 1997 - 2010; however, only 100 unique radiography licensees reported in that time frame.

Figure 3.1 shows the number of individuals with measurable dose, the total collective dose, and the average measurable dose per individual for both types of industrial radiography licensees from 1997 through 2010. In the last 3 years, the combination of increased individuals with measurable dose plus slightly lower collective TEDE generated a lower average measurable TEDE per individual.

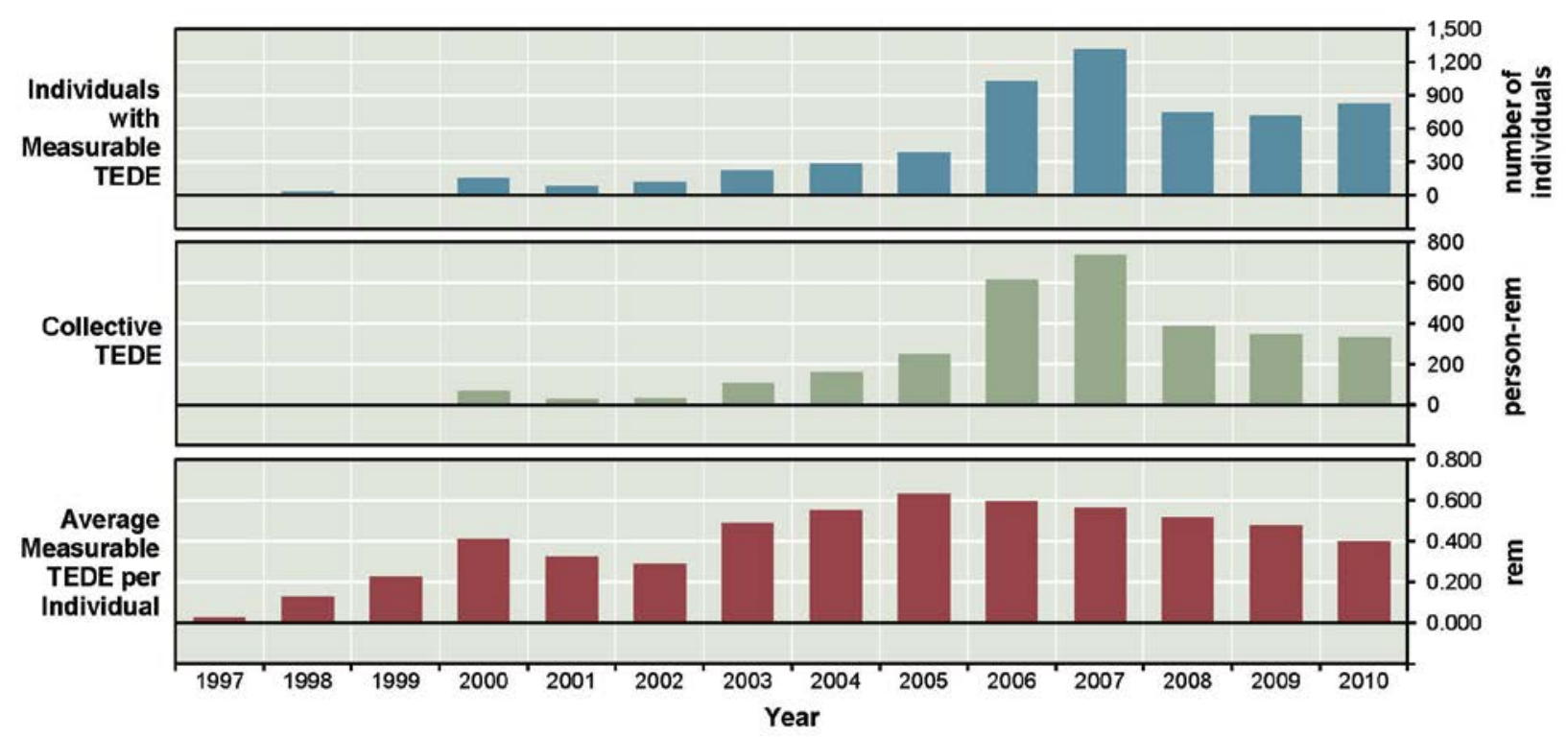

FIGURE 3.1

Annual Values for Industrial Radiography Licensees

1997-2010

Whereas industrial radiographers represent nineteen percent of the reported individuals with a measurable dose (shown in Table 3.2), they received just over half (51.9\%) of the total collective dose. In addition, for this time period, 245 workers (4\%) received measurable doses greater than or equal to 2 rem. These dose records augment the other 2,120 exposure records for NRC-licensed industrial radiographers that were in the REIRS database for the same time period whose measurable doses also were greater than or equal to 2 rem. 
Table 3.3 summarizes the reported data for the two types of industrial radiography licensees for 2008,2009 , and 2010. Table 3.3 also shows that over $99 \%$ of the collective dose was attributed to radiographers working at temporary job sites. It is difficult for these individuals to avoid exposure to radiation at temporary job sites in the field. Conditions are not always favorable to provide shielding or to use distance as a means of reducing exposure.

\section{TABLE 3.3}

Annual Exposure Information for Industrial Radiographers 2008-2010

\begin{tabular}{|c|c|c|c|c|c|c|}
\hline Year & Type of License & $\begin{array}{l}\text { Number of } \\
\text { Licensees }\end{array}$ & $\begin{array}{l}\text { Number of } \\
\text { Monitored } \\
\text { Individuals }\end{array}$ & $\begin{array}{l}\text { Individuals with } \\
\text { Measurable } \\
\text { Dose }\end{array}$ & $\begin{array}{l}\text { Collective } \\
\text { Dose } \\
\text { (person-rem) }\end{array}$ & $\begin{array}{c}\text { Average } \\
\text { Measurable } \\
\text { Dose (rem) }\end{array}$ \\
\hline \multirow{3}{*}{2008} & Fixed Location & 4 & 34 & 14 & 1.870 & 0.13 \\
\hline & Temporary Job Sites & 27 & 836 & 734 & 386.072 & 0.53 \\
\hline & Total & 31 & 870 & 748 & 387.942 & 0.52 \\
\hline \multirow{3}{*}{2009} & Fixed Location & 1 & 9 & 1 & 0.126 & 0.13 \\
\hline & Temporary Job Sites & 38 & 957 & 722 & 344.849 & 0.48 \\
\hline & Total & 39 & 966 & 723 & 344.975 & 0.48 \\
\hline \multirow{3}{*}{2010} & Fixed Location & 1 & 10 & 6 & 0.083 & 0.01 \\
\hline & Temporary Job Sites & 40 & 1,035 & 818 & 329.972 & 0.40 \\
\hline & Total & 41 & 1,045 & 824 & 330.055 & 0.40 \\
\hline
\end{tabular}

\subsubsection{Manufacturing and Distribution Licenses}

Manufacturing and distribution (M\&D) licenses are issued to allow the manufacture and distribution of radionuclides in various forms for a number of diverse purposes. The products are usually distributed to organizations/companies specifically licensed by NRC or an Agreement State. Nuclear pharmacies, the largest licensee contributor, are involved in the compounding and dispensing of radioactive materials for use in nuclear medicine procedures. Table 3.1 lists the number of licensees that submitted annually, with 199 unique manufacturing and distribution licensees reporting from 1998 through 2010.

Figure 3.2 shows the number of individuals with measurable dose, the total collective dose, and the average measurable dose per individual for Type "A" Broad, Type "B" Broad and other, and nuclear pharmacies licensees from 1998 through 2010. In 2010, a large decrease in both the number of individuals reported and the collective TEDE created a slight increase in the average measurable TEDE.

Whereas nuclear pharmacy workers represent nearly $78 \%$ of the reported individuals with a measurable dose (shown in Table 3.2), they received $40.9 \%$ of the total collective dose. In addition, for this time period, 52 workers $(0.2 \%)$ received measurable doses greater than or equal to 2 rem. These dose records augment the other 561 exposure records for NRC-licensed nuclear pharmacy workers that were in the REIRS database for the same time period whose measurable doses also were greater than or equal to 2 rem. 


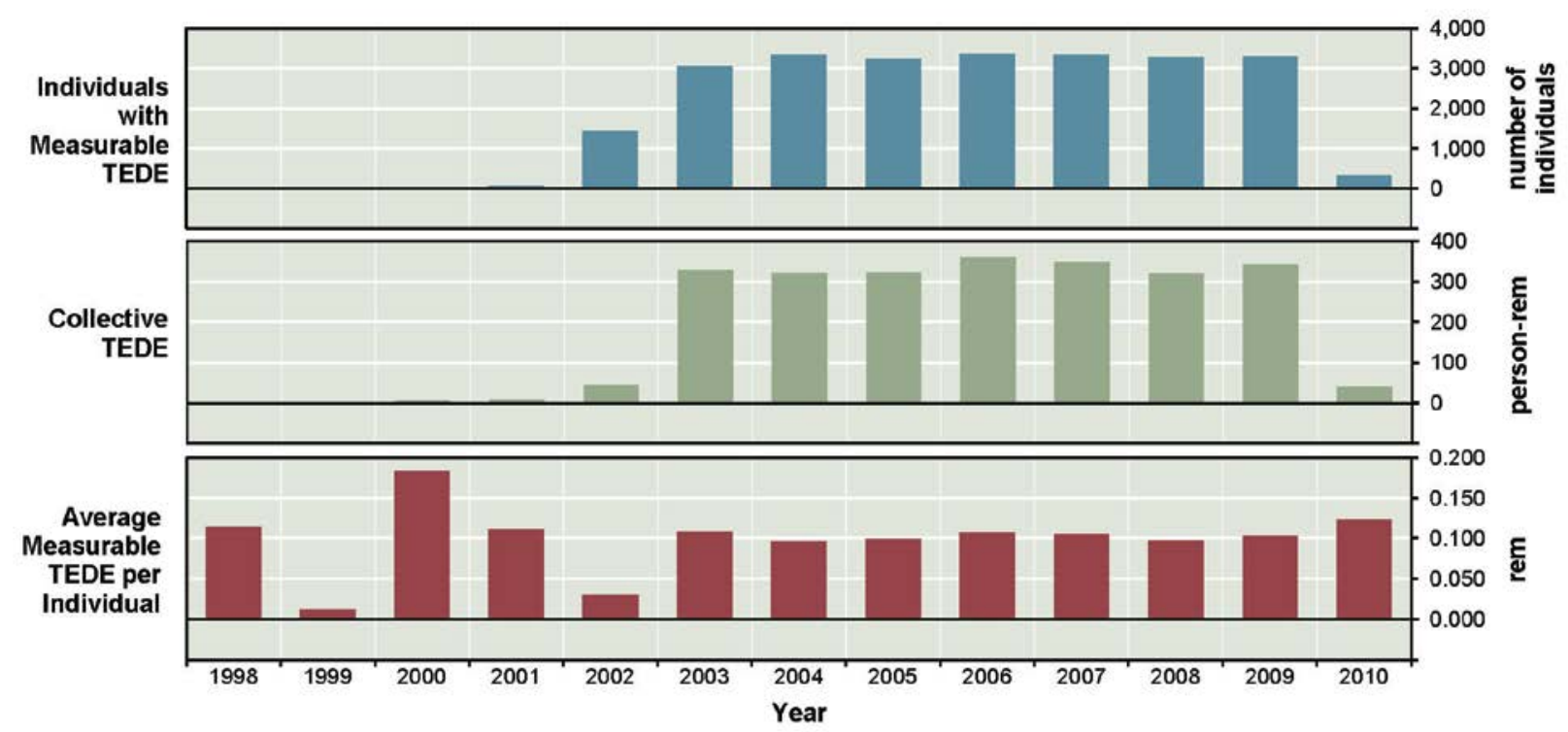

FIGURE 3.2

Annual Values for Manufacturing \& Distribution and Nuclear Pharmacies

$1998-2010$

Table 3.4 summarizes the reported data for manufacturing and distribution licensees for 2008 , 2009, and 2010, with the exception of Type "A" Broad licensees that did not submit dose records in any of these 3 years.

TABLE 3.4

Annual Exposure Information for Manufacturing and Distribution 2008-2010

\begin{tabular}{|l|l|r|r|r|r|r|}
\hline & \multicolumn{1}{|c|}{$\begin{array}{c}\text { Tympe of License } \\
\text { Year }\end{array}$} & $\begin{array}{c}\text { Number of } \\
\text { Licensees }\end{array}$ & $\begin{array}{c}\text { Number of } \\
\text { Monitored } \\
\text { Individuals }\end{array}$ & $\begin{array}{c}\text { Average } \\
\text { Individuals with } \\
\text { Measurable Dose }\end{array}$ & $\begin{array}{c}\text { Collective Dose } \\
\text { (person-rem) }\end{array}$ & $\begin{array}{c}\text { Measurable } \\
\text { Dose (rem) }\end{array}$ \\
\hline
\end{tabular}




\subsubsection{Waste Disposal Burial and Service Processing and/or Repackaging}

Waste disposal burial and service processing and/or repackaging licenses are issued to allow the processing or repackaging of radionuclides in various forms for shipment and ultimate disposal. Three unique waste disposal licensees submitted reports from 1997 through 2010.

Figure 3.3 shows the number of individuals with measurable dose, the total collective dose, and the average measurable dose per individual for waste disposal service from 1997 through 2010. As illustrated by Figure 3.3, no data have been received for 2004. Table 3.1 and Figure 3.3 may be updated in the future if data are voluntarily submitted for this specific year.

Table 3.5 summarizes the reported data for waste disposal licensees for 2008, 2009, and 2010.

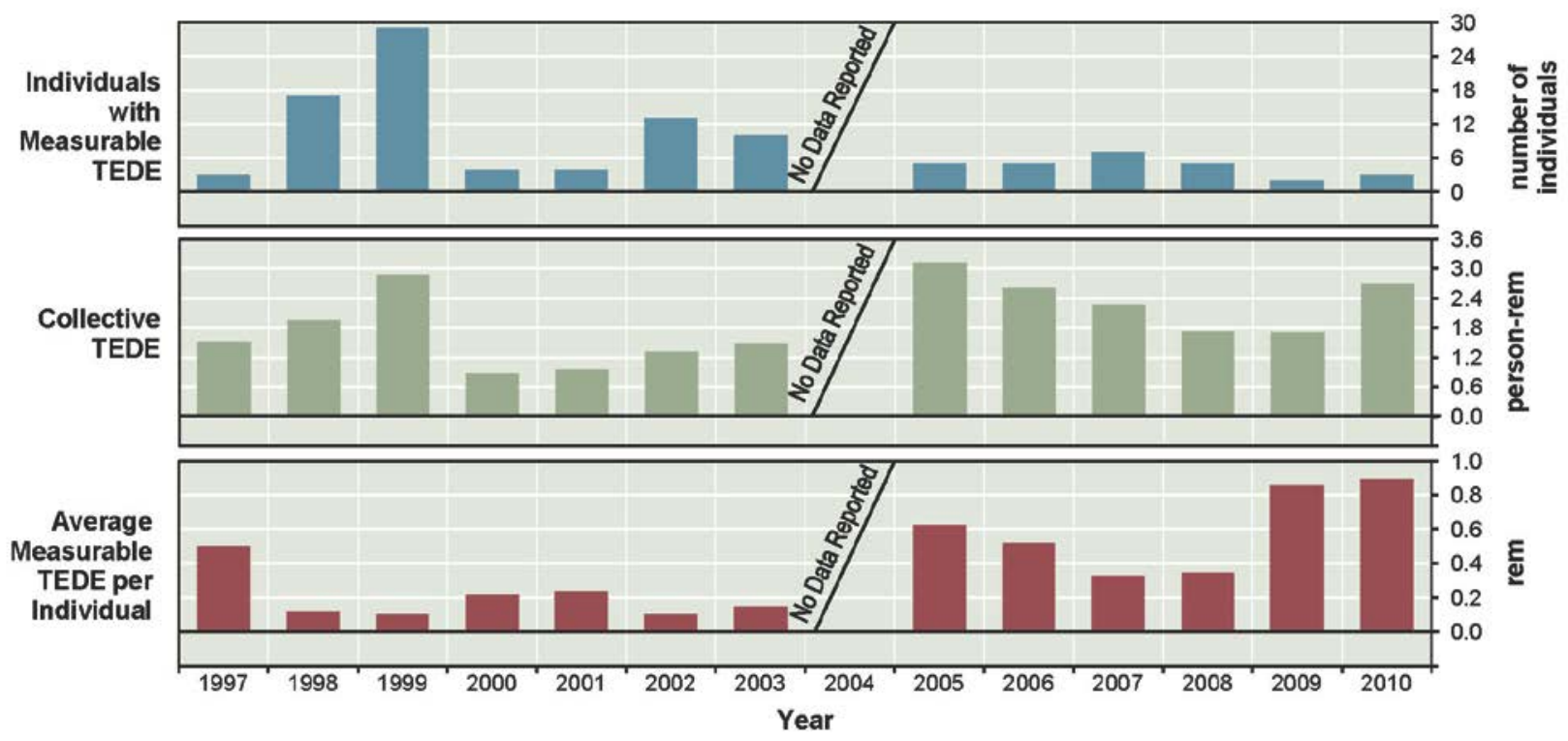

FIGURE 3.3

Annual Values for Waste Disposal Burial and Service Processing and/or Repackaging 1997-2010 
TABLE 3.5

Annual Exposure Information for Waste Disposal Burial and Service Processing and/or Repackaging 2008-2010

\begin{tabular}{|c|c|c|c|c|c|c|}
\hline Year & Type of License & $\begin{array}{l}\text { Number of } \\
\text { Licensees }\end{array}$ & $\begin{array}{l}\text { Number of } \\
\text { Monitored } \\
\text { Individuals }\end{array}$ & $\begin{array}{l}\text { Individuals with } \\
\text { Measurable } \\
\text { Dose }\end{array}$ & $\begin{array}{l}\text { Collective Dose } \\
\text { (person-rem) }\end{array}$ & $\begin{array}{l}\text { Average } \\
\text { Measurable } \\
\text { Dose (rem) }\end{array}$ \\
\hline \multirow{2}{*}{2008} & Waste Disposal & 1 & 5 & 5 & 1.717 & 0.34 \\
\hline & Total & 1 & 5 & 5 & 1.717 & 0.34 \\
\hline \multirow{2}{*}{2009} & Waste Disposal & 1 & 3 & 2 & 1.712 & 0.86 \\
\hline & Total & 1 & 3 & 2 & 1.712 & 0.86 \\
\hline \multirow{2}{*}{2010} & Waste Disposal & 1 & 3 & 3 & 2.681 & 0.89 \\
\hline & Total & 1 & 3 & 3 & 2.681 & 0.89 \\
\hline
\end{tabular}

\subsubsection{Irradiators Other Less Than 10000 Curies}

Irradiators other less than 10000 curies licenses are issued for use in irradiation of products, food for human consumption, or research purposes. One single irradiator licensee reported annually from 2000 through 2009.

Figure 3.4 shows the number of individuals with measurable dose, the total collective dose, and the average measurable dose per individual for irradiator licensees from 1997 through 2010. In the past 6 years, the collective TEDE has remained relatively level.

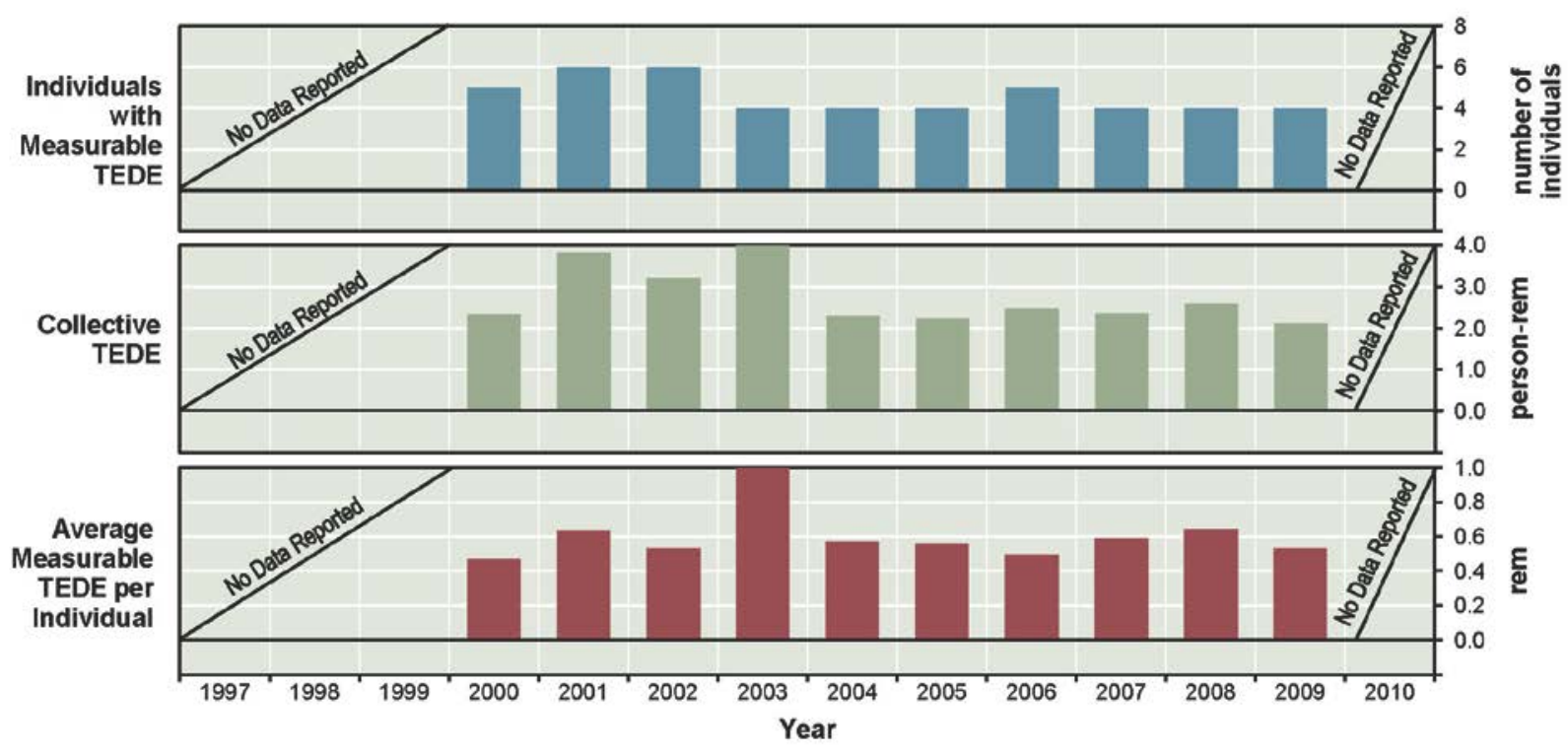

FIGURE 3.4

Annual Values for Irradiators Other Less Than 10000 Curies $1997-2010$

Table 3.6 summarizes the reported data for irradiators for 2008, 2009, and 2010. 
TABLE 3.6

Annual Exposure Information for Irradiators Other Less than 10000 Curies 2008-2010

\begin{tabular}{|c|c|c|c|c|c|c|}
\hline Year & Type of License & $\begin{array}{l}\text { Number of } \\
\text { Licensees }\end{array}$ & $\begin{array}{l}\text { Number of } \\
\text { Monitored } \\
\text { Individuals }\end{array}$ & $\begin{array}{l}\text { Individuals with } \\
\text { Measurable Dose }\end{array}$ & $\begin{array}{c}\text { Collective Dose } \\
\text { (person-rem) }\end{array}$ & $\begin{array}{c}\text { Average } \\
\text { Measurable } \\
\text { Dose (rem) }\end{array}$ \\
\hline \multirow{2}{*}{2008} & Irradiators Other $<10000$ Curies & 1 & 10 & 4 & 2.575 & 0.64 \\
\hline & Total & 1 & 10 & 4 & 2.575 & 0.64 \\
\hline \multirow{2}{*}{2008} & Irradiators Other $<10000$ Curies & 1 & 10 & 4 & 2.113 & 0.53 \\
\hline & Total & 1 & 10 & 4 & 2.113 & 0.53 \\
\hline \multirow{2}{*}{2010} & Irradiators Other $<10000$ Curies & \multicolumn{5}{|c|}{ No Data Reported } \\
\hline & Total & - & - & - & - & - \\
\hline
\end{tabular}

\subsubsection{Well Logging Byproduct and/or Special Nuclear Material (SNM) Sealed Sources Only and Measuring Systems Portable Gauges}

Licenses for sealed byproduct materials are issued for well logging, tracer operations, and research and development. Licenses for portable gauge devices are issued to measure moisture, density, and thickness using sealed sources in a variety of gauge designs. Only two well logging and portable gauge licensees reported from 2000 through 2010.

Figure 3.5 shows the number of individuals with measurable dose, the total collective dose, and the average measurable dose per individual for well logging and portable gauge licensees from 1997 through 2010.

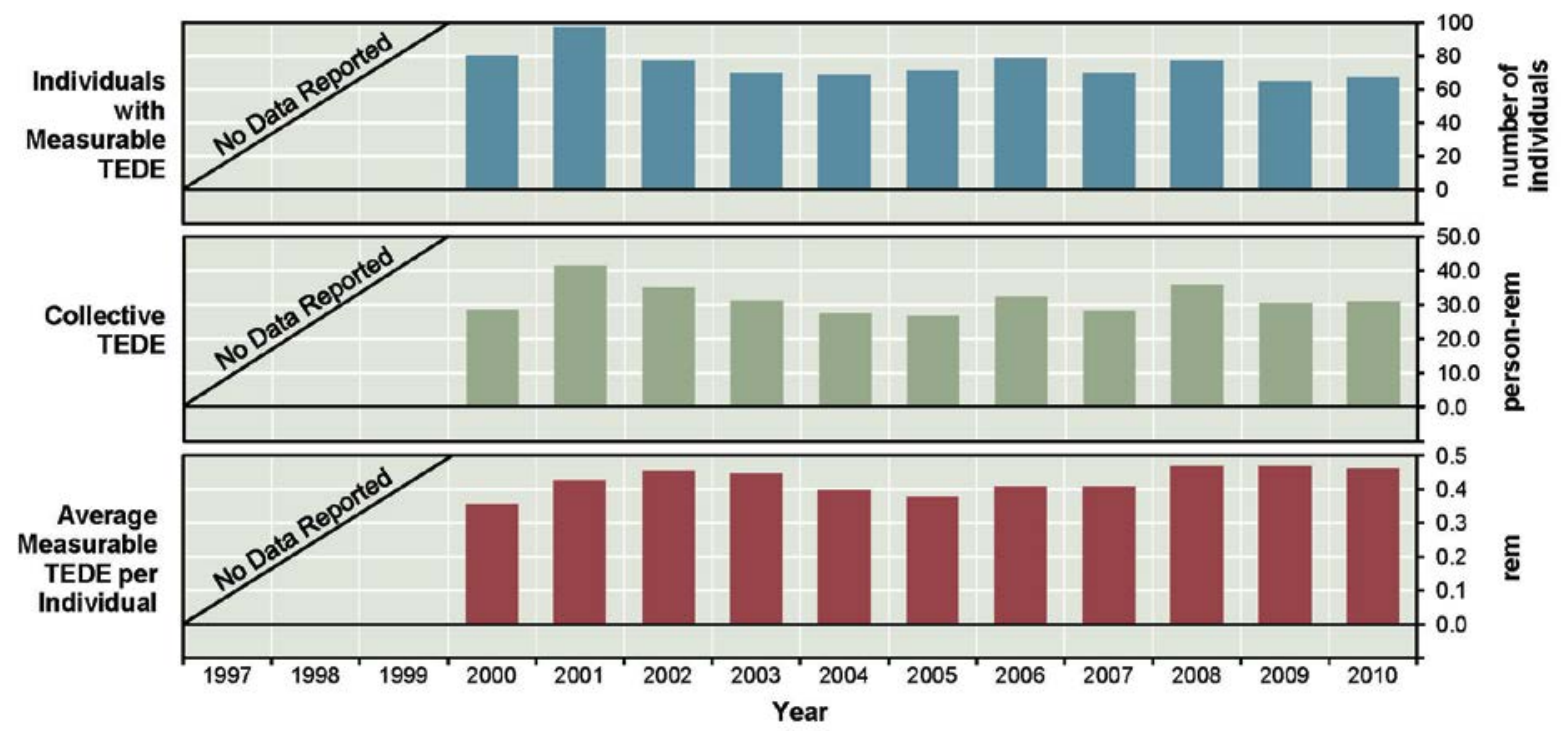

FIGURE 3.5

Annual Values for Well Logging Measuring Systems

1997-2010 
Three percent of the reported individuals with measurable dose (shown in Table 3.2) were monitored by well logging, sealed source facilities, and measuring systems and portable gauge facilities, where they received $5.9 \%$ of the total collective dose.

Table 3.7 summarizes the reported data for well logging and measuring systems for 2008,2009 , and 2010.

TABLE 3.7

Annual Exposure Information for Well Logging Byproduct and/or SNM Sealed Sources Only and Measuring Systems Portable Gauges 2008-2010

\begin{tabular}{|c|c|c|c|c|c|c|}
\hline Year & Type of License & $\begin{array}{l}\text { Number of } \\
\text { Licensees }\end{array}$ & $\begin{array}{l}\text { Number of } \\
\text { Monitored } \\
\text { Individuals }\end{array}$ & $\begin{array}{c}\text { Individuals with } \\
\text { Measurable } \\
\text { Dose }\end{array}$ & $\begin{array}{c}\text { Collective Dose } \\
\text { (person-rem) }\end{array}$ & $\begin{array}{c}\text { Average } \\
\text { Measurable } \\
\text { Dose (rem) }\end{array}$ \\
\hline \multirow{3}{*}{2008} & Well Logging and/or SNM Sealed Sources Only & 1 & 70 & 65 & 34.384 & 0.53 \\
\hline & Measuring Systems Portable Gauges & 1 & 12 & 12 & 1.595 & 0.13 \\
\hline & Total & 2 & 82 & 77 & 35.979 & 0.47 \\
\hline \multirow{3}{*}{2009} & Well Logging and/or SNM Sealed Sources Only & 1 & 68 & 65 & 30.503 & 0.47 \\
\hline & Measuring Systems Portable Gauges & \multicolumn{5}{|c|}{ No Data Reported } \\
\hline & Total & 1 & 68 & 65 & 30.503 & 0.47 \\
\hline \multirow{3}{*}{2010} & Well Logging and/or SNM Sealed Sources Only & 1 & 68 & 56 & 27.050 & 0.48 \\
\hline & Measuring Systems Portable Gauges & 1 & 15 & 11 & 3.900 & 0.35 \\
\hline & Total & 2 & 83 & 67 & 30.950 & 0.46 \\
\hline
\end{tabular}

\subsubsection{Veterinary Non-Human}

Veterinary use includes diagnostic, therapeutic, and research veterinary uses of radioactive drugs and devices. These licenses usually are issued for the treatment of domestic pets and non-food animals. At the present time, no radioactive veterinary drugs have been approved for use in animals intended for the human food supply.

No licensees in this category reported data in 2008 and 2009. Only one licensee in this category reported in 2010 with no measurable dose.

\subsubsection{Instrument Calibration Service Only - Source > 100 Curies/Other Services}

Instrument calibration services are involved in the calibration of radiation survey and monitoring instruments. Other services possess and use radioactive material for various commercial services, such as teletherapy, industrial gauge servicing, or nuclear laundry. Two licensees reported in these categories from 2008 through 2010. 
Figure 3.6 shows the number of individuals with measurable dose, the total collective dose, and the average measurable dose per individual for instrument calibration service only - source > 100 curies, and for other services from 1997 through 2010.

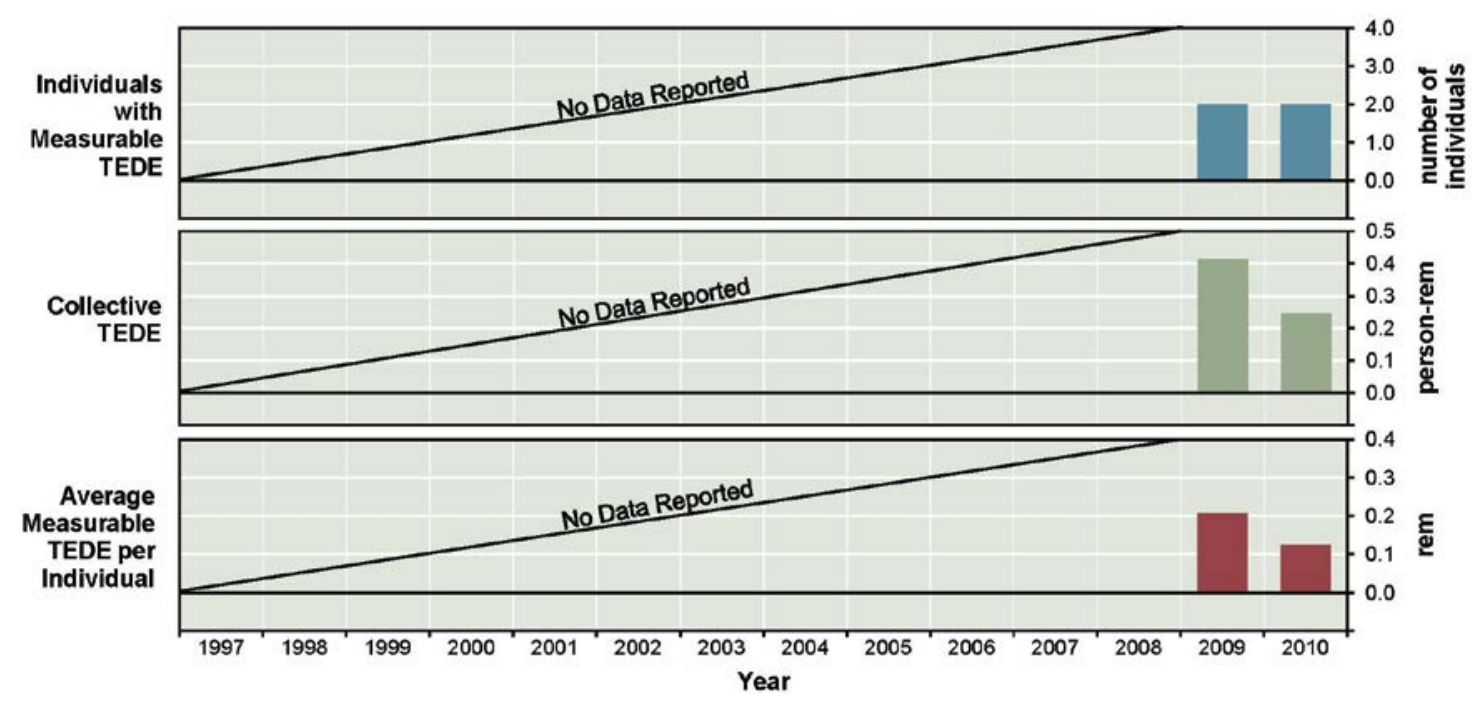

FIGURE 3.6

Annual Values for Instrument Calibration and Other Services

$1997-2010$

Table 3.8 summarizes the reported data for these licensees for 2008, 2009, and 2010. In 2009 and 2010 , licensees for instrument calibration service only - source $>100$ curies and veterinary non-human submitted all individuals with no measurable exposure. These individuals were monitored and doses were reported as ND or non-detectable, which is represented by zero in Table 3.8. Therefore, no average measurable dose was calculated.

TABLE 3.8

Annual Exposure Information for Veterinary Non-Human, Instrument Calibration Service, Other Services 2008-2010

\begin{tabular}{|c|c|c|c|c|c|c|}
\hline Year & Type of License & $\begin{array}{l}\text { Number of } \\
\text { Licensees }\end{array}$ & $\begin{array}{l}\text { Number of } \\
\text { Monitored } \\
\text { Individuals }\end{array}$ & $\begin{array}{l}\text { Individuals with } \\
\text { Measurable } \\
\text { Dose }\end{array}$ & $\begin{array}{l}\text { Collective Dose } \\
\text { (person-rem) }\end{array}$ & $\begin{array}{c}\text { Average } \\
\text { Measurable } \\
\text { Dose (rem) }\end{array}$ \\
\hline \multirow{4}{*}{2008} & Veterinary Non-Human & \multicolumn{5}{|c|}{ No Data Reported } \\
\hline & $\begin{array}{l}\text { Instrument Calibration Service Only - } \\
\text { source }>100 \text { Curies }\end{array}$ & \multicolumn{5}{|c|}{ No Data Reported } \\
\hline & Other Services & 1 & 3 & 0 & 0.000 & - \\
\hline & Total & 1 & 3 & 0 & 0.000 & - \\
\hline \multirow{4}{*}{2009} & Veterinary Non-Human & \multicolumn{5}{|c|}{ No Data Reported } \\
\hline & $\begin{array}{l}\text { Instrument Calibration Service Only - } \\
\text { source }>100 \text { Curies }\end{array}$ & 1 & 34 & 0 & 0.000 & - \\
\hline & Other Services & 1 & 2 & 2 & 0.414 & 0.21 \\
\hline & Total & 2 & 36 & 2 & 0.414 & 0.21 \\
\hline \multirow{4}{*}{2010} & Veterinary Non-Human & 1 & 4 & 0 & 0.000 & - \\
\hline & $\begin{array}{l}\text { Instrument Calibration Service Only - } \\
\text { source }>100 \text { Curies }\end{array}$ & 1 & 35 & 0 & 0.000 & - \\
\hline & Other Services & 1 & 2 & 2 & 0.247 & 0.12 \\
\hline & Total & 3 & 41 & 2 & 0.247 & 0.12 \\
\hline
\end{tabular}





\section{EXPOSURES TO PERSONNEL IN EXCESS OF REGULATORY LIMITS}

\section{$\underline{4.1 \text { Reporting Categories }}$}

Doses in excess of regulatory limits are sometimes referred to as "overexposures." The phrase "doses in excess of regulatory limits" is preferred to overexposures because the latter suggests that an individual has been subjected to an unacceptable biological risk, which may or may not be the case.

The implementation date for the revised 10 CFR Part 20 was January 1, 1994. 10 CFR Part 20 includes requirements for summing internal and external dose equivalents to yield TEDEs and to implement a similar limitation system for organs and tissues (such as the gonads, red bone marrow, bone surfaces, lung, thyroid, and breast). 10 CFR 20.1201 limits the TEDE of individuals to ionizing radiation from licensed material and other sources of radiation within the licensee's control. The annual occupational dose limit for adults is 5 rem.

10 CFR 20.2202 and 10 CFR 20.2203 require that all licensees submit reports of all occurrences involving personnel radiation doses that exceed certain control levels, thus providing for investigations and corrective actions as necessary. Based on the magnitude of the dose, the occurrence may be placed into one of three categories as follows:

\section{Category $A$}

10 CFR 20.2202(a)(1) - a TEDE to any individual of 25 rem or more, a lens dose equivalent of 75 rem or more, or a shallow-dose equivalent to the skin or extremities of 250 rad or more. The Commission must be notified immediately of these events.

2. Category $B$

10 CFR 20.2202(b)(1) - In a 24-hour period, the Commission must be notified of the following events: a TEDE to any individual exceeding 5 rem, a lens dose equivalent exceeding 15 rem, or a shallow-dose equivalent to the skin or extremities exceeding $50 \mathrm{rem}$.

3. Category $\mathrm{C}$

10 CFR 20.2203 — In addition to the notification required by 10 CFR 20.2202 (Category A or B events), each licensee must submit a written report within 30 days after learning of any of the following occurrences:

a. Any incident for which notification is required by 10 CFR 20.2202

b. Doses that exceed the limits in $\S 20.1201, \S 20.1207$, §20.1208, or $\S 20.1301$ (for adults, minors, the embryo/fetus of a declared pregnant woman, and the public, respectively) or any applicable limit in the license

c. Levels of radiation or concentrations of radioactive material that exceed any applicable license limit for restricted areas or that, for unrestricted areas, are in excess of 10 times 
any applicable limit set forth in 10 CFR Part 20 or in the license (whether or not involving dose of any individual in excess of the limits in §20.1301)

d. For licensees subject to the provisions of the Environmental Protection Agency's generally applicable environmental radiation standards in 40 CFR 190, levels of radiation or releases of radioactive material in excess of those standards or license conditions related to those standards

Exposure events reported as either Category A, B, or C typically undergo an investigation and evaluation process by the licensee, the state department responsible for radiation protection, and NRC inspectors when applicable. Preliminary dose estimates submitted by licensees are often conservatively high and do not represent the final (record) dose assigned for the event. It is, therefore, not uncommon for a dose in excess of a regulatory limit event to be reassessed and the final assigned dose to be categorized as not having been in excess of a regulatory limit. In other cases, the exposure event may not be identified until a later date, such as during the next scheduled audit or inspection of the licensee's event records.

The exposure events summary presented here are for events that occurred between 1997 though 2010. An event that has been reassessed and determined not to be a dose in excess of a regulatory limit is not included in this report. The reader should note that the summary presented here represents a snapshot of the status of events through the end of calendar year 2010.

It is important to note that this summary of events includes only

- Occupational radiation doses in excess of the TEDE regulatory limit

- Events at Agreement State-licensed facilities

It does not include

- Medical events as defined in 10 CFR Part 35

- Doses in excess of the regulatory limits to the general public

- Doses in excess of shallow dose equivalent to the maximally exposed extremity (SDE-ME) and shallow dose equivalent to the whole body (SDE-WB)

- Other radiation-related violations, such as high dose-rate areas or effluent limits

- NRC-licensed facilities

- Exposures to dosimeters that, upon evaluation, have been determined to be high dosimeter readings only and are not assigned to an individual as the dose of record by the licensee

\subsection{Summary of Occupational Radiation Doses in Excess of NRC Regulatory Limits}

From 1997 through 2010, there were three events that resulted in exposures that exceeded the annual TEDE of 5 rem. Two of these incidents were reported to NRC's Nuclear Material Events Database (NMED) and one event was reported to the appropriate Agreement State Radiation 
Control Program. Each event underwent an inspection, and the licensees developed a corrective action plan that was reviewed by either the NRC or the appropriate Agreement State Radiation Control Program, to prevent the recurrence of similar events.

In November 2005, a radiation safety officer conducted an update of the radiation exposure reports for their radiography firm. It was noted that for one of the radiographers, a past employer exposure history report could not be located. The past employer history report was eventually found and the radiographer had received 3.918 rem from work conducted at this previous company. When this dose was added to the dose received under his current employer, $1.795 \mathrm{rem}$, his annual dose was $5.713 \mathrm{rem}$. The licensee reported this event to the Texas Department of State Health Services and an event description was included in NRC's NMED. This was a category $C$ event with a dose that exceeded the 5 rem TEDE limit.

In June 2007, a positron emission tomography technician received a dose of 5.440 rem while trouble shooting an error on a Chemistry Synthesis Unit (CSU) at a nuclear pharmacy. He made three attempts to inspect and repair the vacuum line behind the CSU without checking his pocket dosimeter. When this dose was added to his current dose, it brought his annual dose to 5.957 rem. The licensee reported this event to the Washington Department of Health. This was a category $C$ event with a dose that exceeded the 5 rem TEDE limit.

In 2008, a radiography licensee received an exposure report for one of its terminated employees. The exposure report indicated that the employee received $8.212 \mathrm{rem}$. The radiography licensee conducted a review of the employee's exposure reports and tried to contact the employee to obtain additional information. Since the radiography licensee was unsuccessful in contacting the former employee, the radiography licensee reported this overexposure to the California Health and Human Services Agency and an event description was included in NRC's NMED. Since this employee conducted work at other facilities, it was determined that the total annual dose was 8.367 rem. This was a Category $C$ event with a dose that exceeded the 5 rem TEDE limit.

\subsection{Summary of Annual Dose Distributions for Certain Agreement State Licensees}

The dose distribution shown in Table 3.2 reflects the number of individuals in each dose range as reported by each licensee. Each licensee reports the radiation exposure records for the individuals that worked at their facility. Individuals may work at more than one licensee during the year, and this is not reflected in the dose distribution compiled per licensee. Individuals monitored at more than one licensee are referred to as "transient" individuals. Transient individuals in the nuclear power industry are common and have a significant impact on the dose distribution. To determine the impact that transients have on the dose distribution for the Agreement State licensees, the doses are summed for each individual during the year (independent of location) to determine the annual value for each individual. Of particular interest are the individuals that may have exceeded a dose limit by receiving doses at multiple facilities. 
Five rem is the regulatory dose limit for TEDE in 10 CFR Part 20.1201. Agreement States enforce this same regulatory limit. Two rem is commonly used as an administrative control level to ensure that doses do not approach the 5 rem limit and also to keep doses ALARA. The $\mathrm{NRC}$ is assessing the possibility of reducing the dose limit from 5 rem per year to 2 rem per year. Since a change to NRC's 5 rem per year regulatory limit could impact Agreement State licensees, assessing the number of individuals that exceed 2 rem per year at Agreement State licensees is included in this report.

Table 4.1 gives a summary of the individuals reported by Agreement State licensees and shows the number of reported individuals exceeding 2 rem and 5 rem per year from 1997 to 2010 . Table 4.1 also shows that for 11 of the past 14 years, the percentage of individuals with less than 2 rem has been greater than 99\%. The number of individuals receiving an annual dose greater than or equal to 5 rem has been less than $0.02 \%$ since 2005 and has been decreasing over the past 3 years. No individual monitored at any of the Agreement State licensee categories included in this report received a dose above the 5 rem annual TEDE limit during the past 2 years. It should be noted that this report contains only those Agreement State licensees that voluntarily reported their data to REIRS. Therefore, this data is only a representative sample of the dose information from all Agreement State licensees.

It is not possible to assess the impact on Agreement State licensees if the regulatory limit is changed to 2 rem because according to Table 4.1, few individuals have exceeded 2 rem. In addition, the data voluntarily reported by Agreement State licensees represents $\sim 2 \%$ of all Agreement State licensees. As noted above, this data set is a representative sample and a generic assessment may not be applicable across the broad range of Agreement State licensee activities. However, as a general assessment, if the current regulatory limit were reduced from 5 rem to 2 rem, licensees may need to improve radiation protection practices, revise procedures, and possibly utilize more workers in certain tasks in order to distribute the dose among the worker population. A combination of these approaches could lessen the impact of a potential change in the regulatory limit, but there may still be challenges in reducing dose further in some occupational situations due to limitations in the availability of skilled workers that could perform certain tasks.

As shown in the Corrected Number column of Table 4.1, the impact of transient individuals to the dose received is minimal. Over the past 14 years, just over $1 \%$ of the total number of reported individuals may have been counted more than once because they worked at more than one facility during the calendar year. 
TABLE 4.1

Summary of Annual Distributions for Certain Agreement State Licensees $1997-2010$

\begin{tabular}{|c|c|c|c|c|c|c|c|}
\hline \multirow[b]{3}{*}{ Year } & \multirow{2}{*}{\multicolumn{2}{|c|}{ Total Number of Monitored Individuals }} & \multicolumn{4}{|c|}{ Individuals with Doses ** } & \multirow{3}{*}{$\begin{array}{l}\text { Individuals } \\
\text { with Doses } \\
>12 \text { rem }\end{array}$} \\
\hline & & & \multirow{2}{*}{$\begin{array}{c}<2 \text { rem } \\
\%\end{array}$} & \multirow{2}{*}{$\begin{array}{l}>2 \mathrm{rem} \\
\text { Number }\end{array}$} & \multirow{2}{*}{$\frac{<5 \text { rem }}{\%}$} & \multirow{2}{*}{$\begin{array}{l}>5 \text { rem } \\
\text { Number }\end{array}$} & \\
\hline & Reported Number & Corrected Number * & & & & & \\
\hline 1997 & 41 & 41 & $100.0 \%$ & 0 & $100.0 \%$ & 0 & 0 \\
\hline 1998 & 123 & 101 & $100.0 \%$ & 0 & $100.0 \%$ & 0 & 0 \\
\hline 1999 & 111 & 111 & $100.0 \%$ & 0 & $100.0 \%$ & 0 & 0 \\
\hline 2000 & 382 & 381 & $99.2 \%$ & 3 & $100.0 \%$ & 0 & 0 \\
\hline 2001 & 357 & 355 & $99.4 \%$ & 2 & $100.0 \%$ & 0 & 0 \\
\hline 2002 & 2,850 & 2,847 & $99.9 \%$ & 2 & $100.0 \%$ & 0 & 0 \\
\hline 2003 & 4,160 & 4,114 & $99.6 \%$ & 17 & $100.0 \%$ & 0 & 0 \\
\hline 2004 & 4,511 & 4,463 & $99.6 \%$ & 16 & $100.0 \%$ & 0 & 0 \\
\hline 2005 & 4,724 & 4,665 & $99.1 \%$ & 42 & $99.98 \%$ & 1 & 0 \\
\hline 2006 & 5,487 & 5,429 & $98.8 \%$ & 67 & $100.0 \%$ & 0 & 0 \\
\hline 2007 & 5,752 & 5,688 & $98.8 \%$ & 68 & $99.98 \%$ & 1 & 0 \\
\hline 2008 & 5,179 & 5,125 & $99.3 \%$ & 35 & $99.98 \%$ & 1 & 0 \\
\hline 2009 & 5,233 & 5,177 & $99.4 \%$ & 31 & $100.0 \%$ & 0 & 0 \\
\hline 2010 & 1,723 & 1,718 & $98.7 \%$ & 22 & $100.0 \%$ & 0 & 0 \\
\hline
\end{tabular}

* This column lists the actual number of individuals who may have been counted more than once because they worked at more than one facility during the calendar year.

** Data for 1997-2010 are based on the distribution of individual doses after adjusting for the multiple counting of transient individuals.

\subsection{Maximum Occupational Radiation Doses Below NRC Regulatory Limits}

Certain researchers have expressed an interest in a listing of the maximum doses received at licensed facilities that do not exceed NRC regulatory limits. This information allows an examination of these doses and could possibly provide insights on where certain improvements can be made regarding licensees' radiation protection programs.

Table 4.2 shows the maximum doses for each dose category required to be reported to the NRC. In addition, the number of doses in certain dose ranges is shown to reflect the number of doses that approach NRC regulatory limits. As shown in Table 4.2, few doses exceed half of the NRC occupational annual limits. The Agreement State occupational data analyzed over the 14year period for this report indicate that 16 individuals exceeded $95 \%$ of the extremity dose limit and 3 individuals exceeded $95 \%$ of the 5 rem TEDE limit. 
TABLE 4.2

Maximum Occupational Exposures* for Each Exposure Category $1997-2010$

\begin{tabular}{|c|c|c|c|c|c|c|c|c|c|}
\hline $\begin{array}{c}\text { Dose } \\
\text { Category * }\end{array}$ & $\begin{array}{l}\text { Annual Does } \\
\text { Limit } \\
\text { 10CFR20 }\end{array}$ & $\begin{array}{l}\text { Maximum } \\
\text { Dose } \\
\text { Reported } \\
\text { (rem) }\end{array}$ & $\begin{array}{l}\text { Max Dose } \\
\text { Percent of } \\
\text { the Limit }\end{array}$ & $\begin{array}{l}\text { Number of } \\
\text { Individuals with } \\
\text { Measurable Dose }\end{array}$ & $\begin{array}{l}\text { Number of } \\
\text { Individuals } \\
>25 \% \text { of } \\
\text { the Limit }\end{array}$ & $\begin{array}{c}\text { Number of } \\
\text { Individuals } \\
>50 \% \text { of } \\
\text { the Limit }\end{array}$ & $\begin{array}{l}\text { Number of } \\
\text { Individuals } \\
>75 \% \text { of } \\
\text { the Limit }\end{array}$ & $\begin{array}{l}\text { Number of } \\
\text { Individuals } \\
>95 \% \text { of } \\
\text { the Limit }\end{array}$ & $\begin{array}{l}\text { Number of } \\
\text { Individuals } \\
>\text { Limit }\end{array}$ \\
\hline SDE-ME & 50 rem & 60.560 & $121 \%$ & 17,874 & 2763 & 404 & 57 & 16 & 10 \\
\hline SDE-WB & 50 rem & 13.412 & $27 \%$ & 31,177 & 2 & 0 & 0 & 0 & 0 \\
\hline LDE & $15 \mathrm{rem}$ & 8.856 & $59 \%$ & 30,302 & 30 & 2 & 0 & 0 & 0 \\
\hline CEDE & & 2.086 & & 2,449 & & & & & \\
\hline $\mathrm{CDE}$ & & 17.197 & & 3,136 & & & & & \\
\hline DDE & & 8.367 & & 31,121 & & & & & \\
\hline TEDE & $5 \mathrm{rem}$ & 8.367 & $167 \%$ & 31,379 & 942 & 147 & 24 & 3 & 3 \\
\hline TODE & 50 rem & 17.362 & $35 \%$ & 30,516 & 3 & 0 & 0 & 0 & 0 \\
\hline
\end{tabular}

* Numbers have been adjusted for the multiple reporting of transient individuals.

** SDE-ME = shallow dose equivalent to the maximally exposed extremity

$S D E-W B=$ shallow dose equivalent to the whole body

$L D E=$ lens dose equivalent

$C E D E=$ committed effective dose equivalent

$C D E=$ committed dose equivalent

$D D E=$ deep dose equivalent

$T E D E=$ total effective dose equivalent

TODE = total organ dose equivalent

*** Shaded boxes represent dose categories that do not have specific dose limits defined in 10 CFR Part 20. 


\section{CONCLUSIONS}

The occupational radiation exposure data submitted in response to the NRC Letter proved to be a valuable addition to the REIRS database. This data provided insight into the non-NRC licensees to better inform the NRC on possible impacts of changing the regulations to coincide with ICRP 103. In particular, the dose records voluntarily submitted in response to the NRC letter added 37,491 records to the REIRS database in nine licensee categories.

From 1997 to 2010, the Agreement State dose records greater than or equal to 2 rem for industrial radiography licensees totaled 4\% (245) of the number with measurable dose, while the dose records greater than or equal to 2 rem for manufacturing and distribution licensees totaled $0.2 \%$ (52) of the number with measurable dose. While the manufacturing and distribution licensees have more individuals with measurable dose than industrial radiography licensees, the percentage of individuals exceeding 2 rem for industrial radiography is larger.

The Agreement State data included in this report show that the percentage of individuals with measurable dose that exceed 2 rem at Agreement State licensees was 1\%. The percentage for all NRC licensees was 0.6\%. With nearly 20,000 licenses issued in Agreement States, this report analyzed dose records from only $312(2 \%)$ Agreement State licensees. As a result of this report, it is expected that there will be an increase in the number of Agreement State licensees who voluntarily submit their data to REIRS for future analysis. 



\section{REFERENCES}

1. SECY-08-0197. "Options to Revise Radiation Protection Regulations and Guidance with Respect to the 2007 Recommendations of the International Commission on Radiological Protection," dated December 18, 2008 (ML083360582).

2. International Commission on Radiological Protection Publication 103. The 2007 Recommendations of the International Commission on Radiological Protection, Annals of the ICRP Volume 37 Nos. 2-4, 2007.

3. SRM-SECY-08-0197. "Options to Revise Radiation Protection Regulations and Guidance with Respect to the 2007 Recommendations of the International Commission on Radiological Protection," dated April 2, 2009 (ML090920103).

4. NRC Letter. Request to Provide Occupational Radiation Dose Data from Industrial Radiography and Nuclear Pharmacy Licensees (ML10210039), dated August, 2010.

5. Agreement State Program. http://www.nrc.gov/about-nrc/state-tribal/agreement-states.html.

6. The Atomic Energy Act of 1954, as amended, dated August 30, 1954.

7. U. S. Nuclear Regulatory Commission. Information Digest 2009-2010, USNRC Report NUREG-1350, Volume 21, August 2009.

8. Organization of Agreement States. http://www.agreementstates.org/.

9. Conference of Radiation Control Programs, Inc. http://www.crcpd.org/about/about.aspx.

10. U. S. Nuclear Regulatory Commission. Management Directive 5.9, "Adequacy and Compatibility of Agreement State Programs, " February 1998 



\section{Appendix A}

\section{LIST OF AGREEMENT STATE LICENSEES, 1997 - 2010}




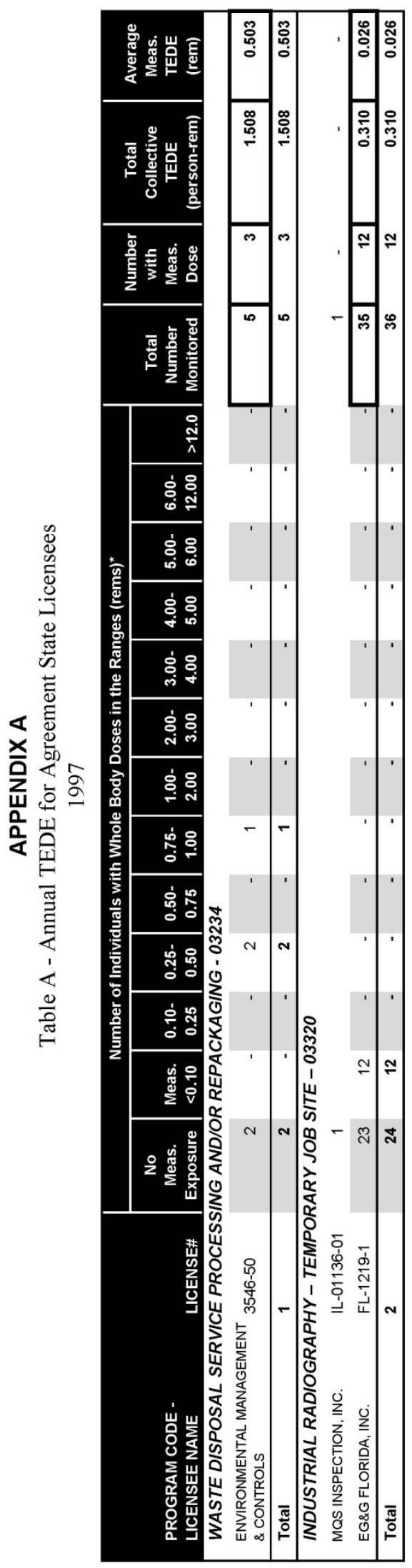




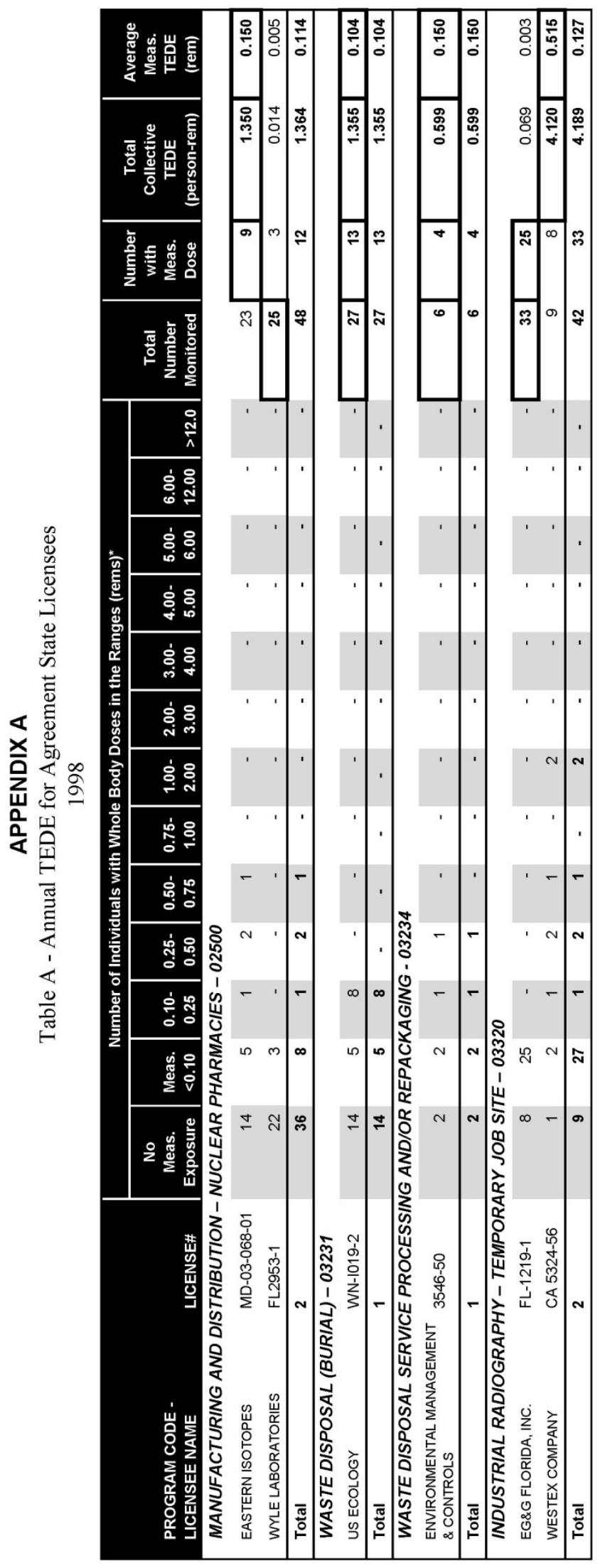




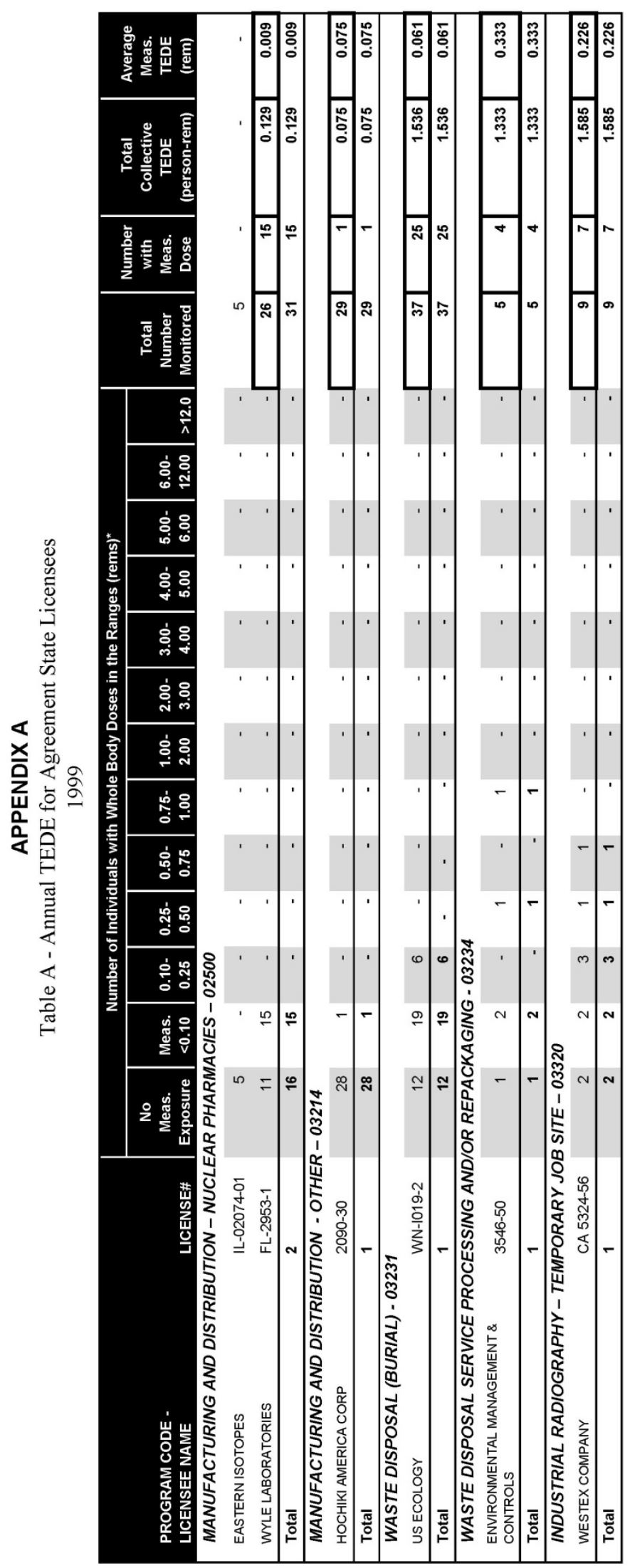




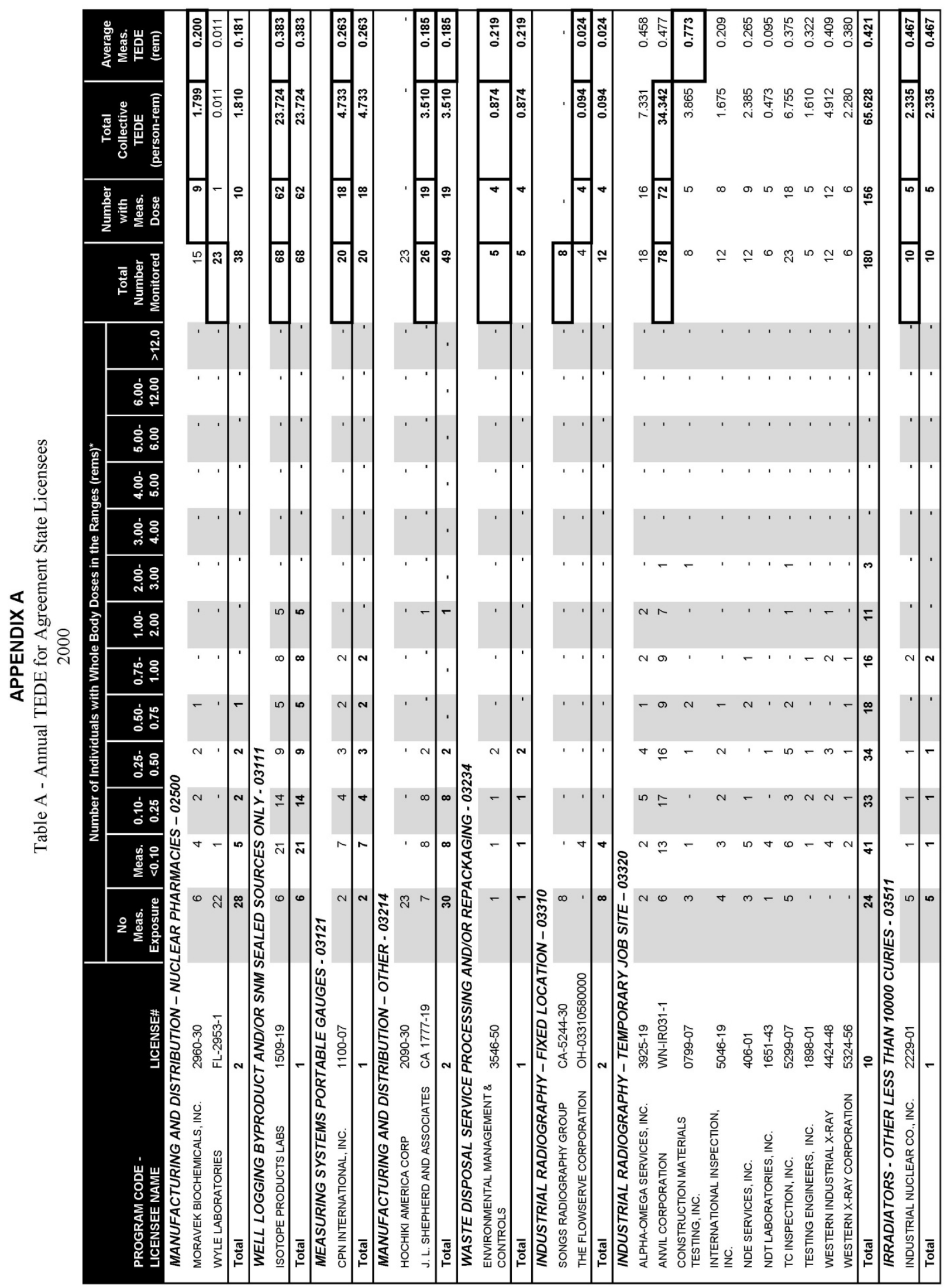




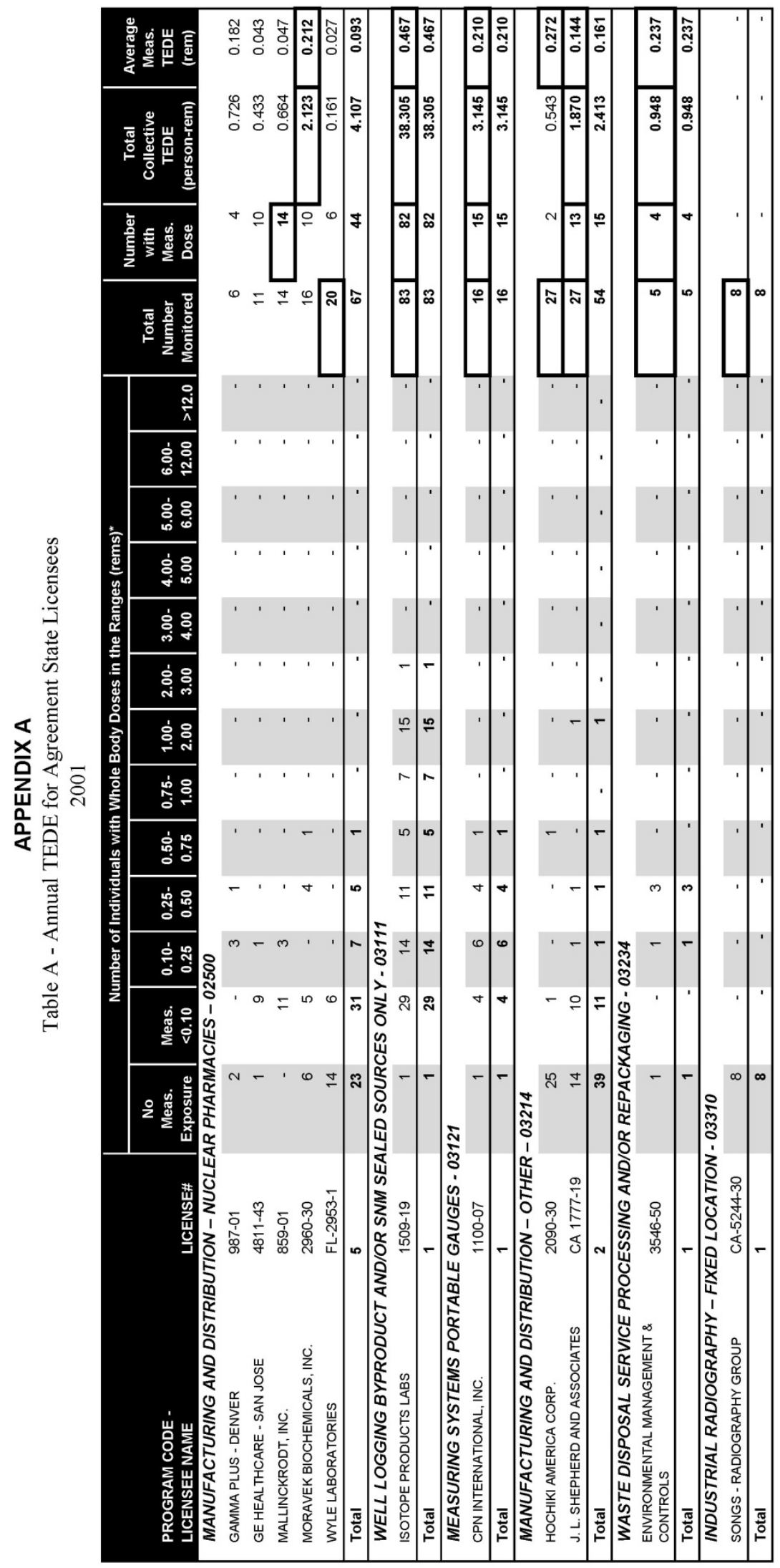




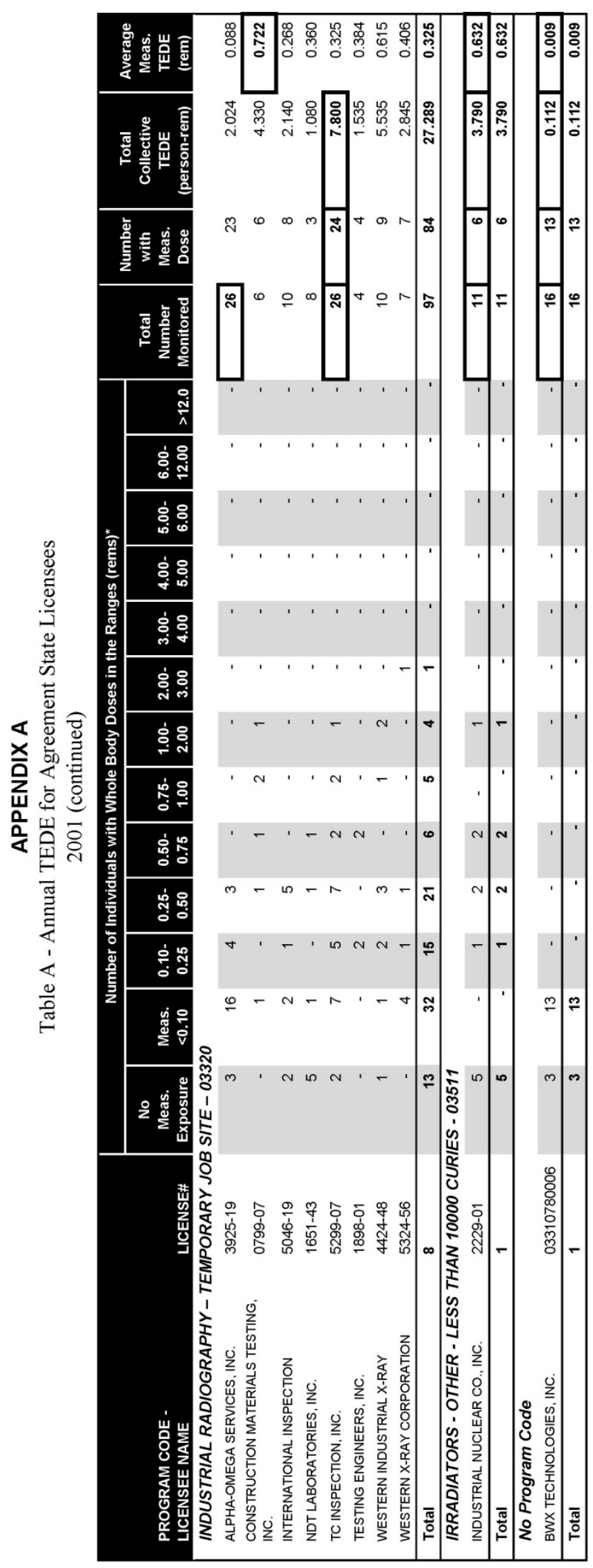




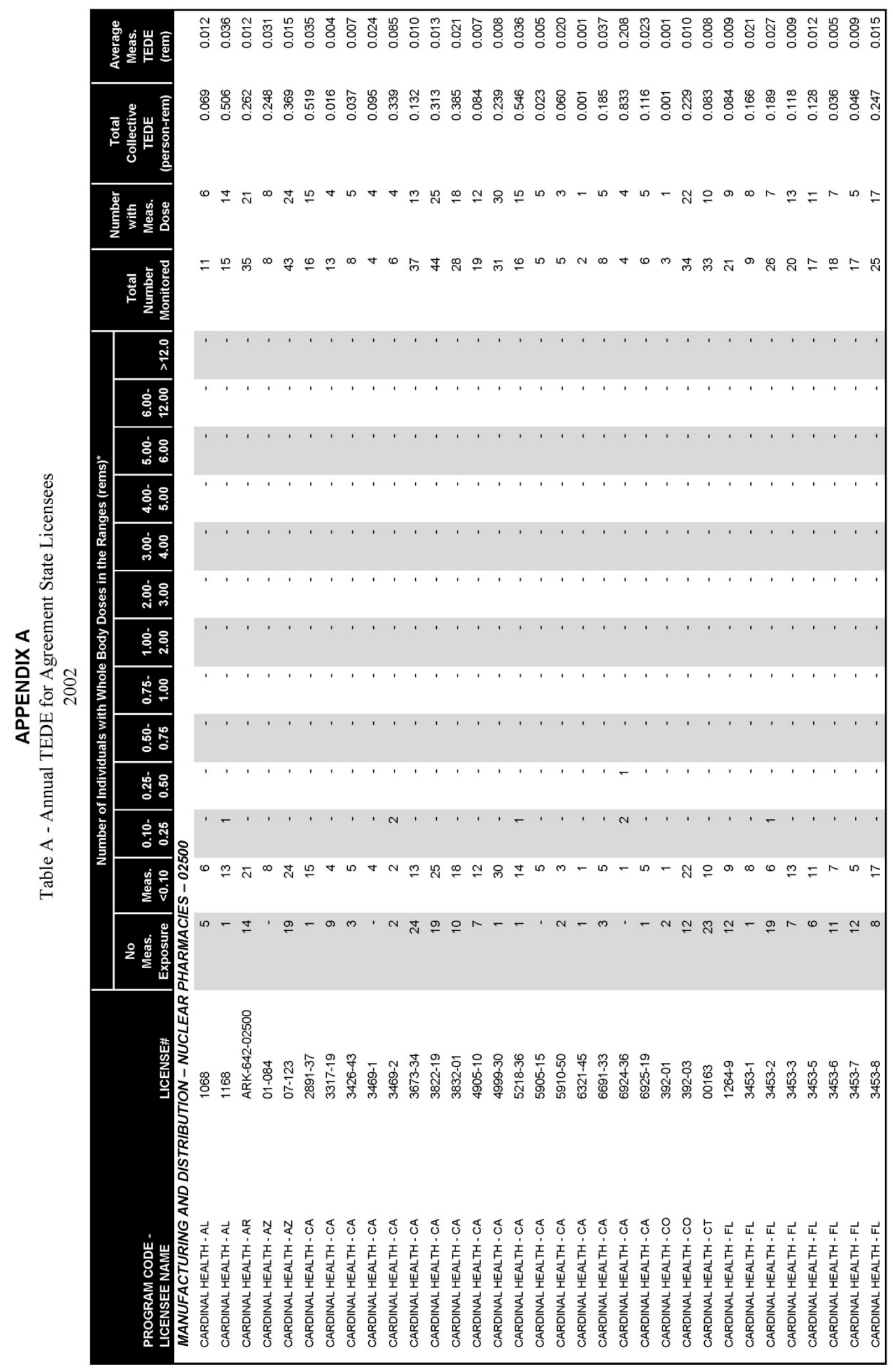




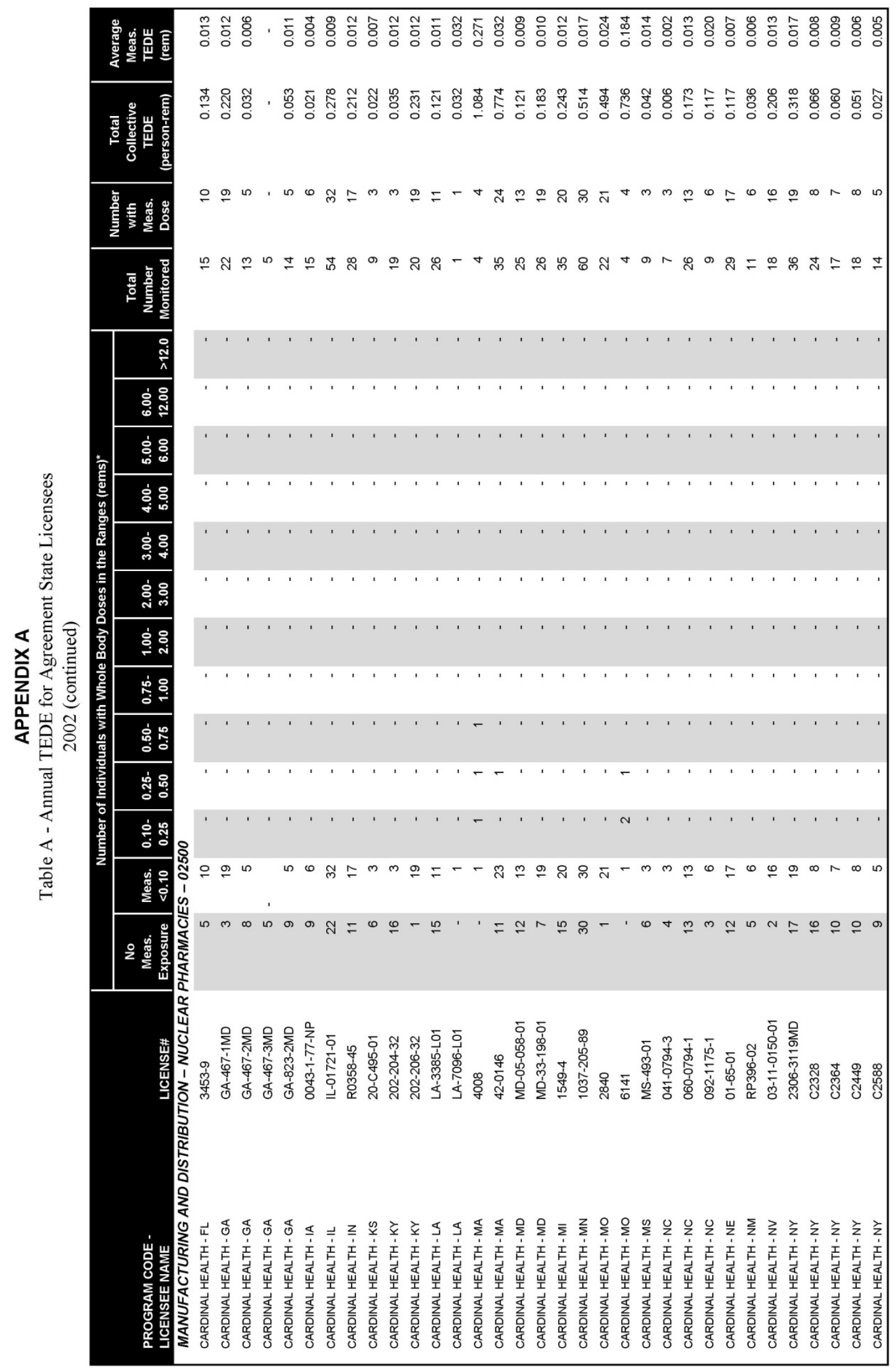




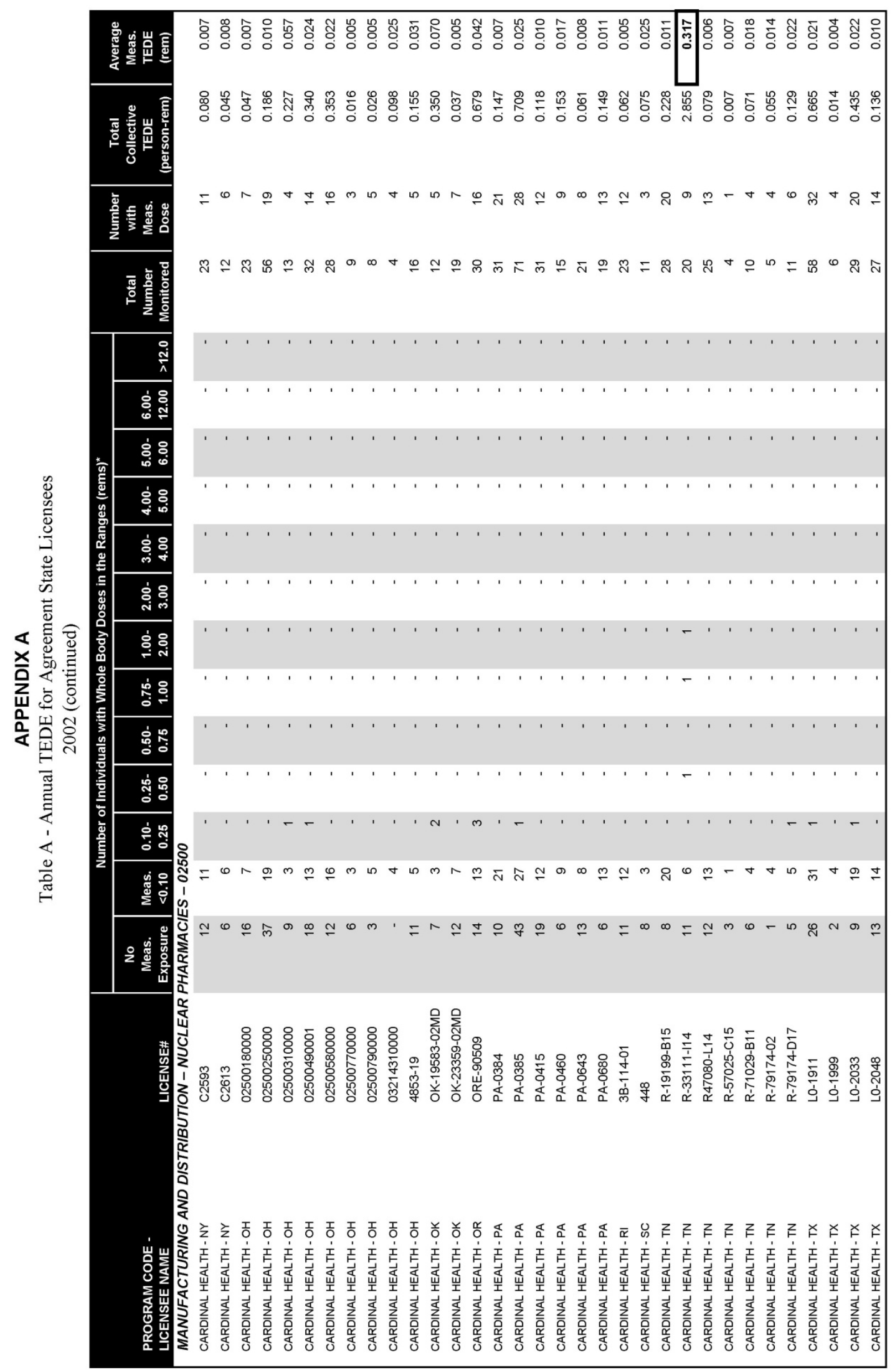




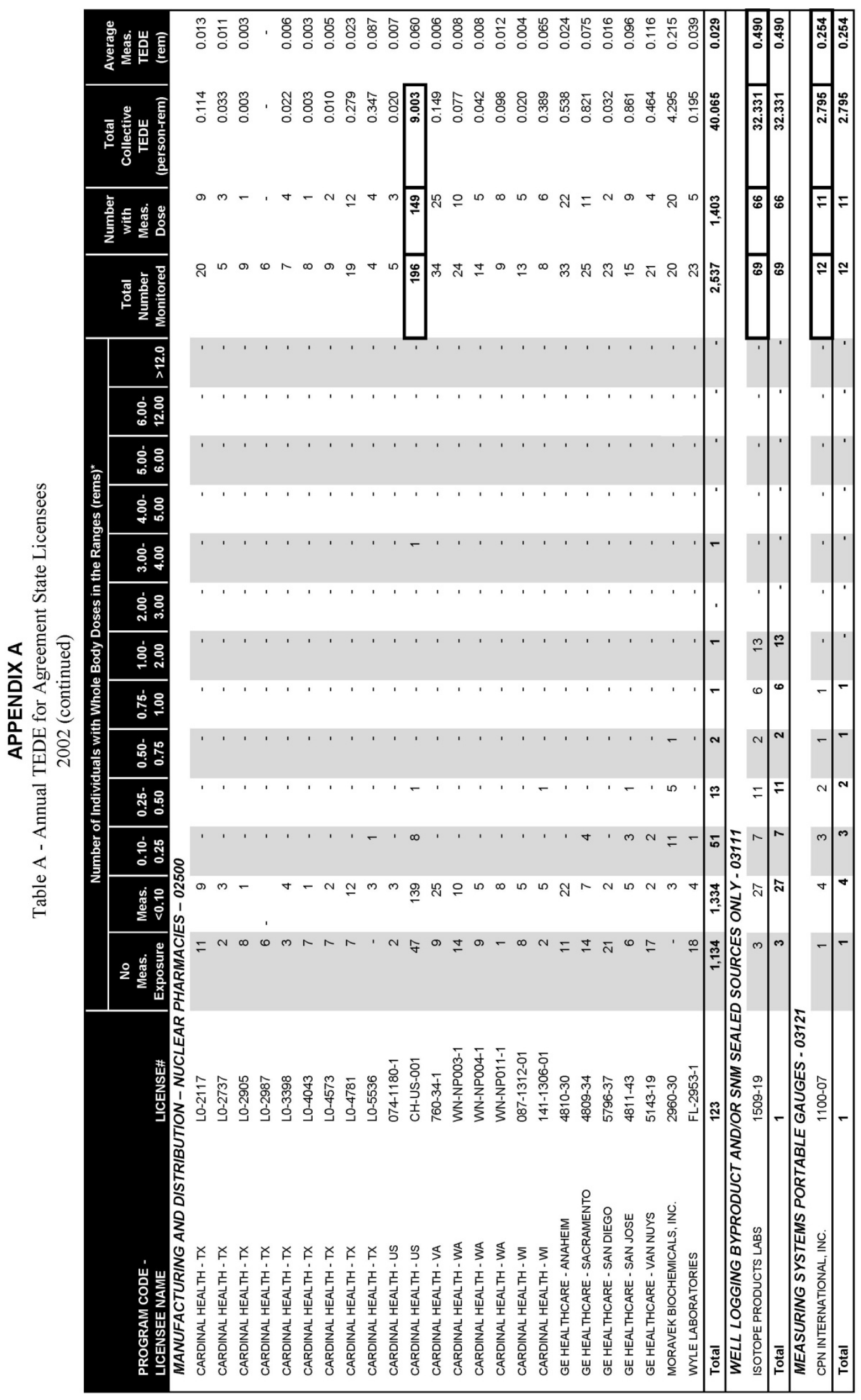




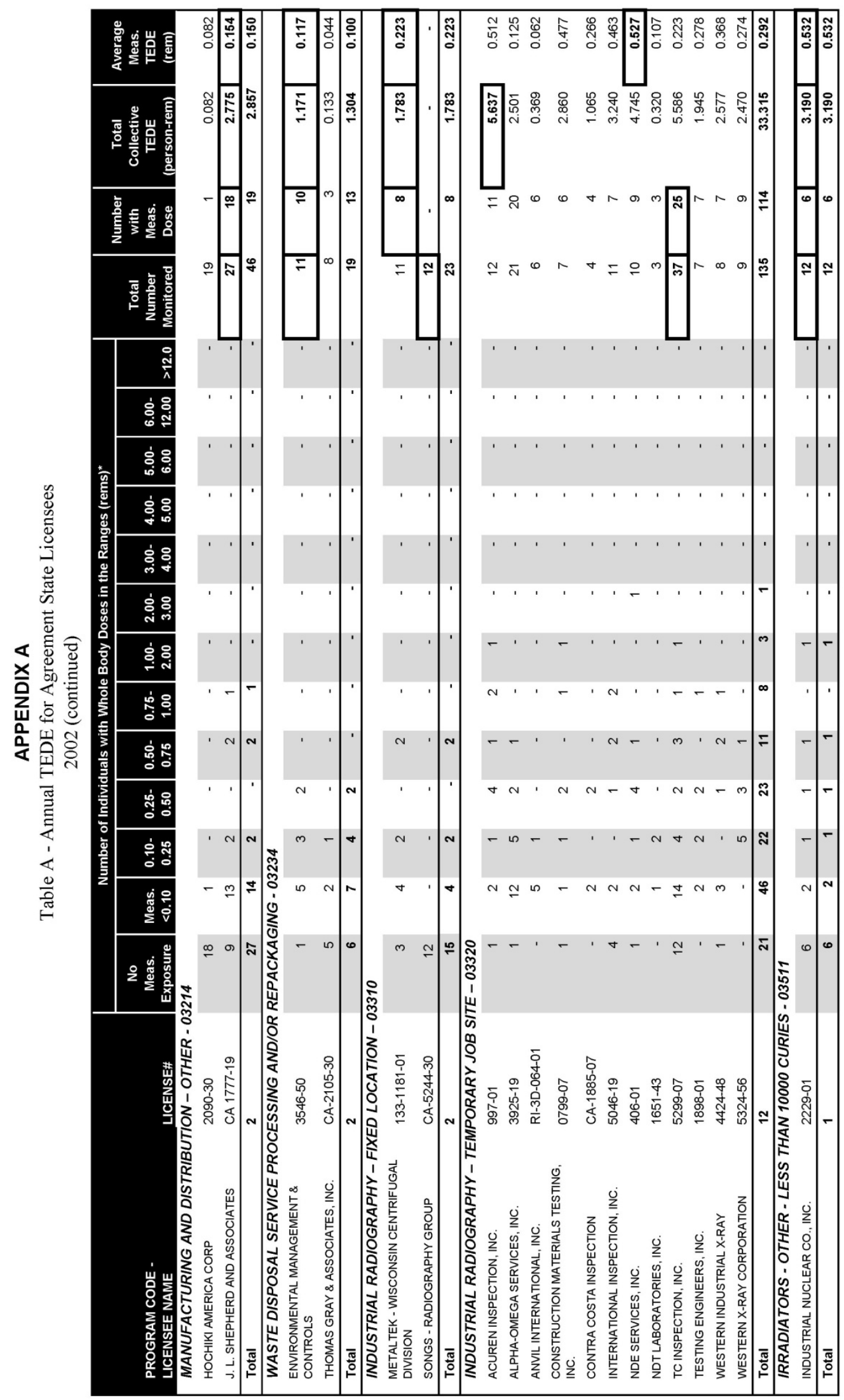




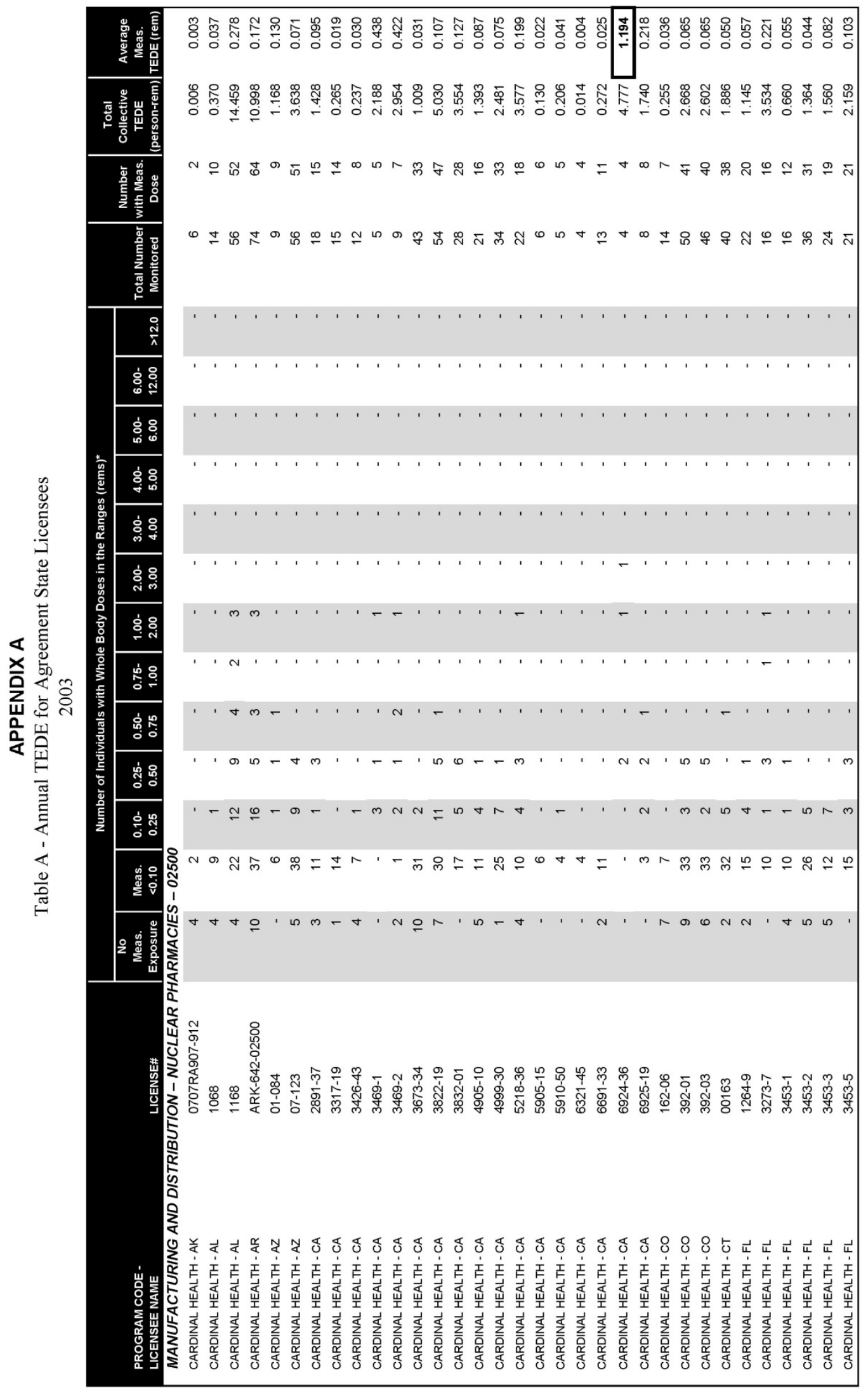




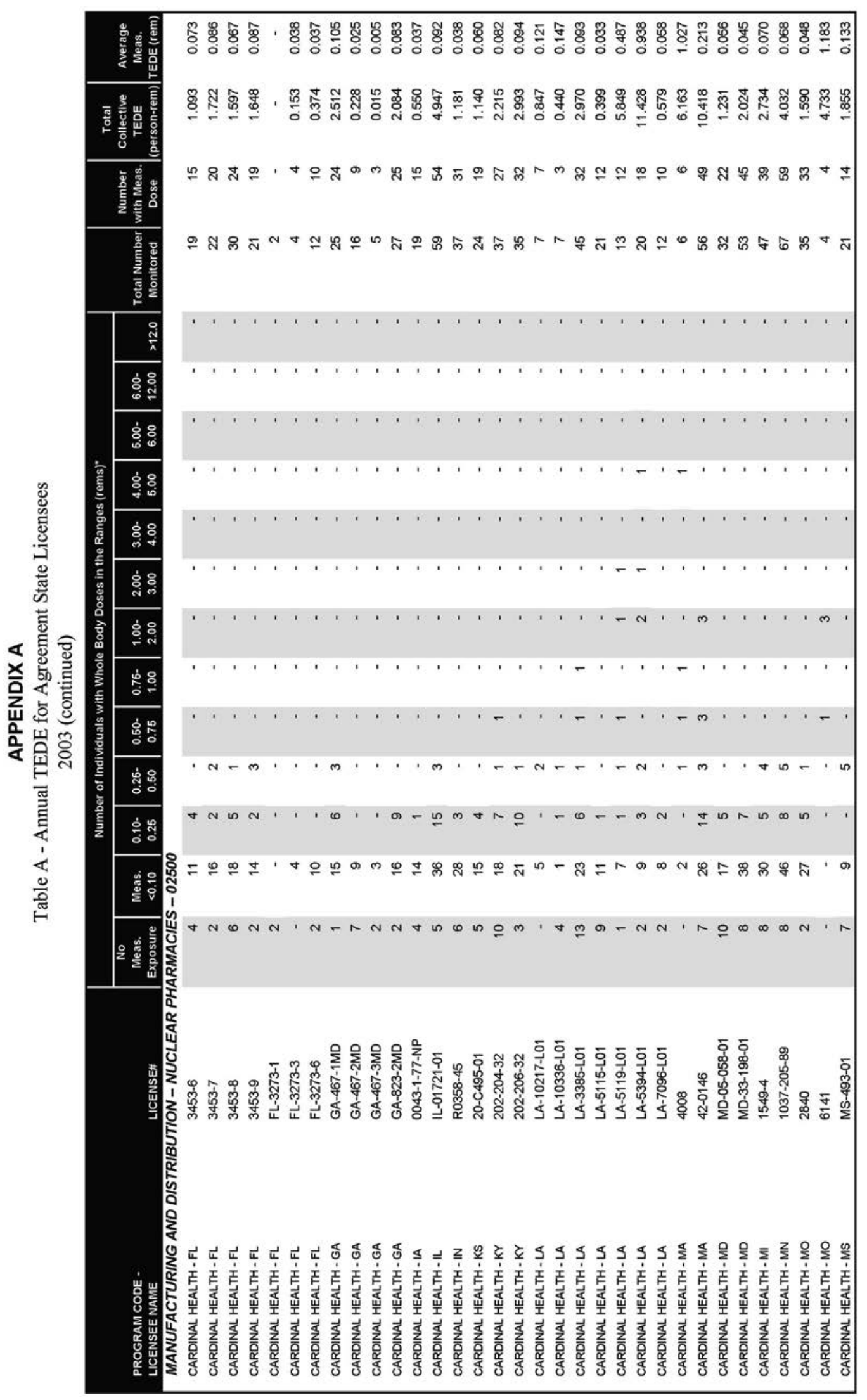




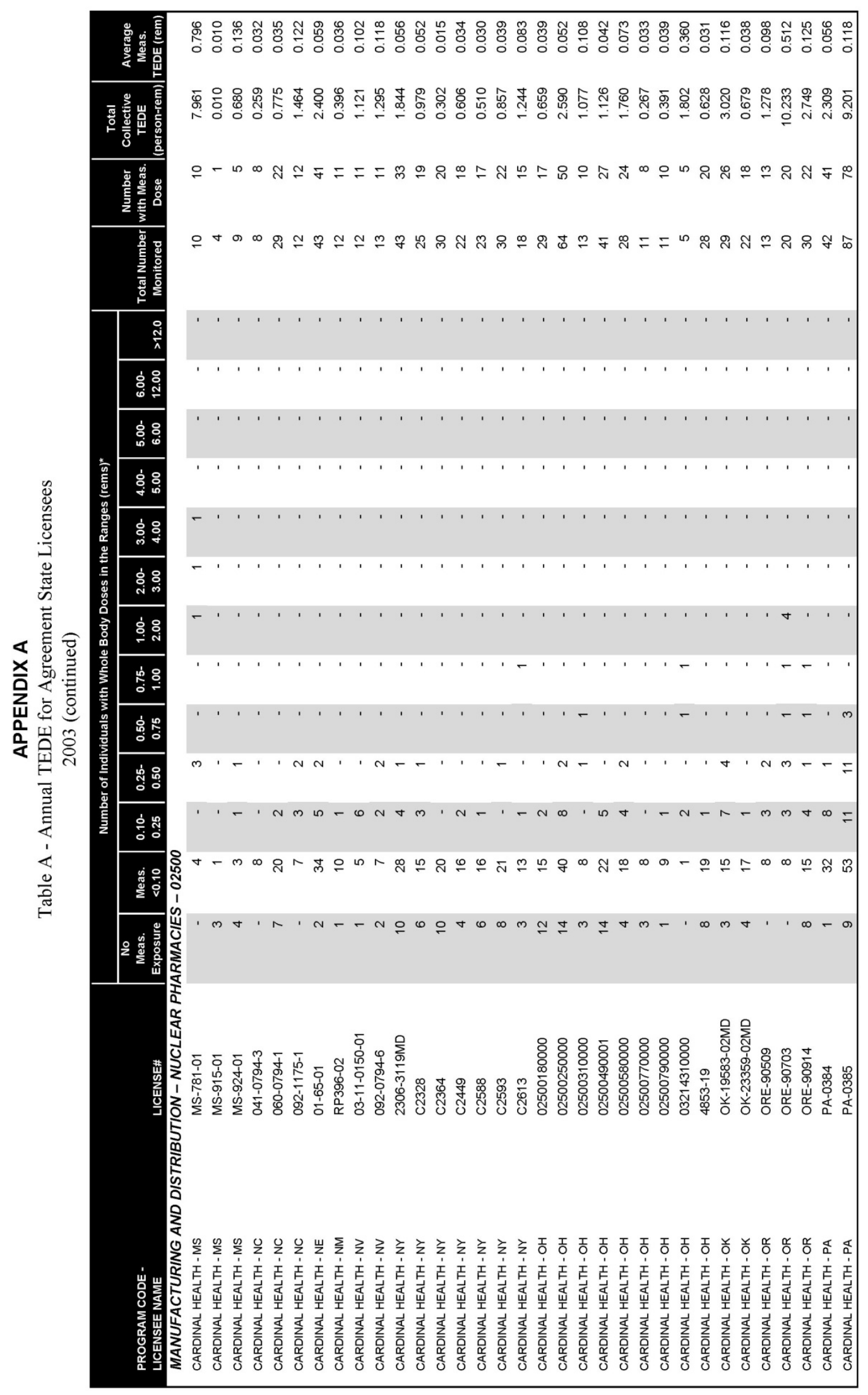




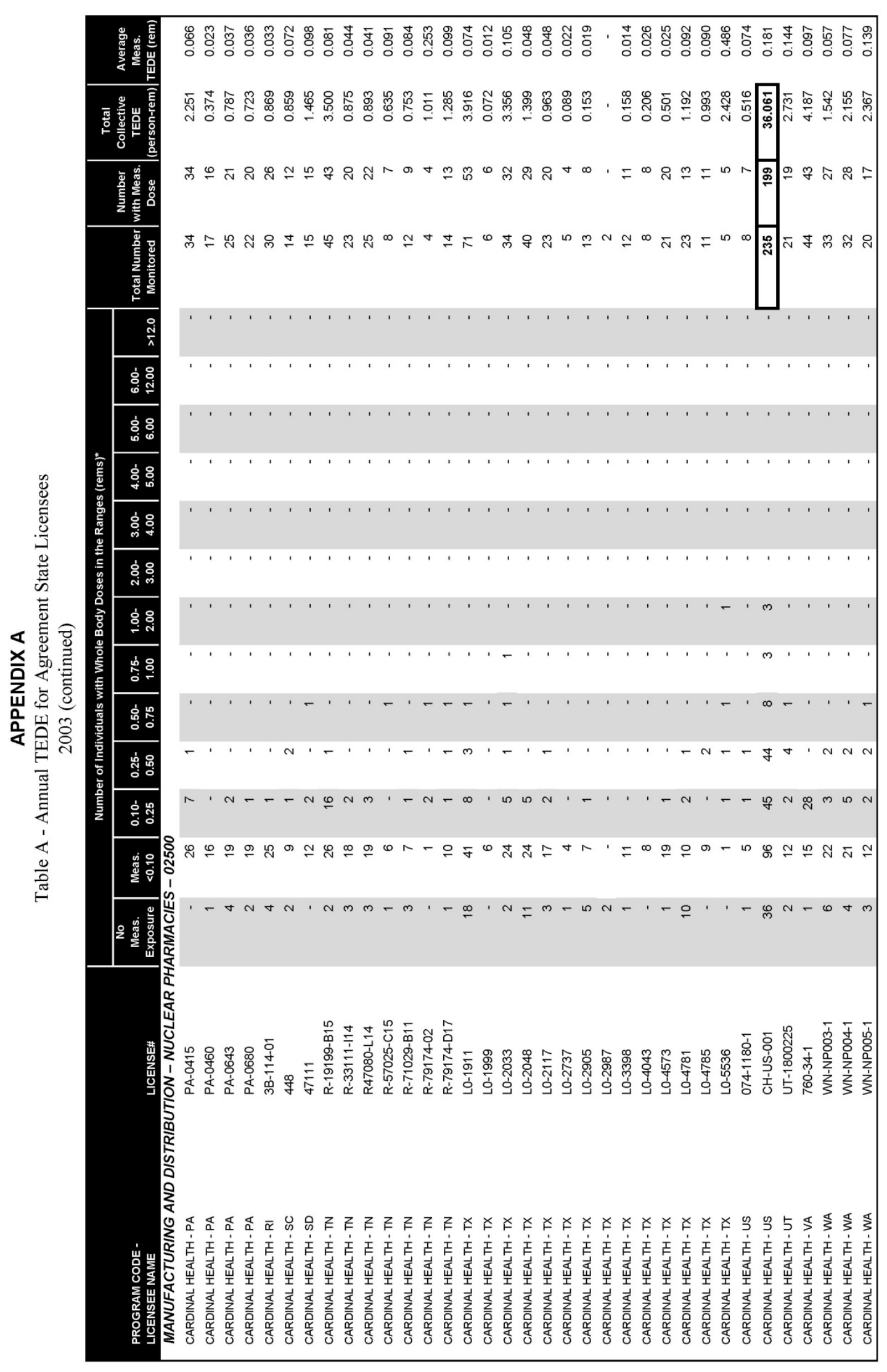




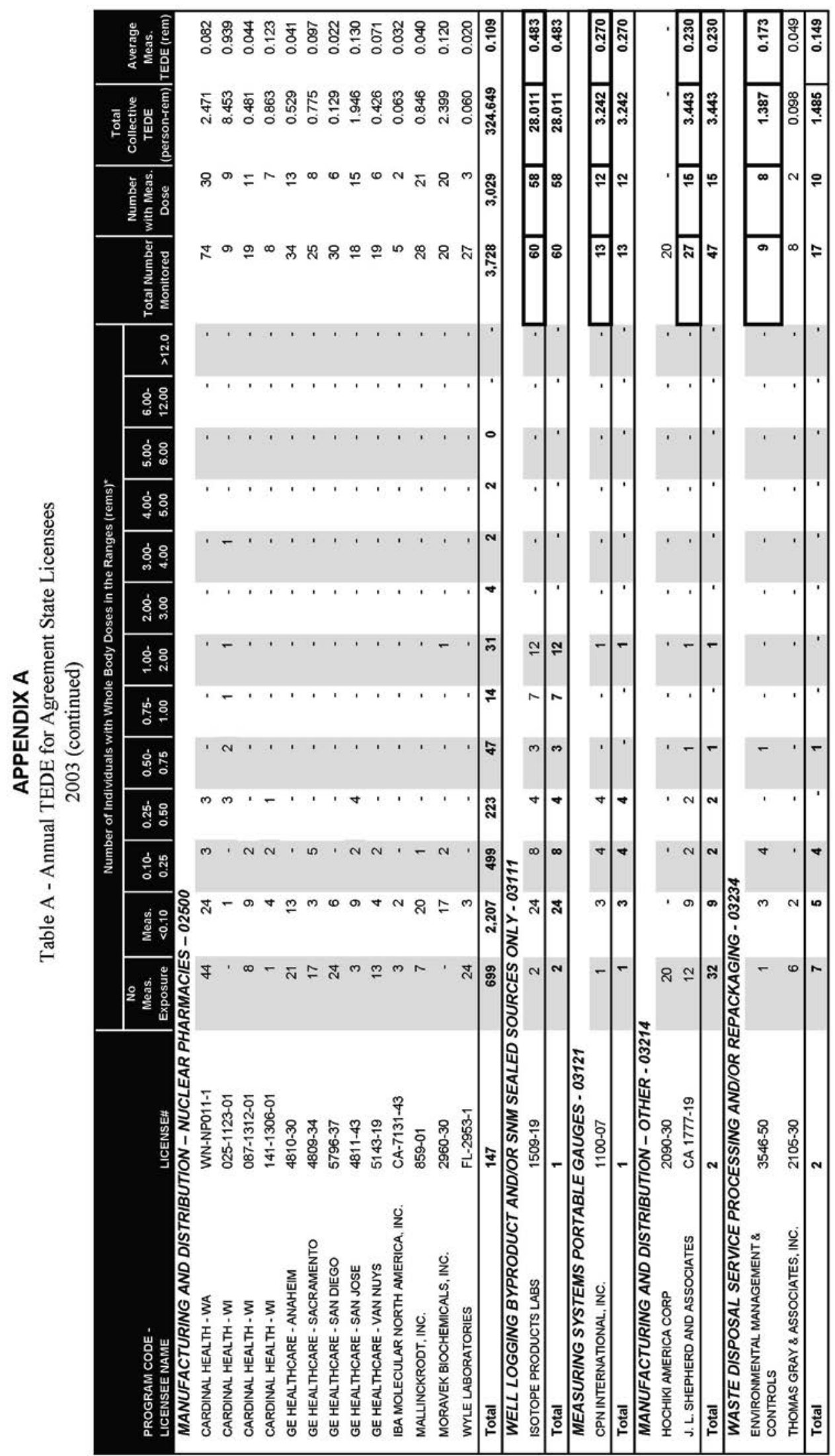




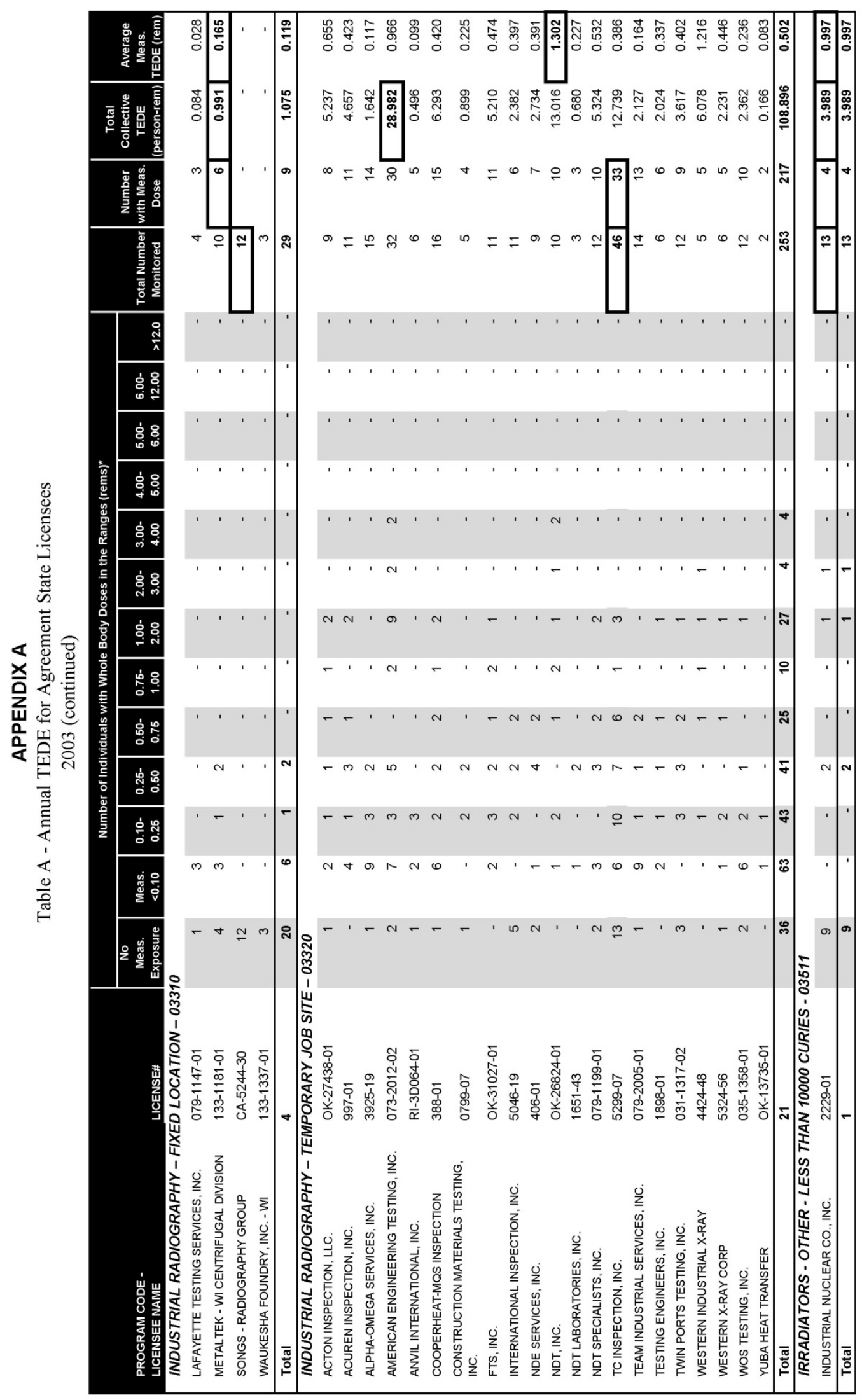




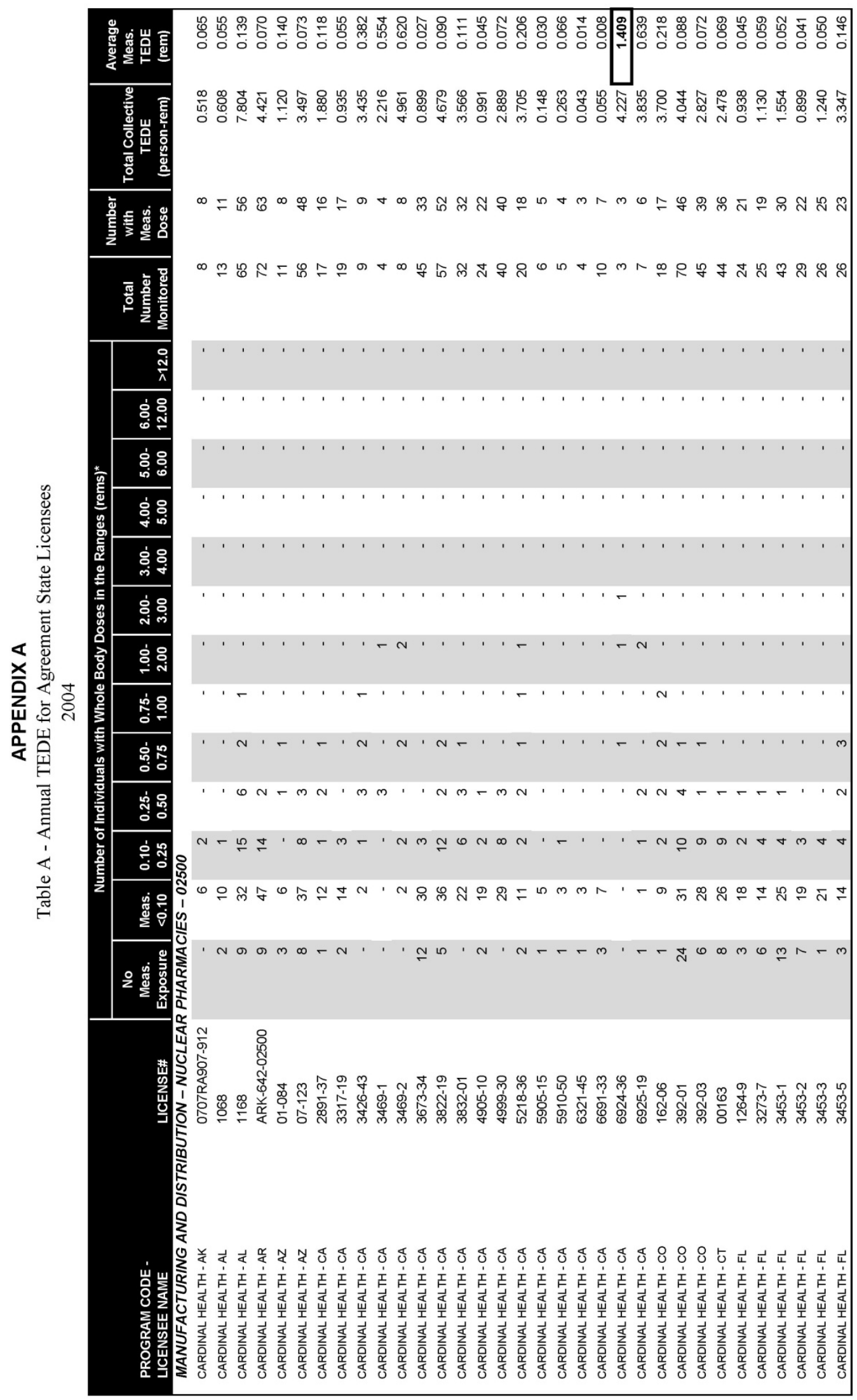




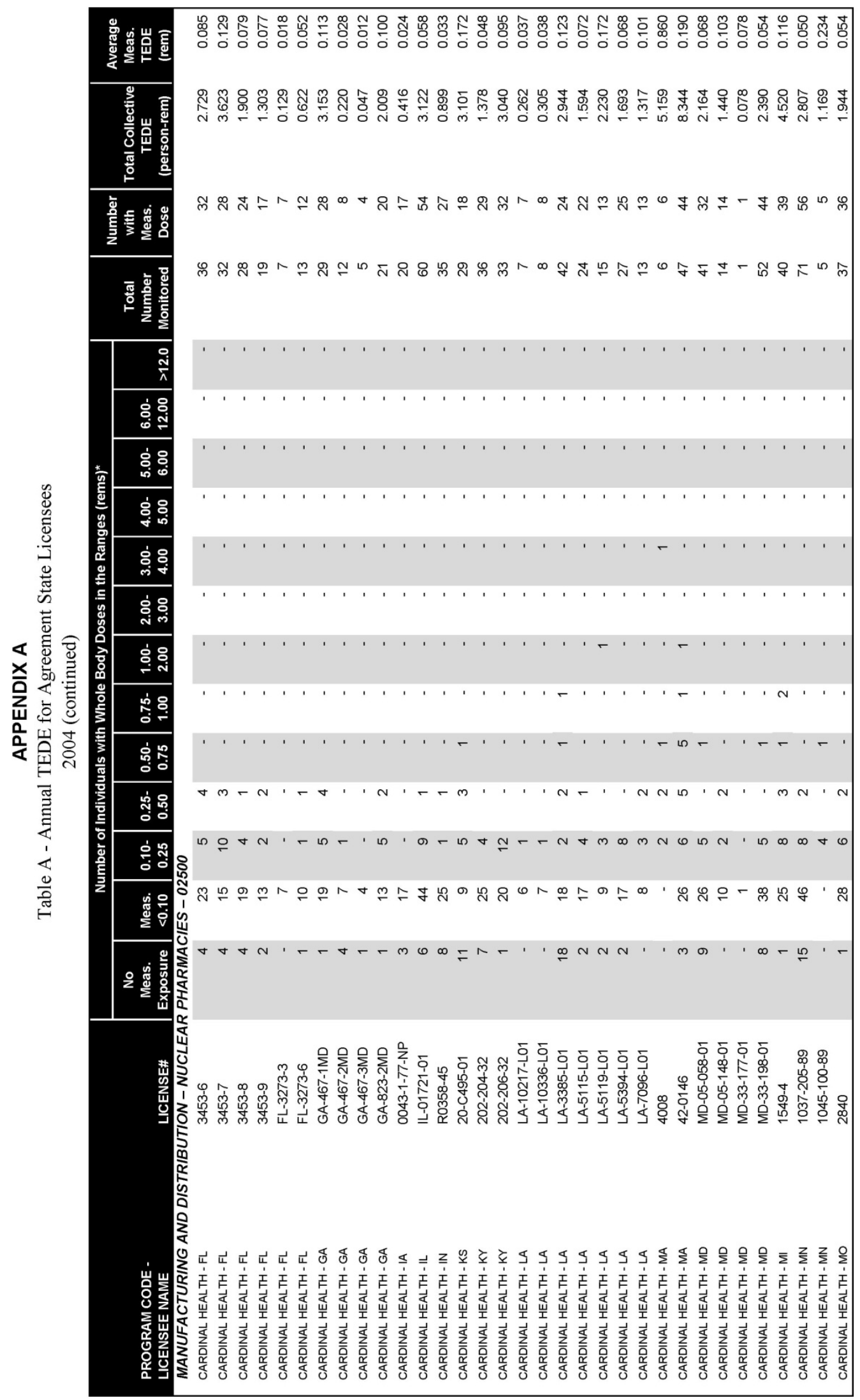




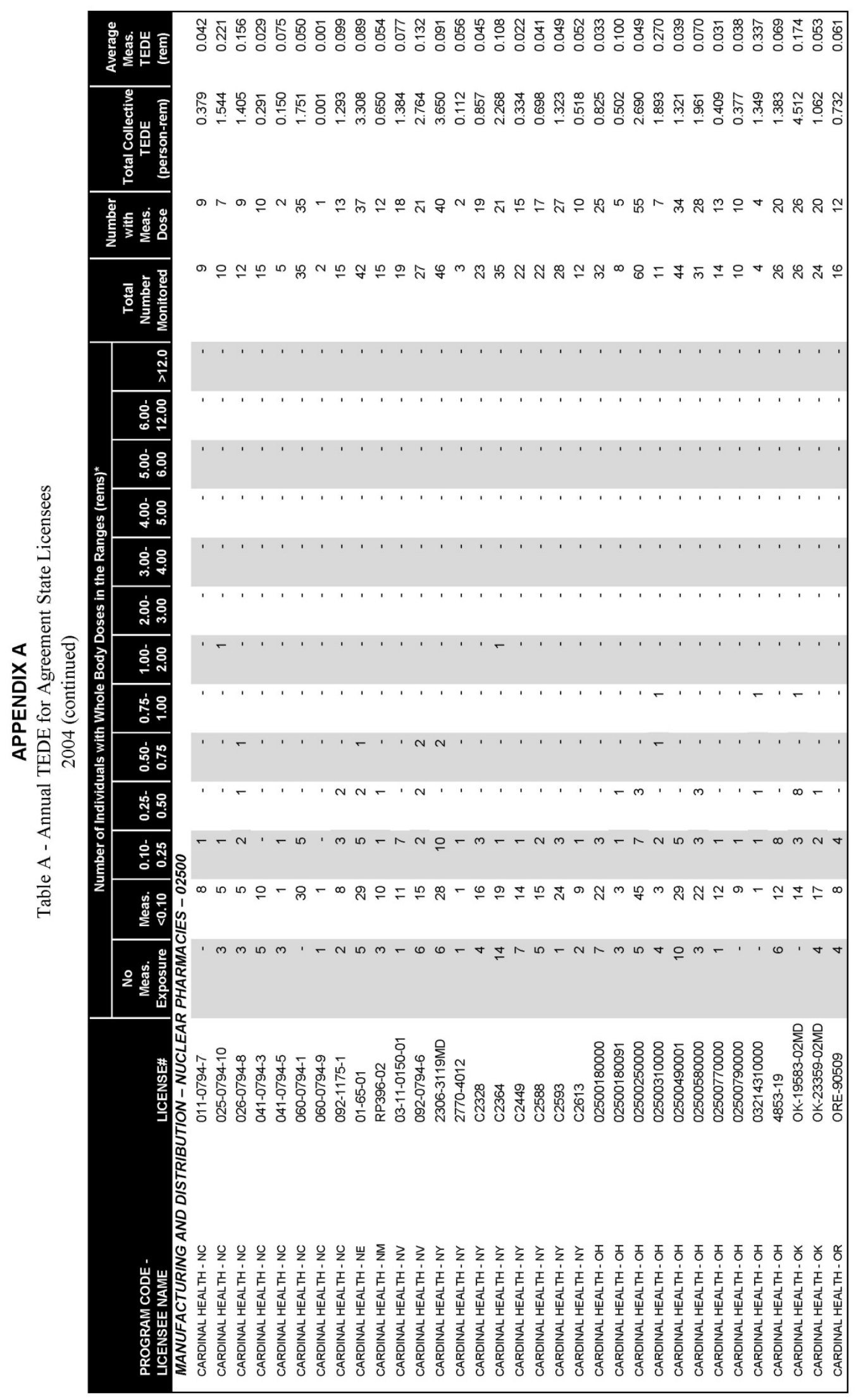




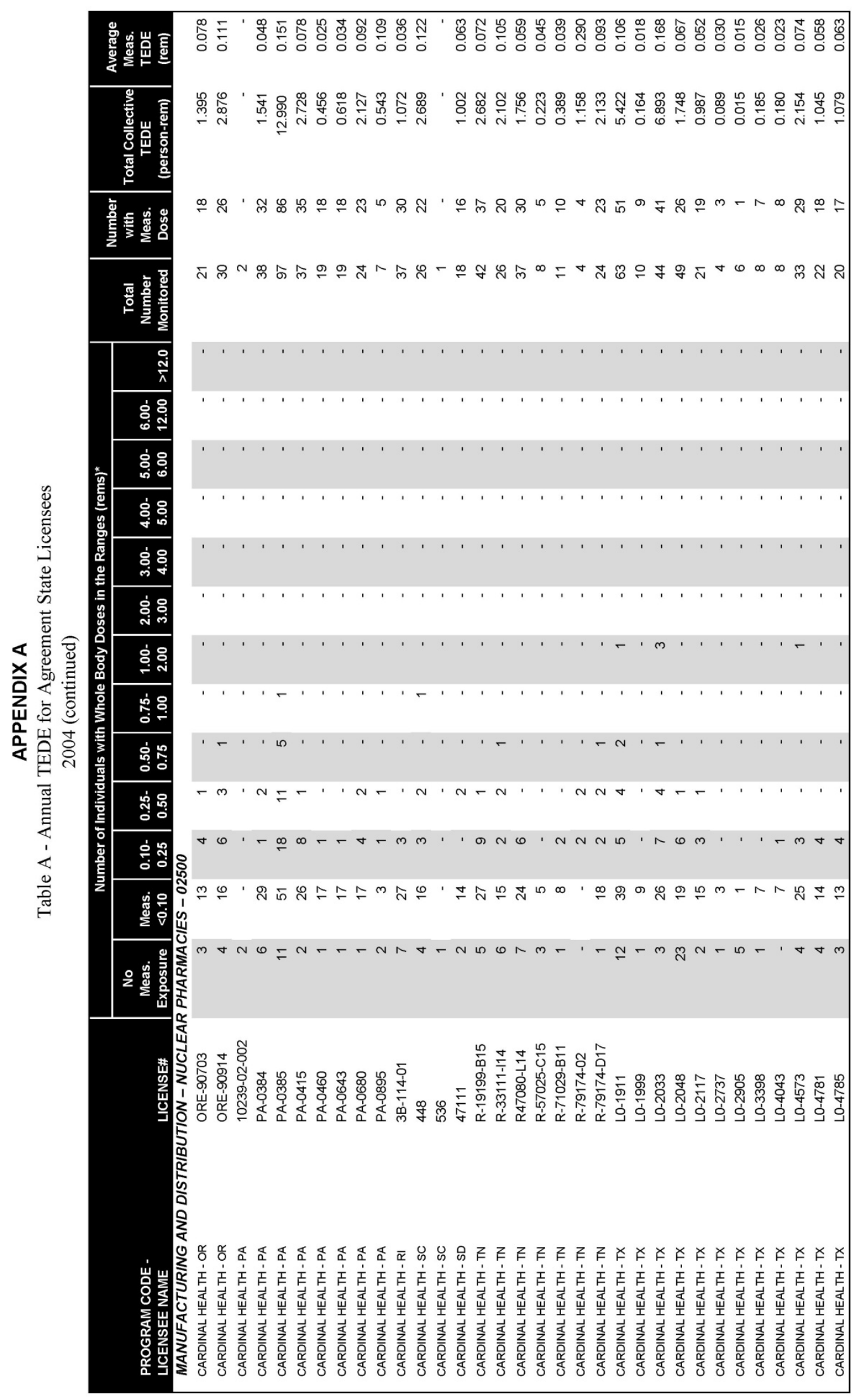




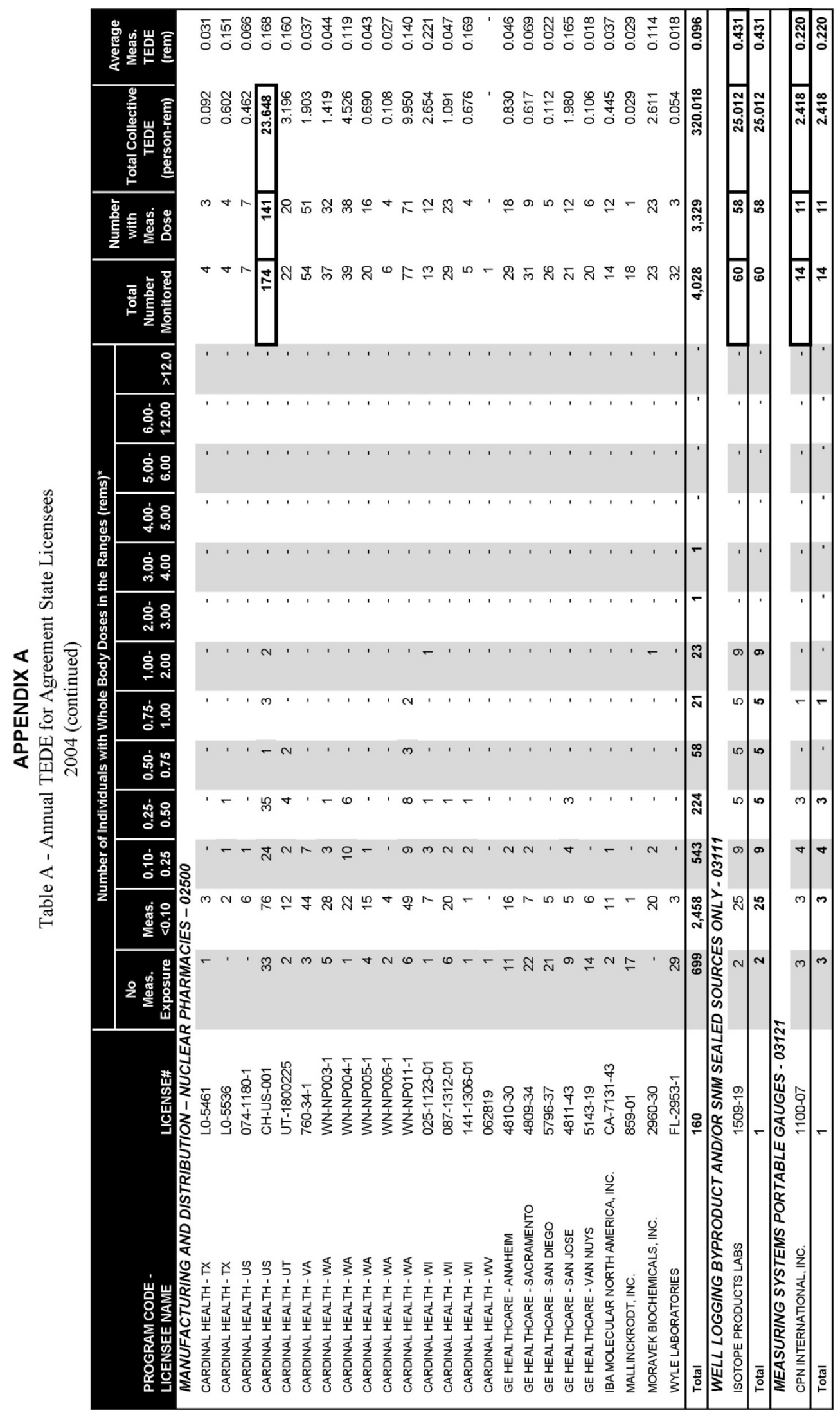




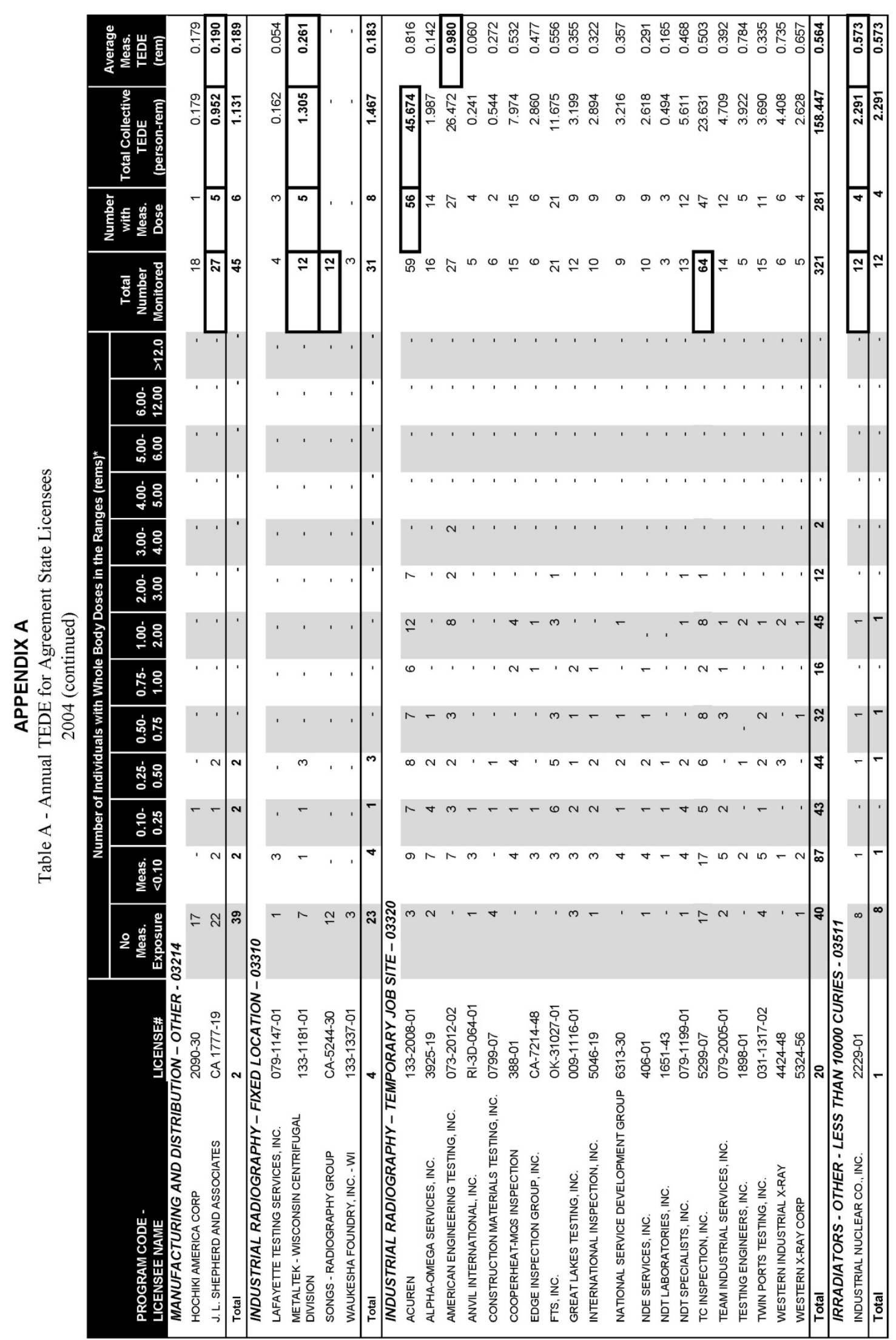




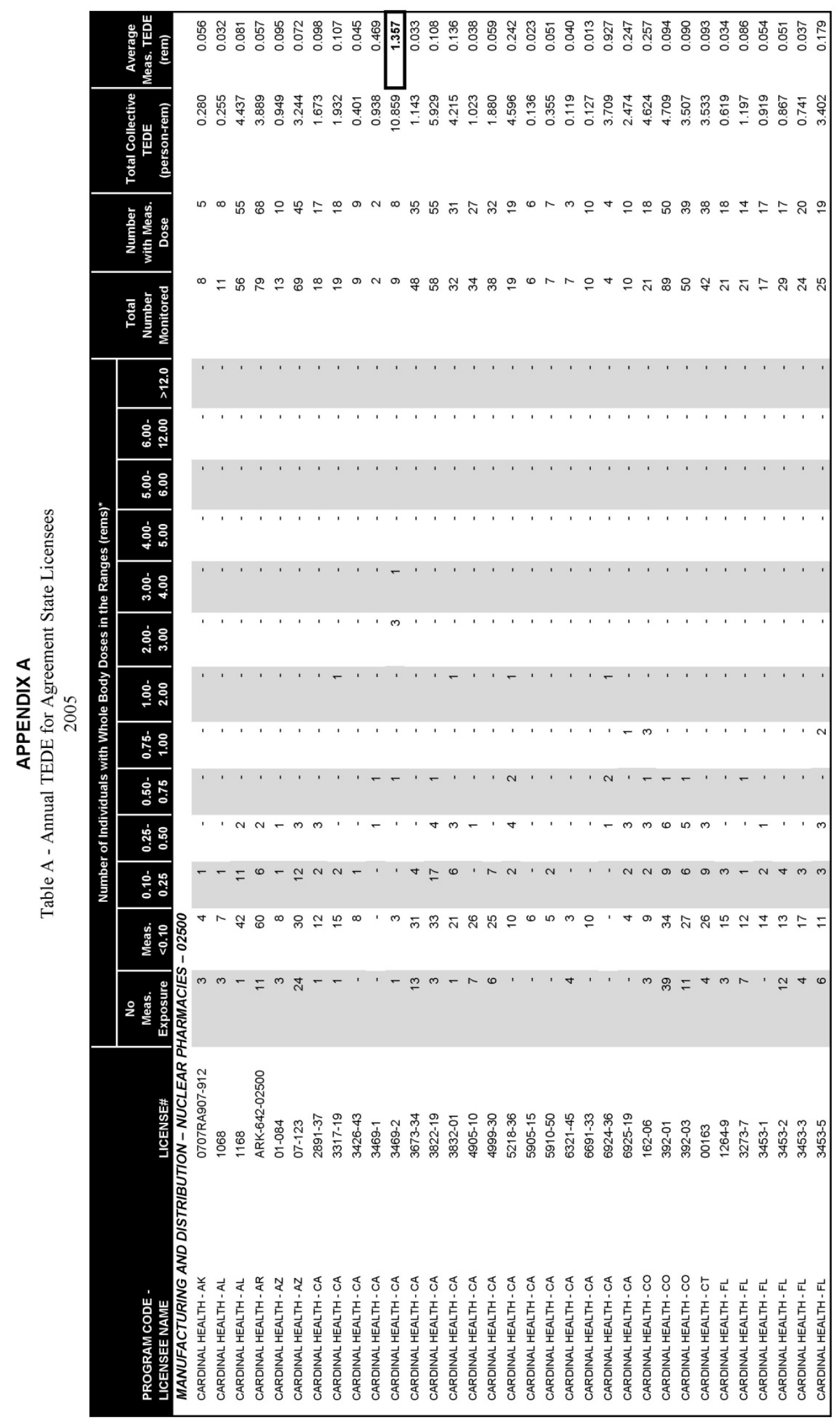




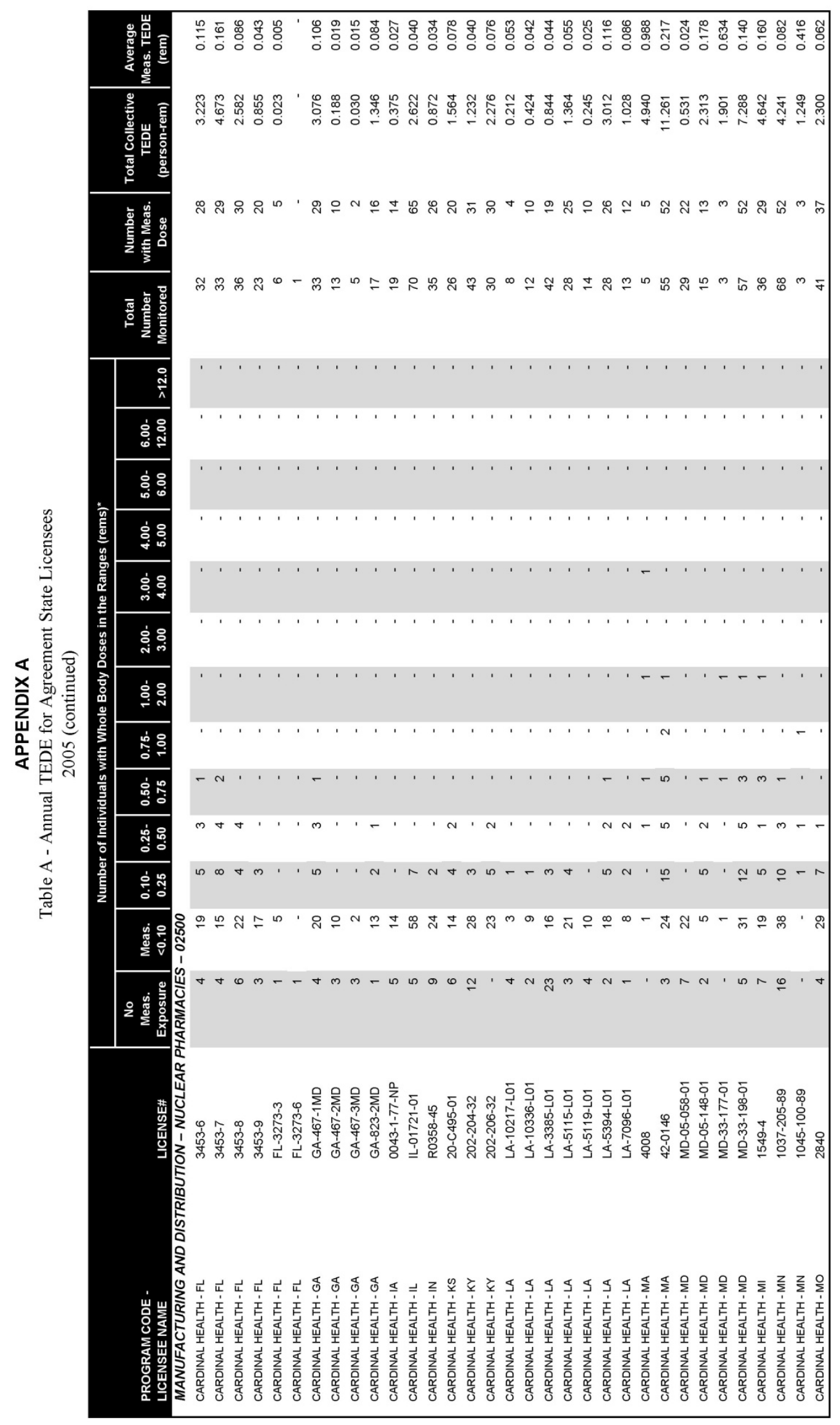




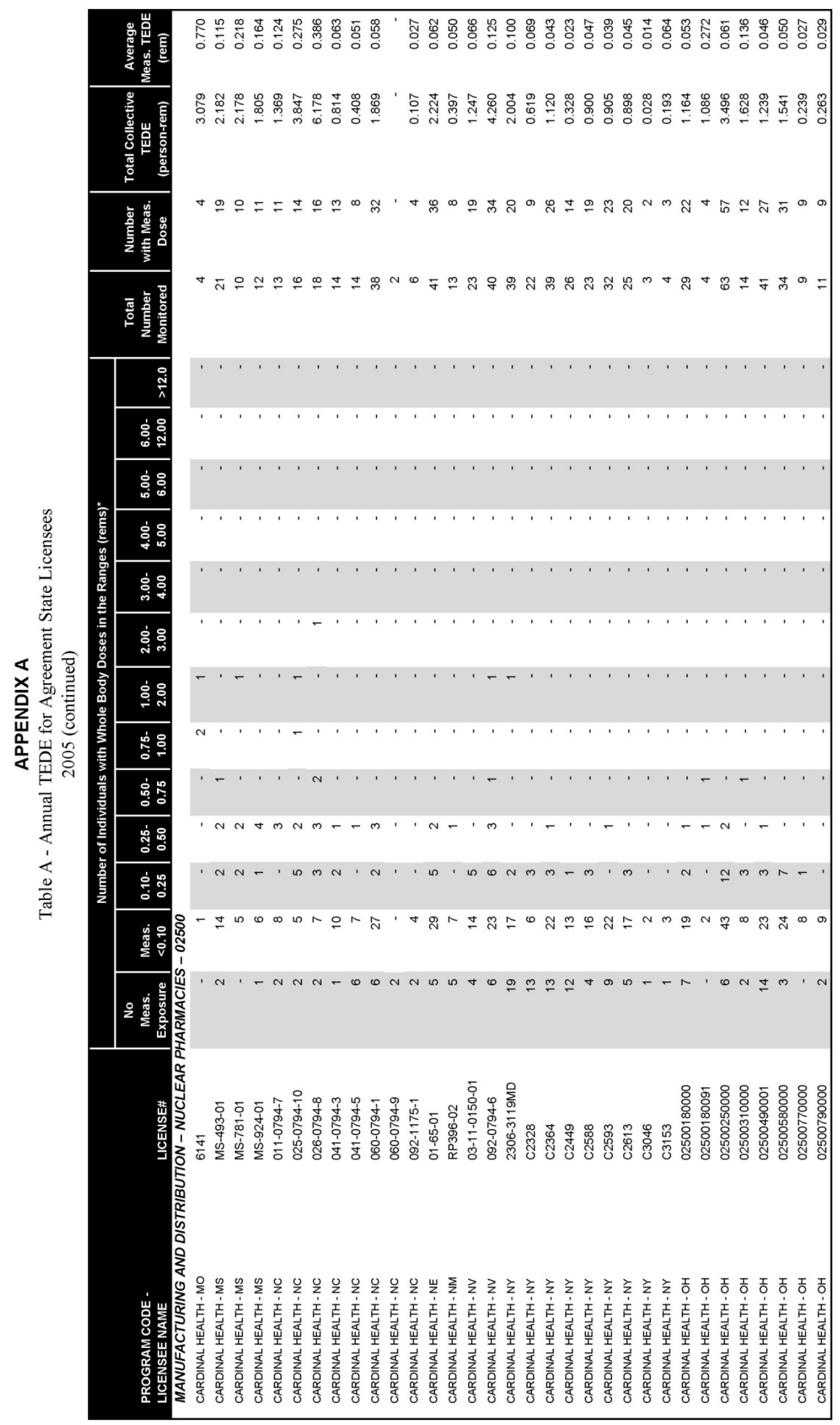




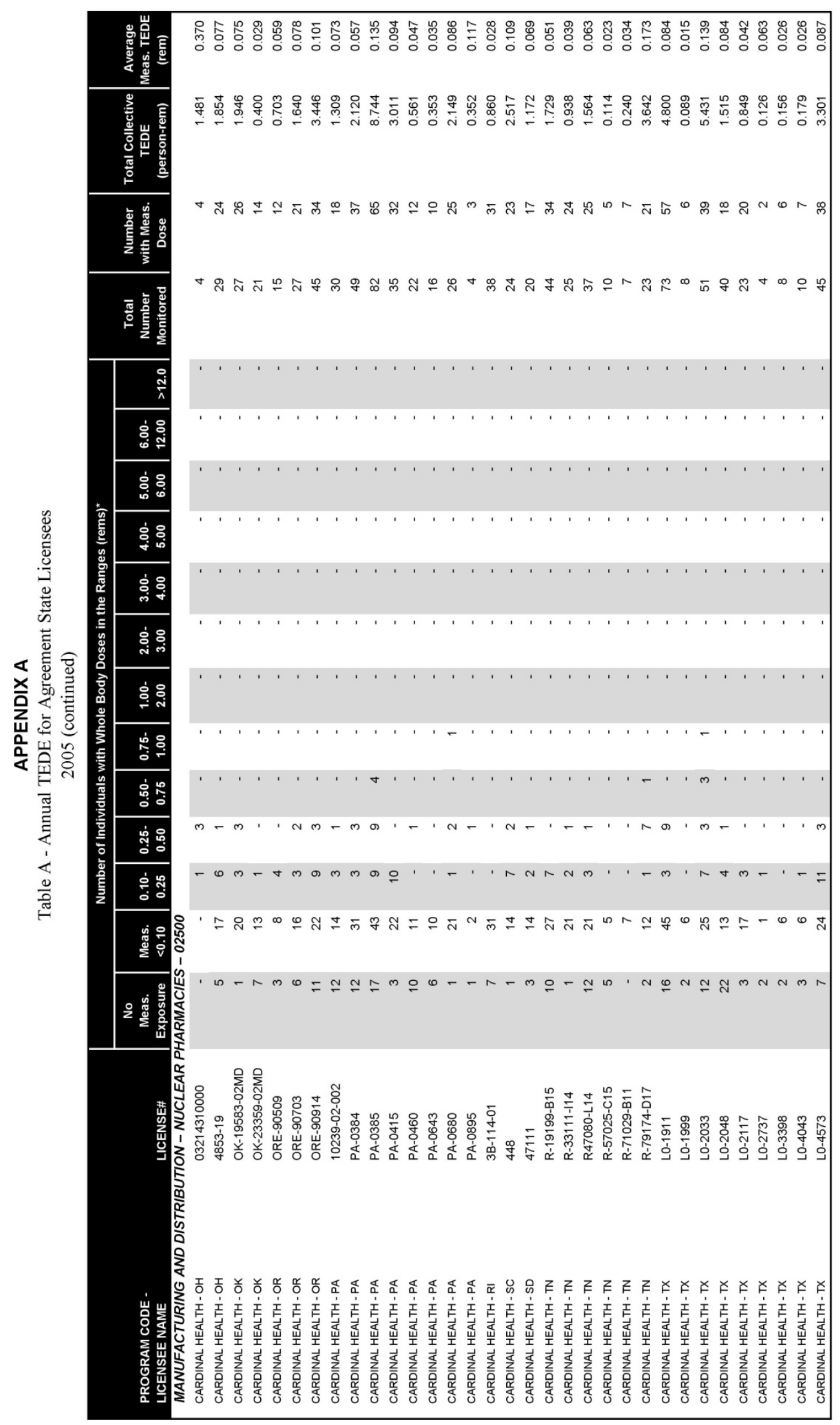




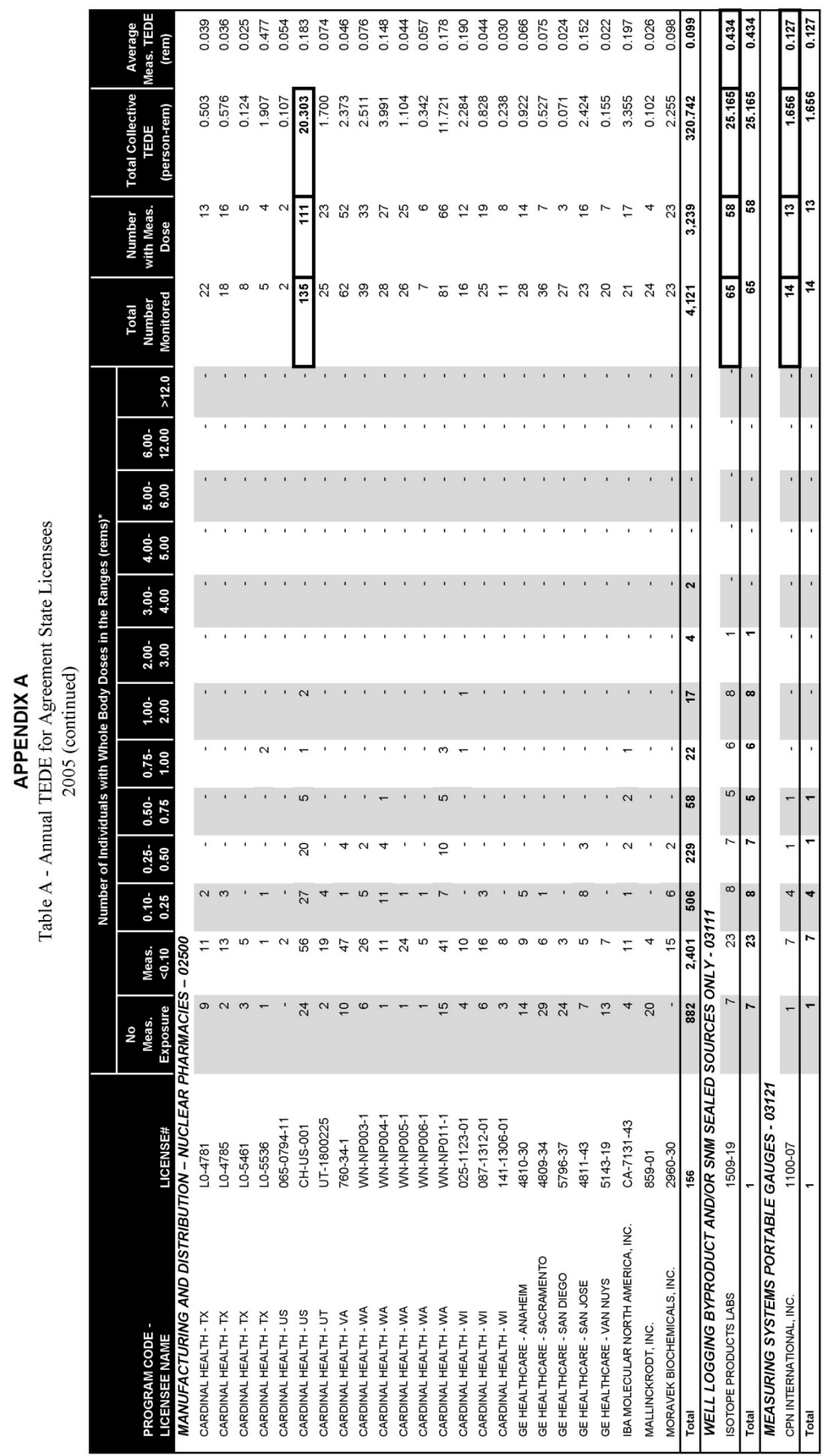




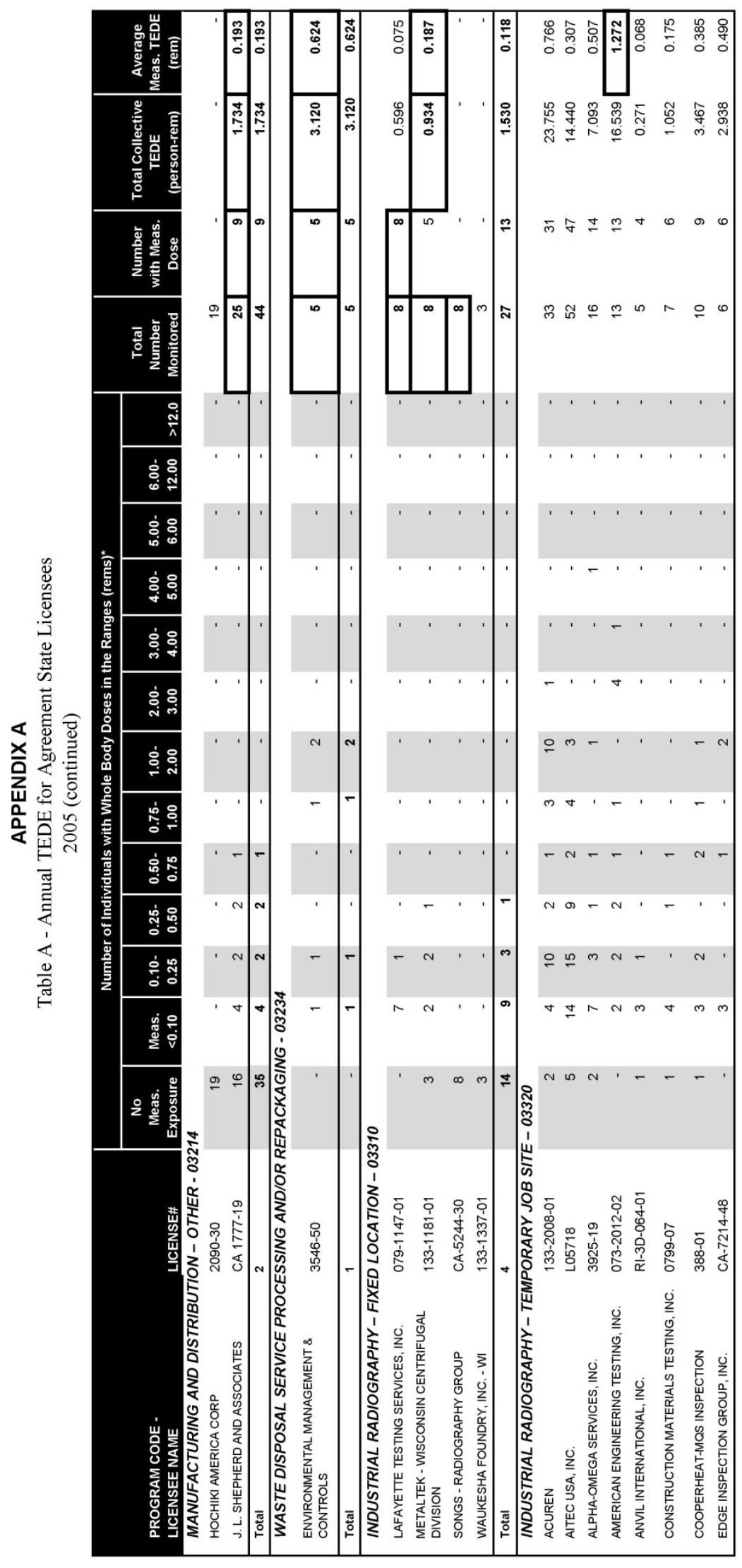




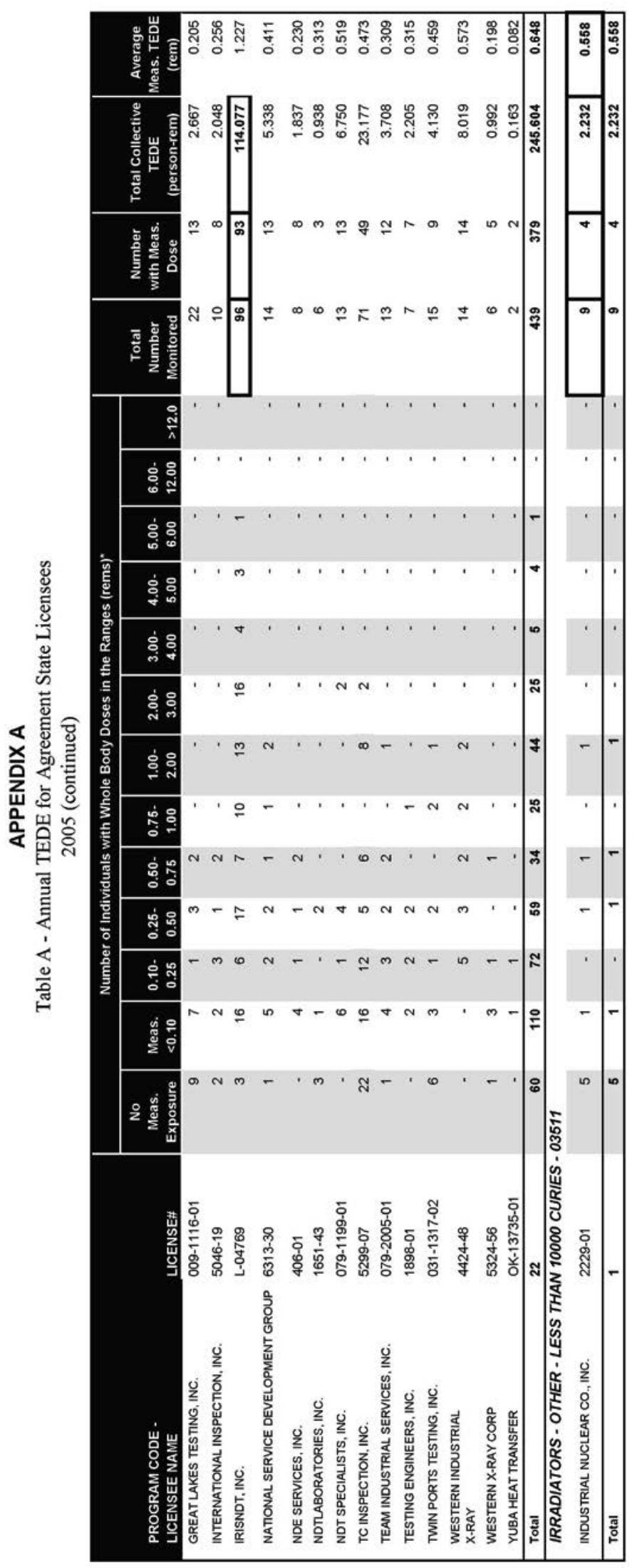




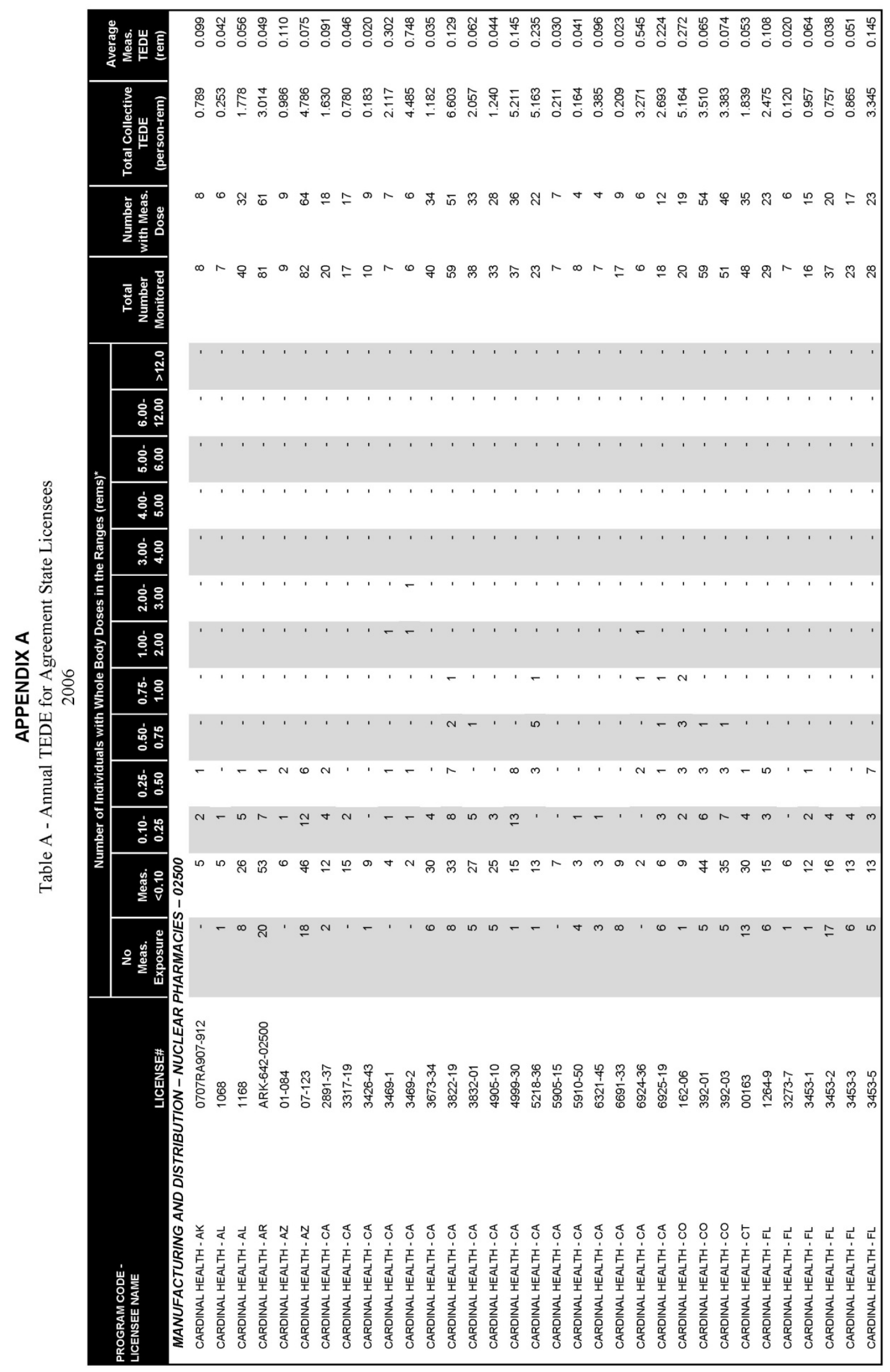




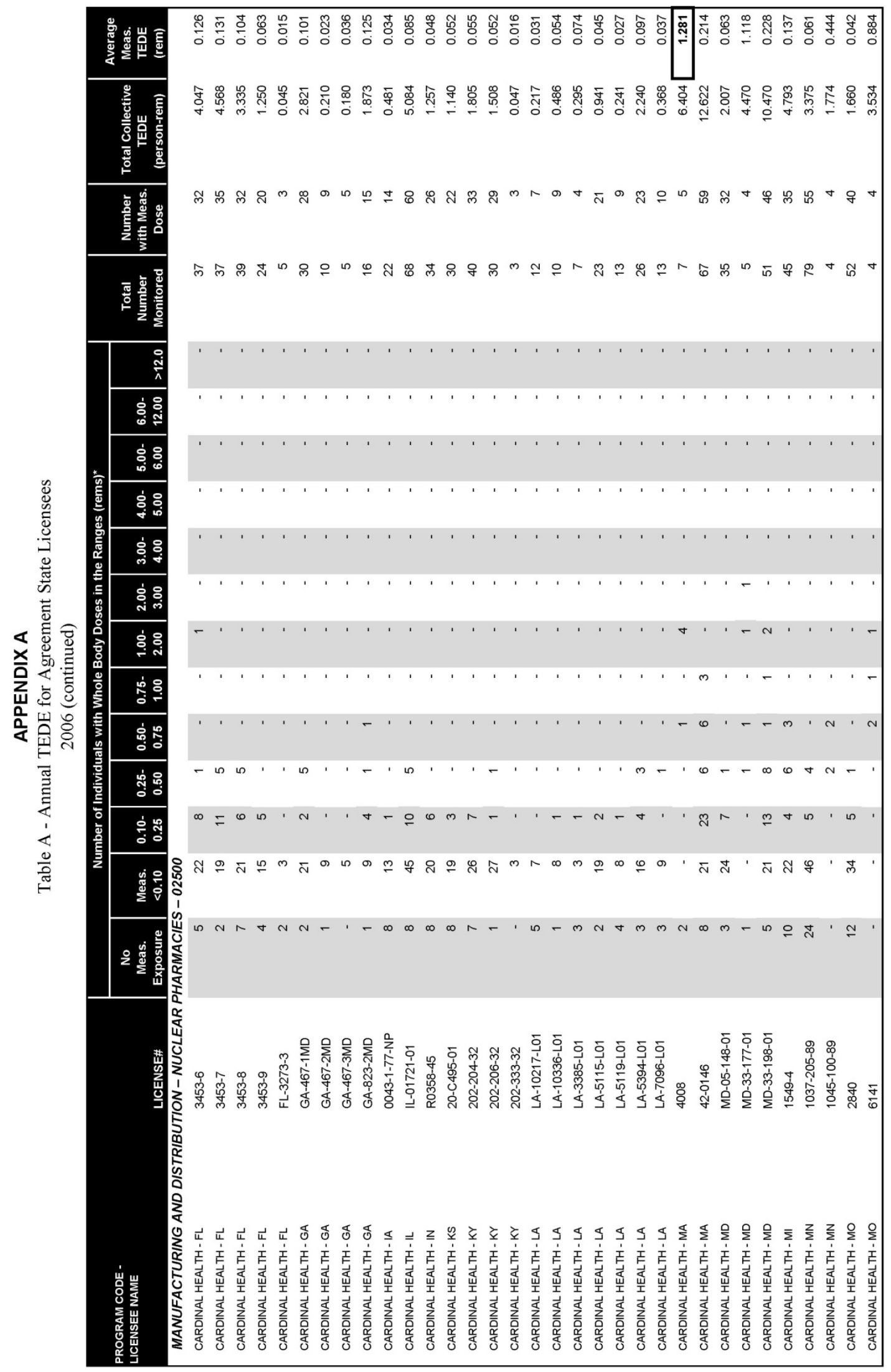




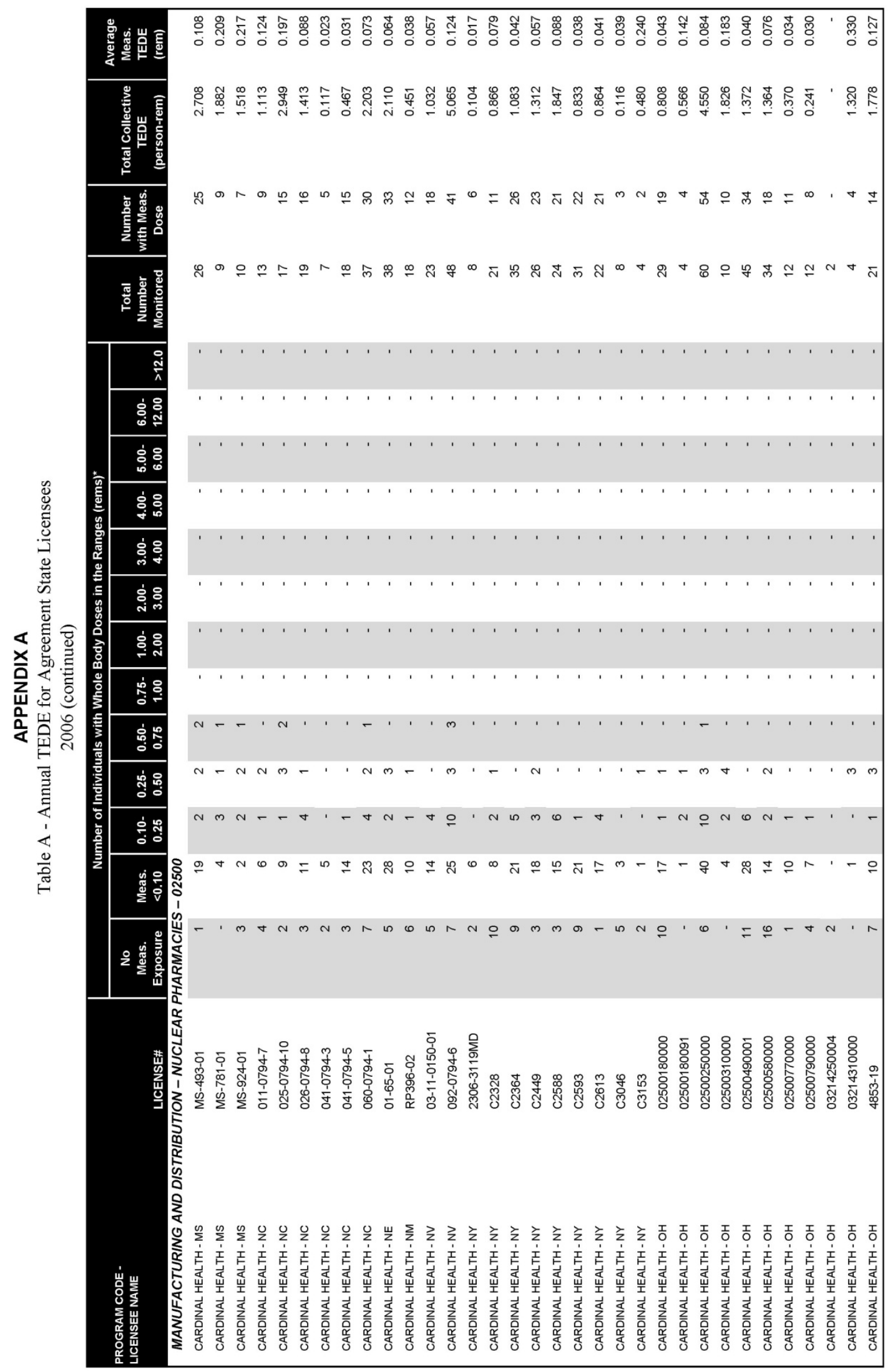




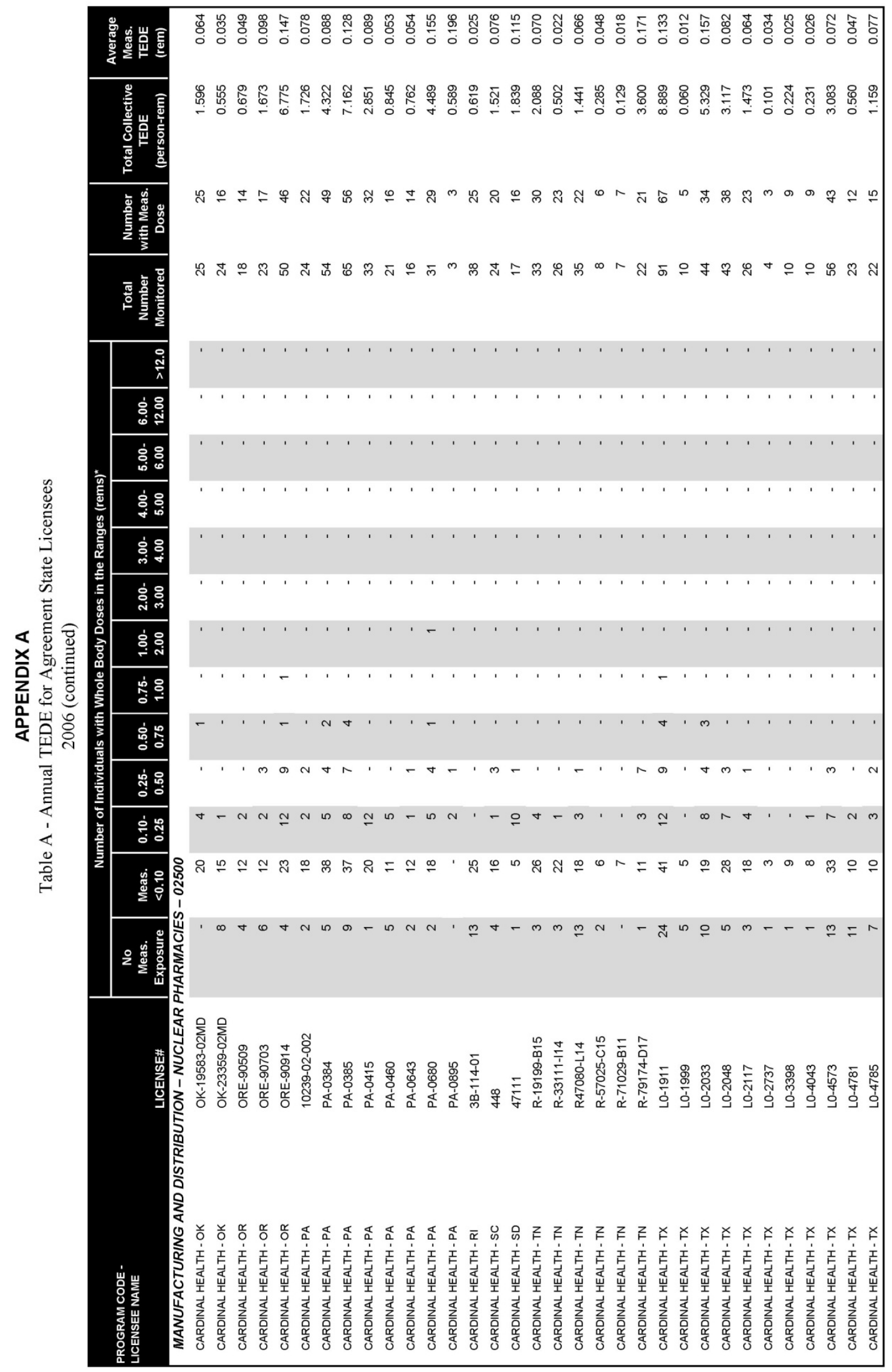




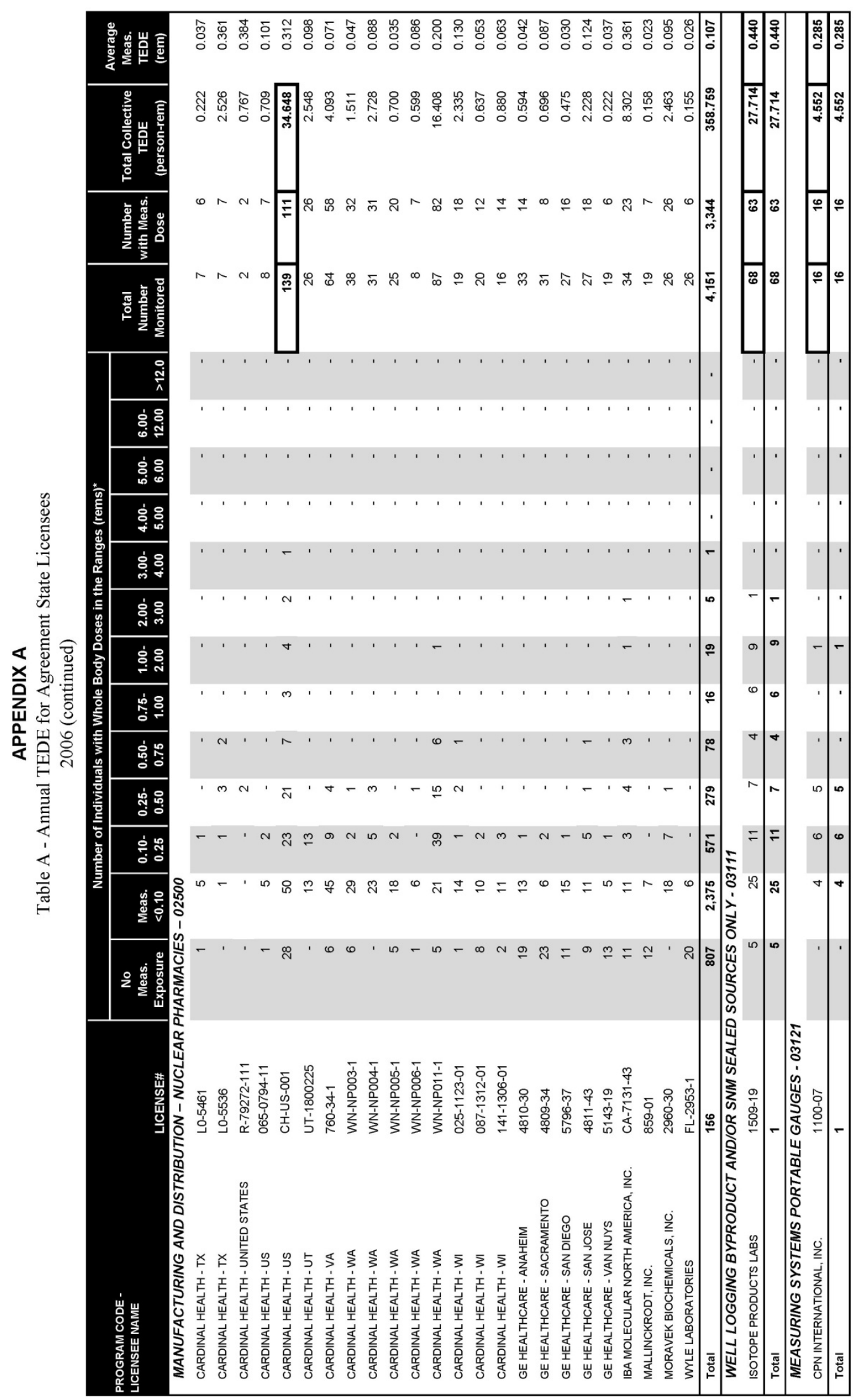




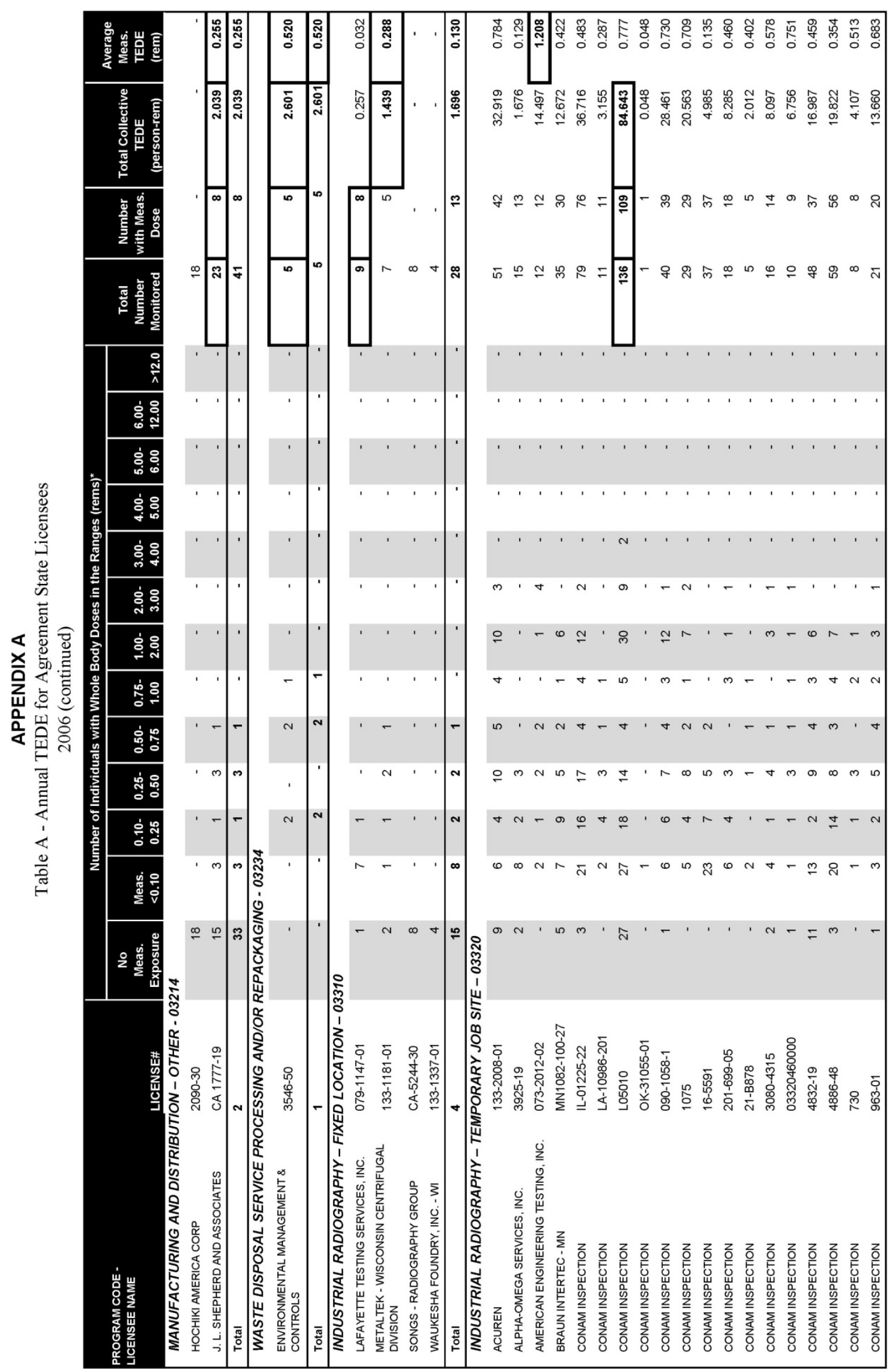




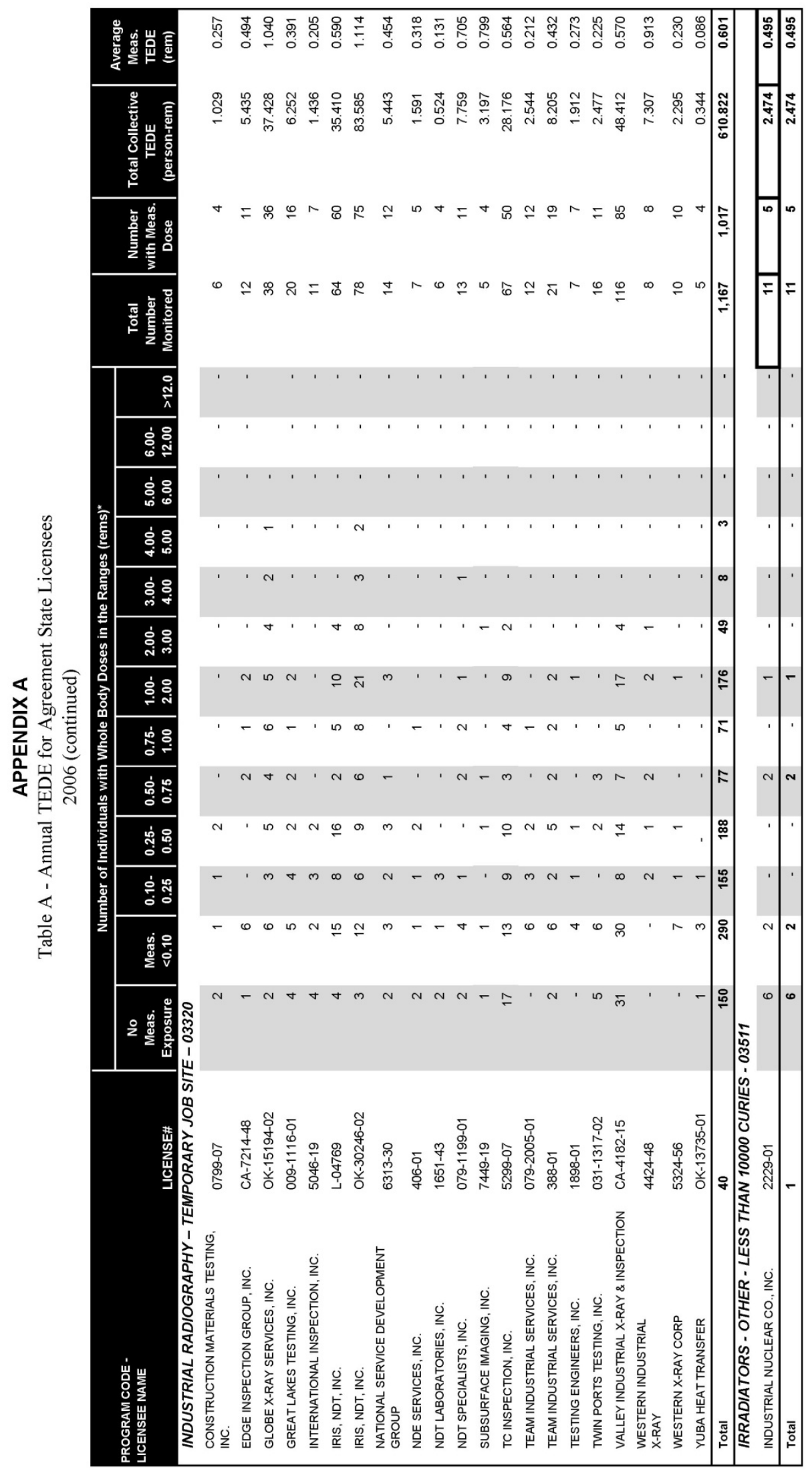




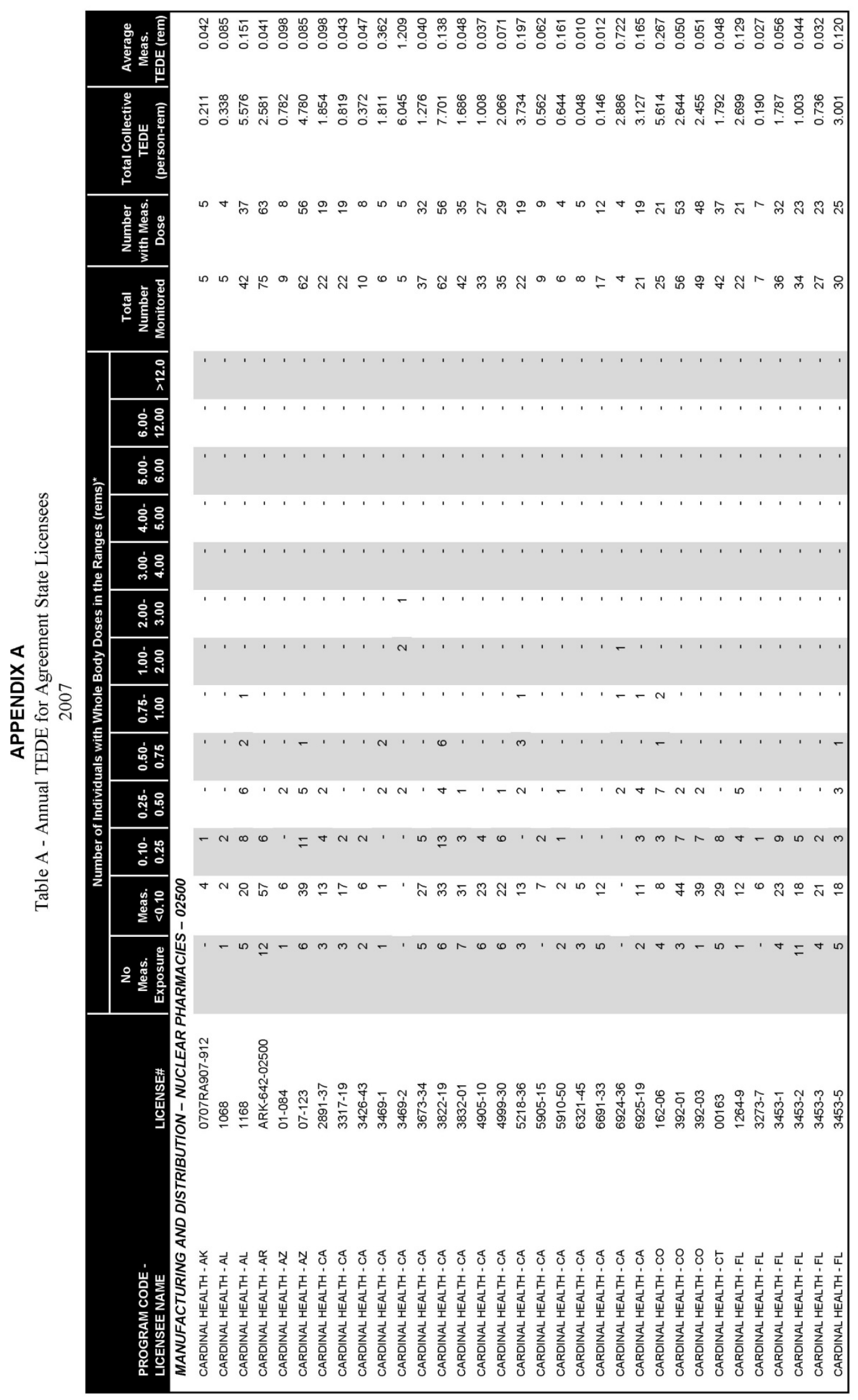




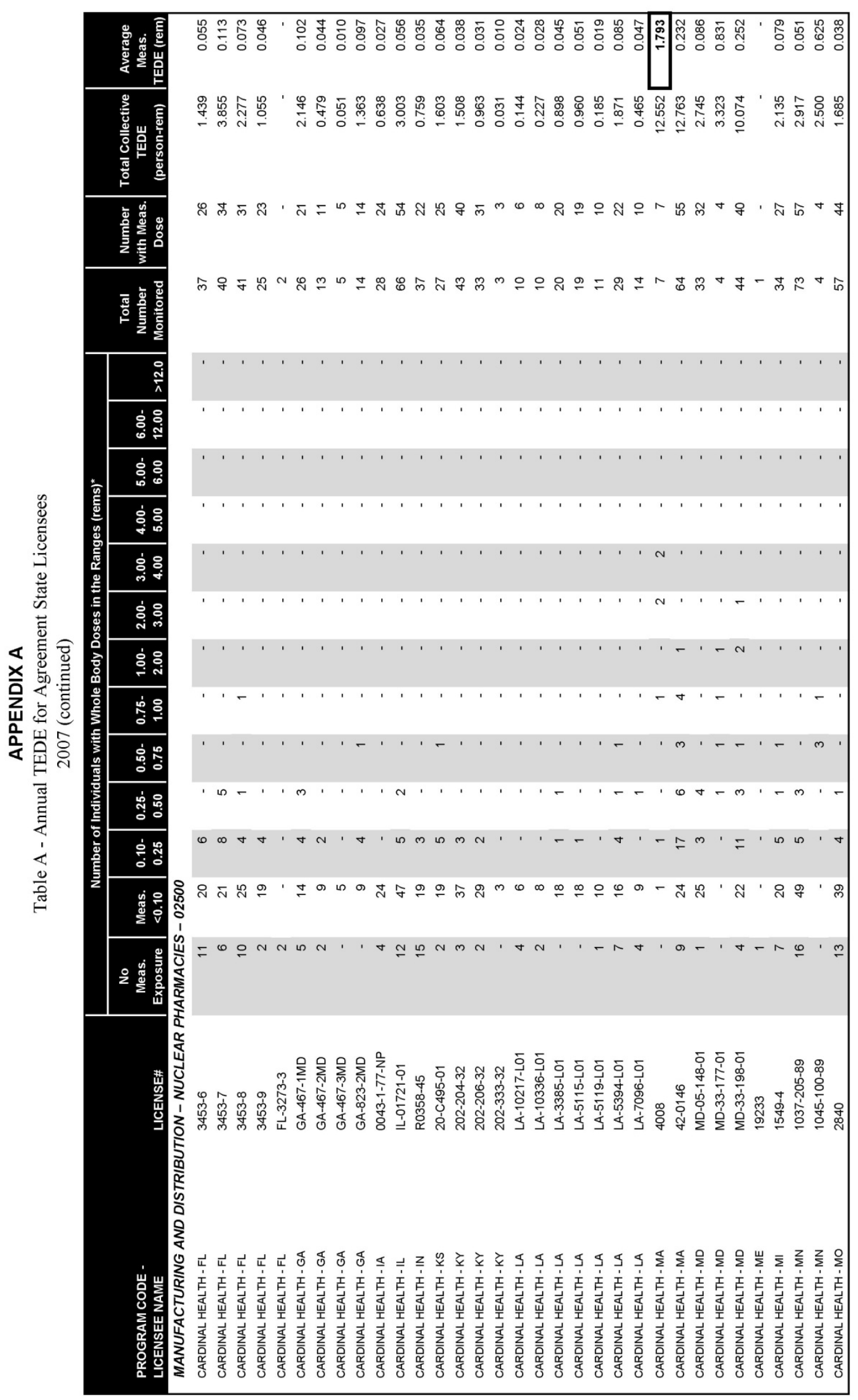




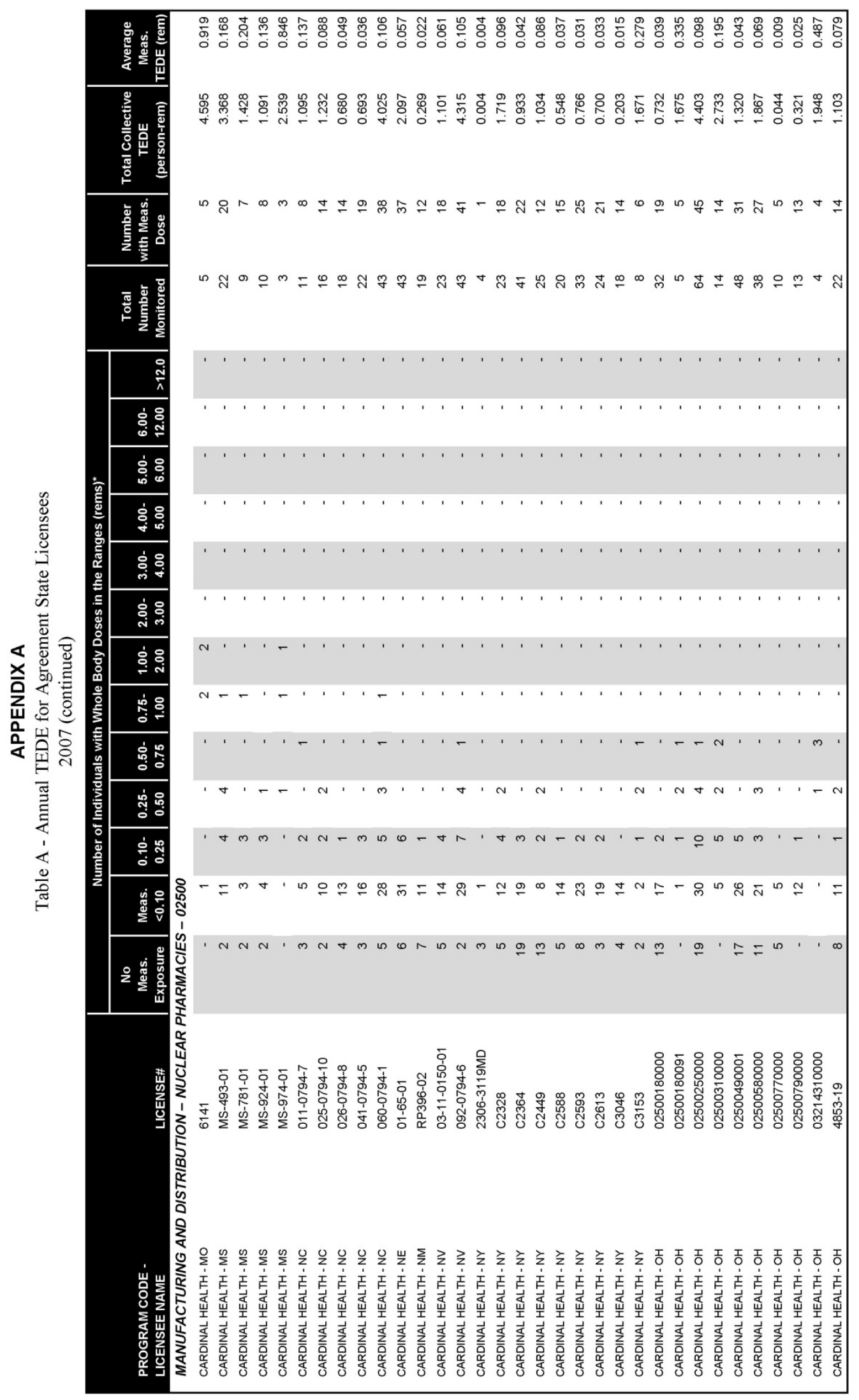




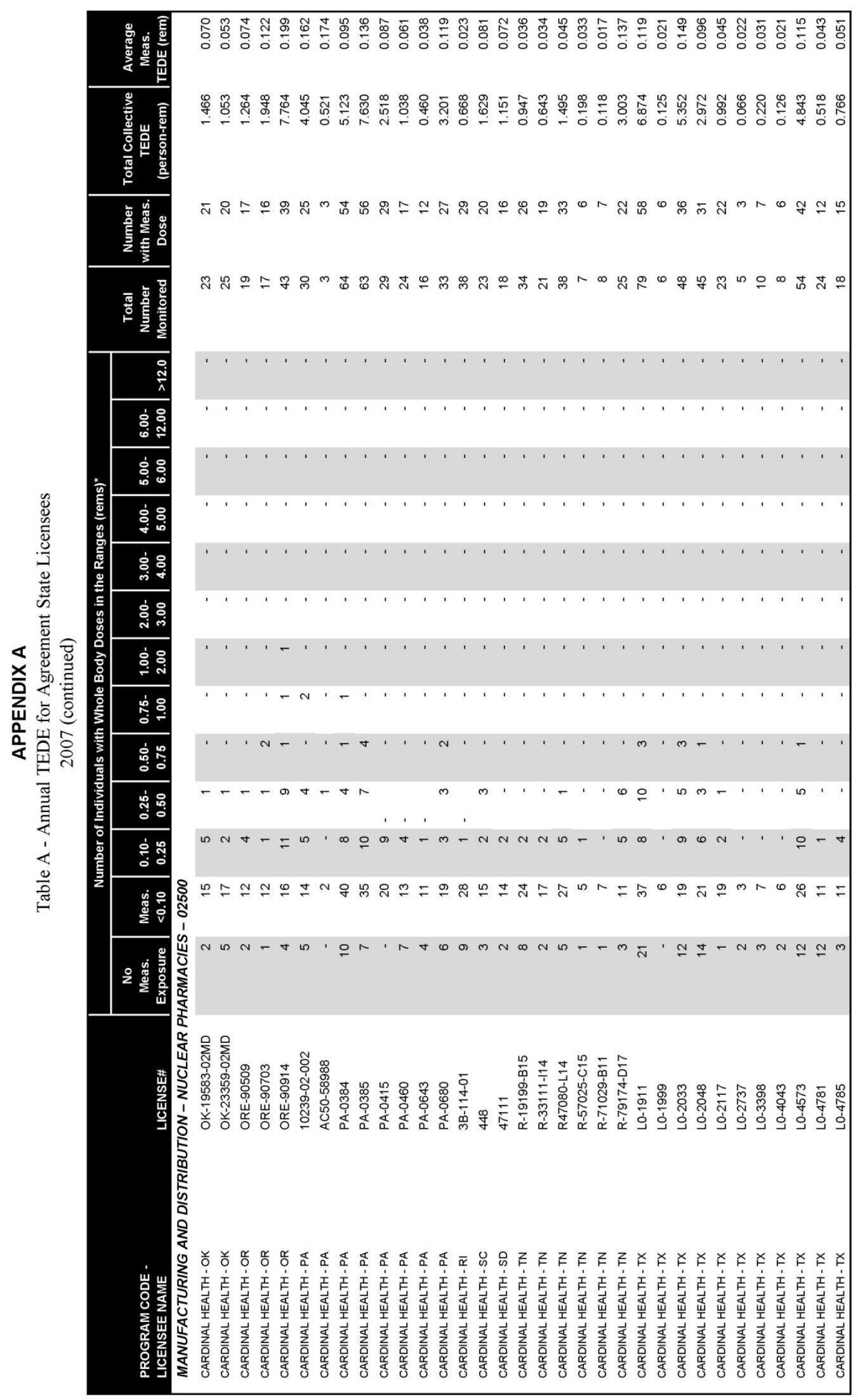




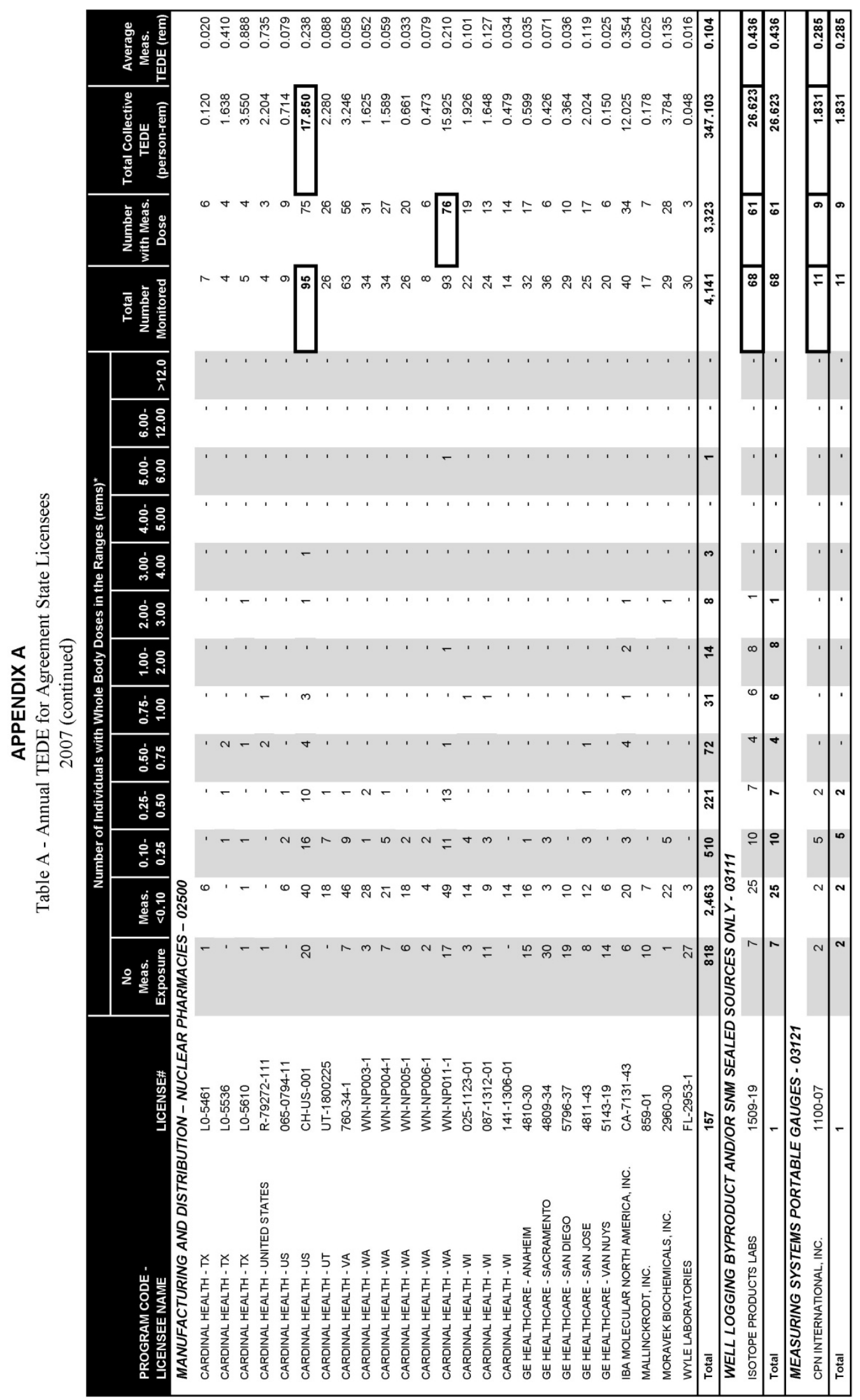




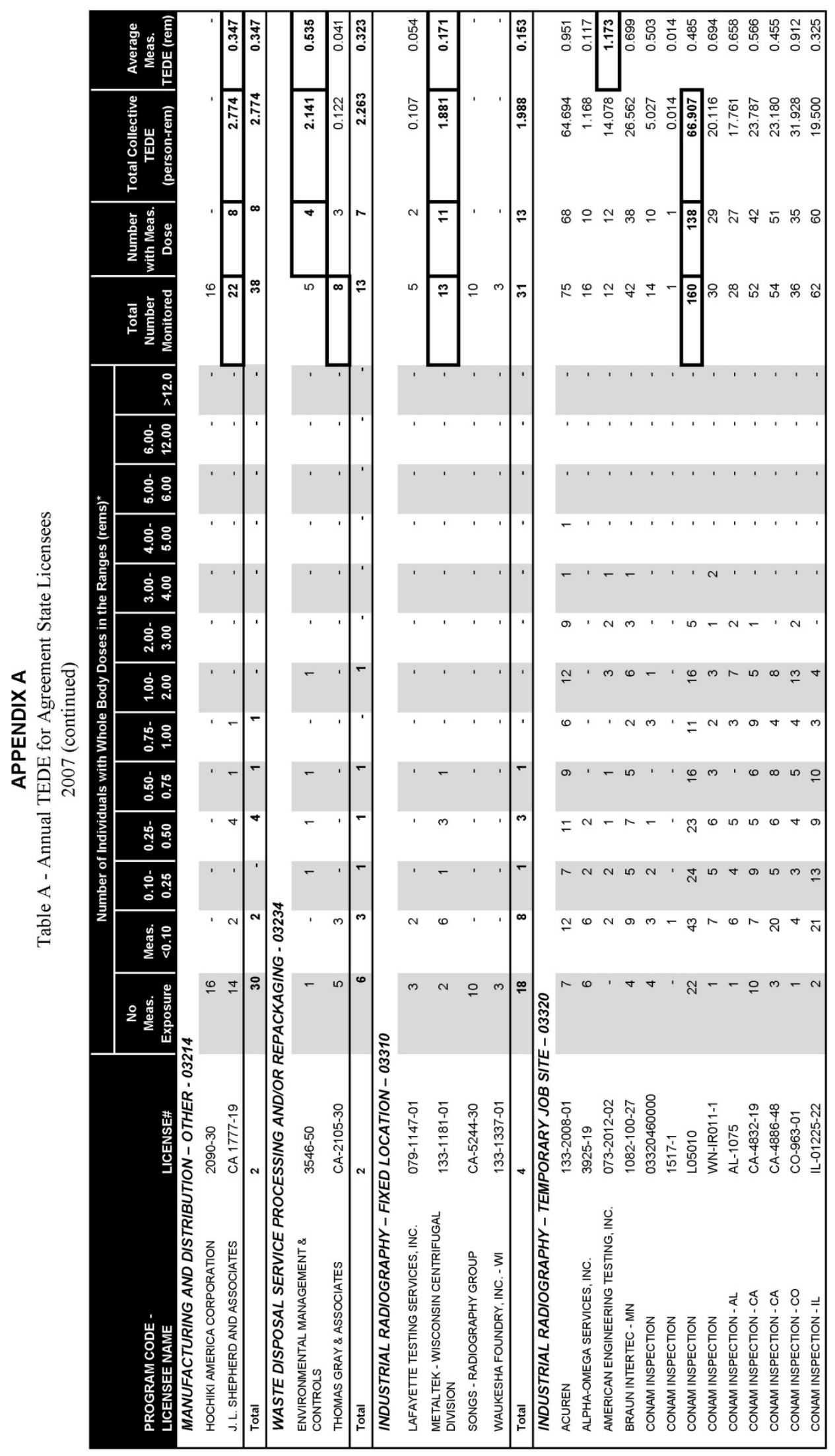




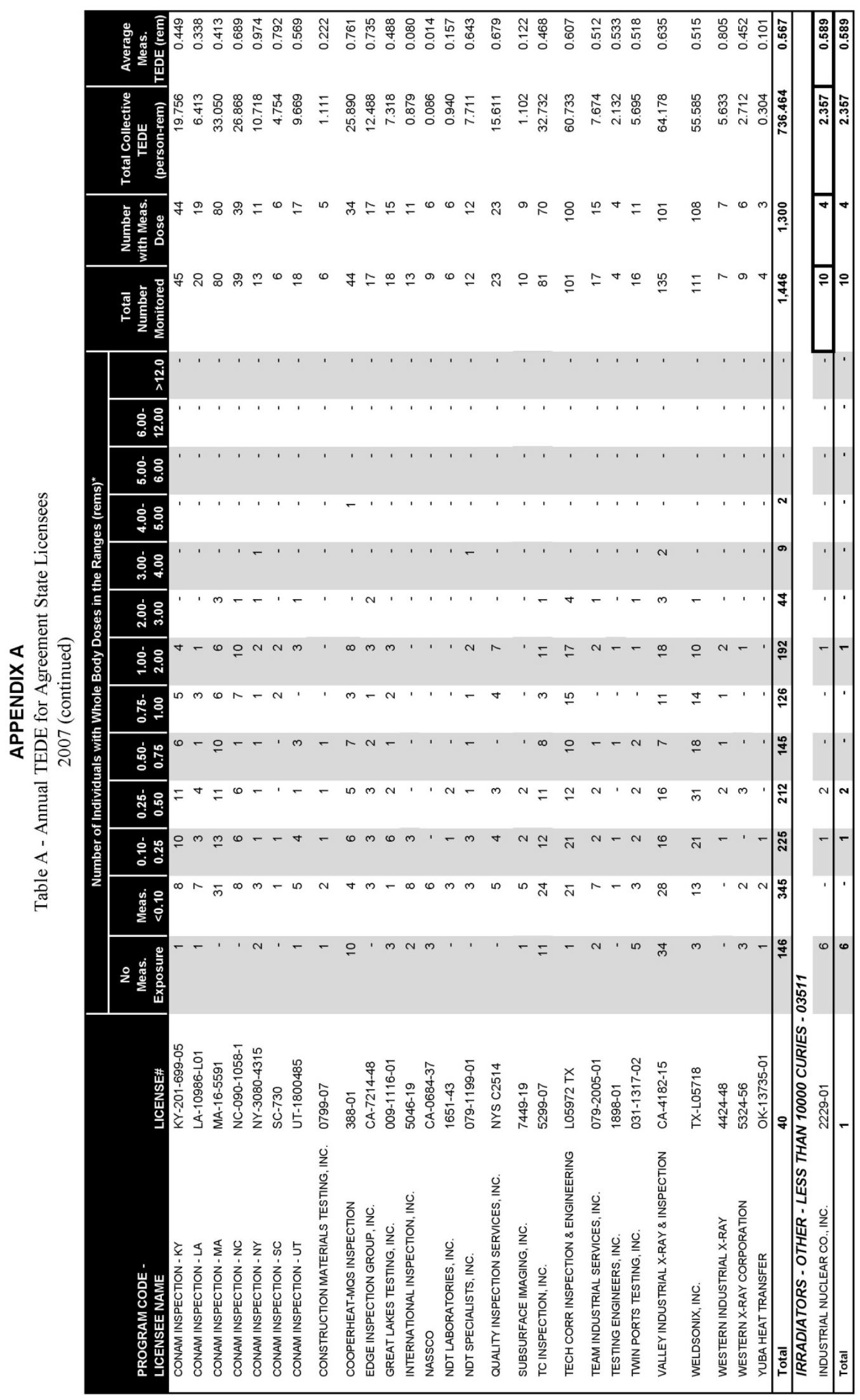




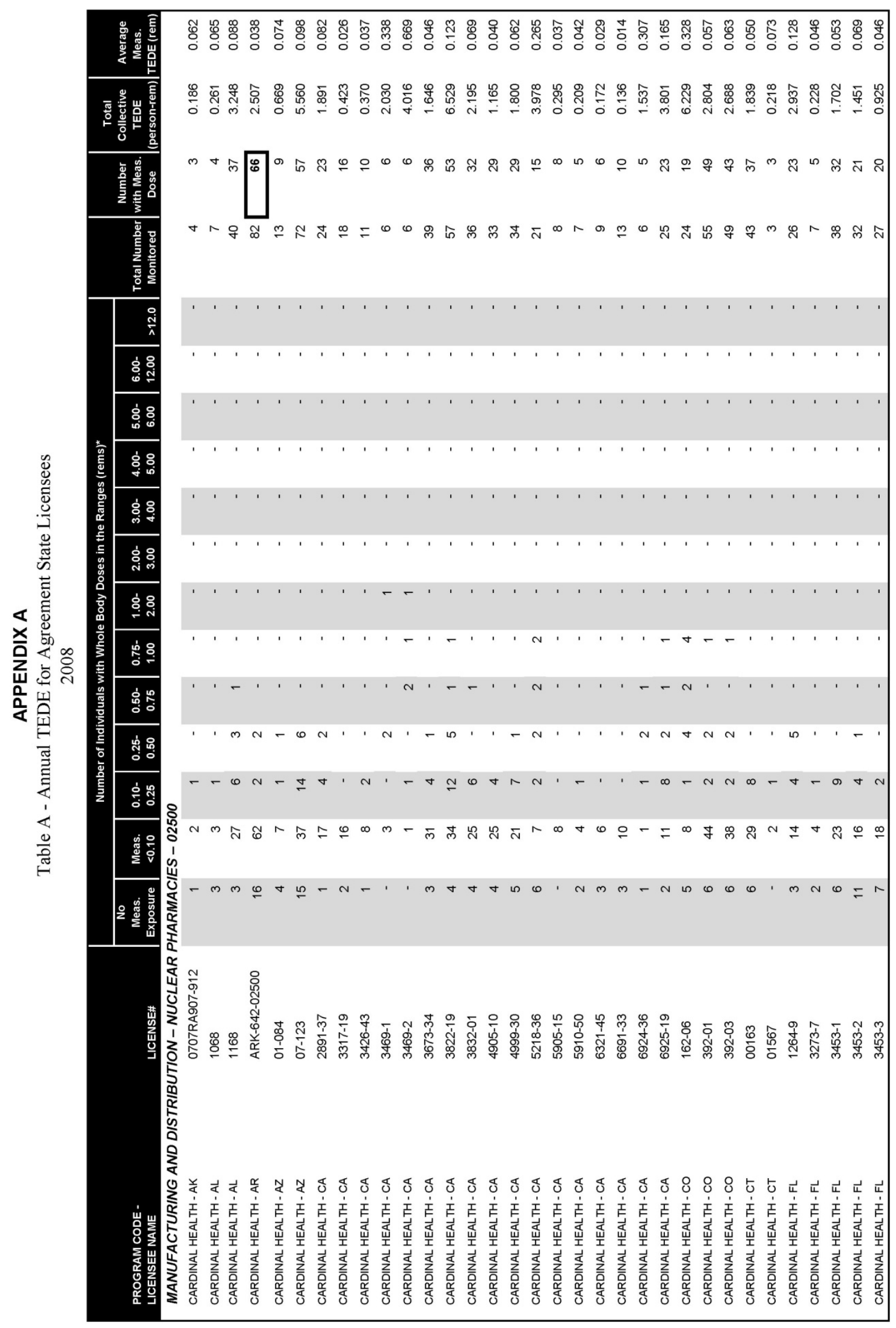




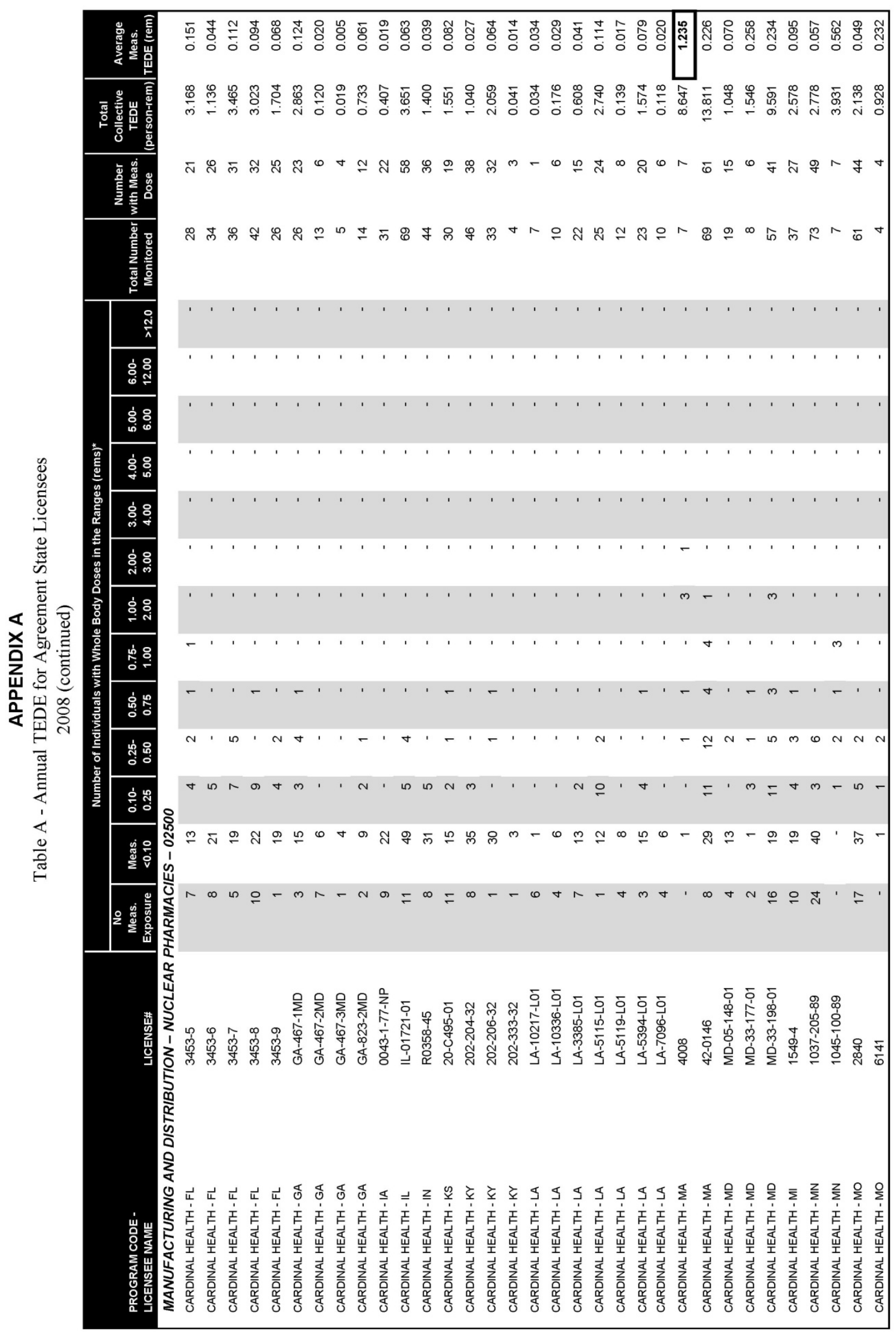




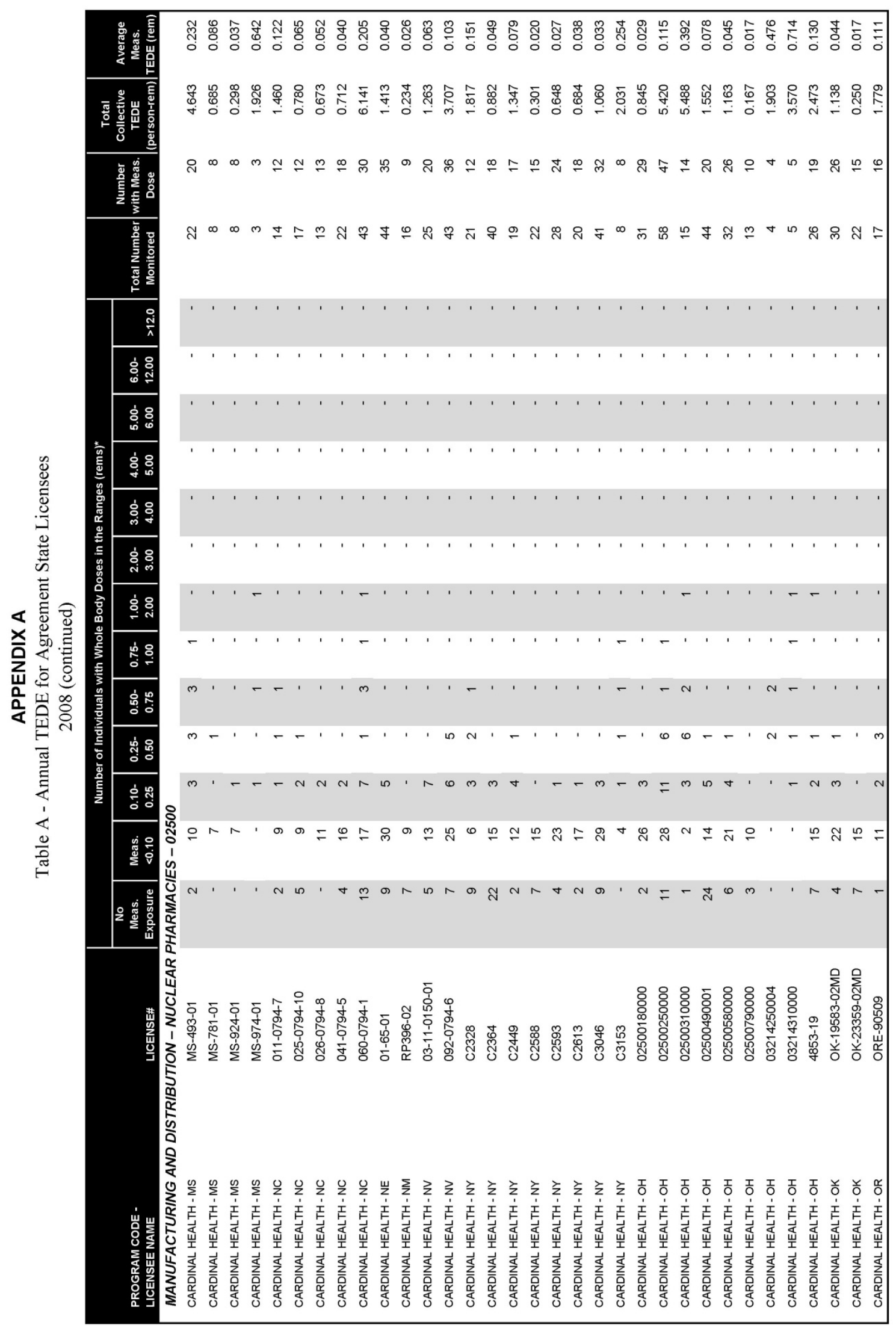




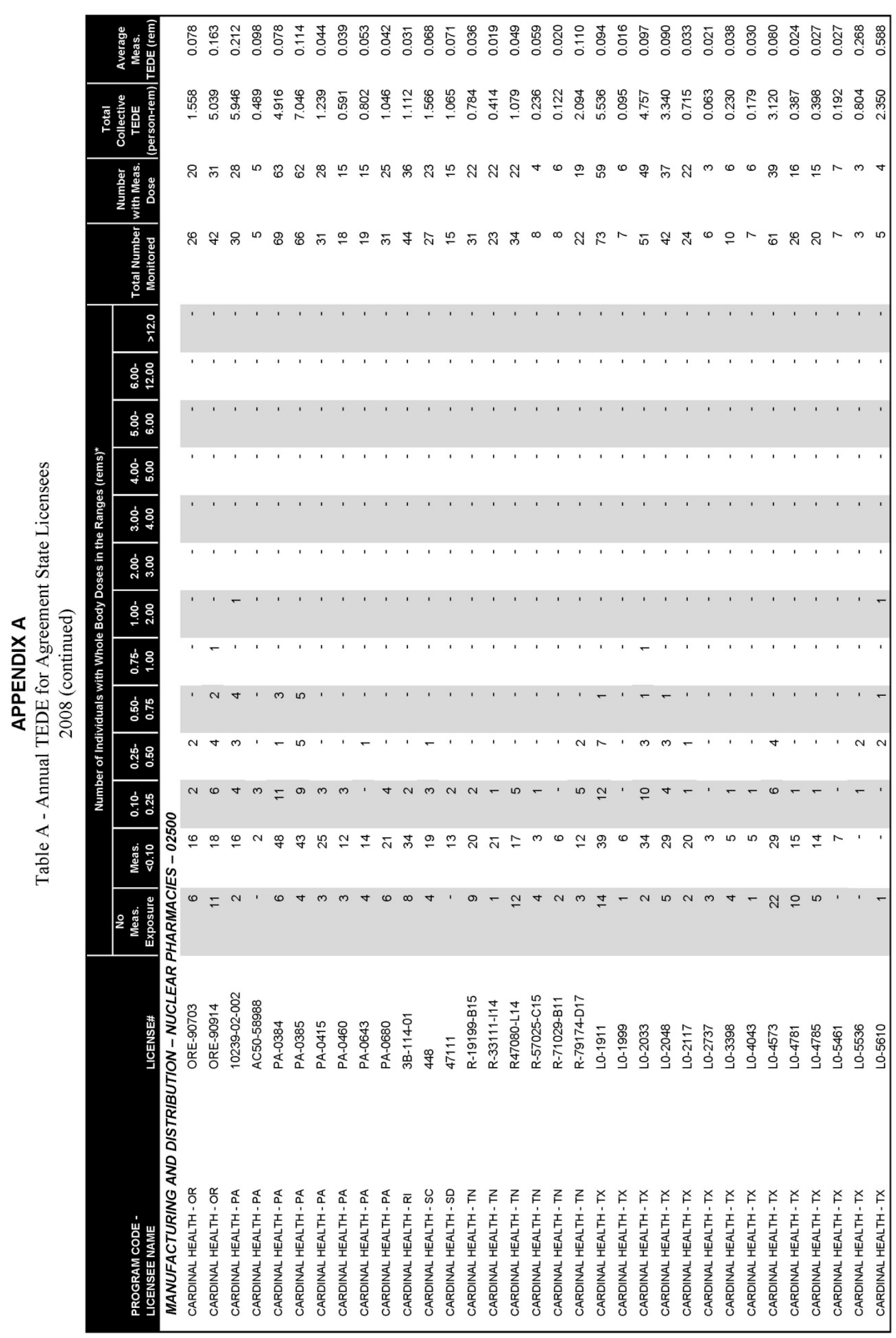




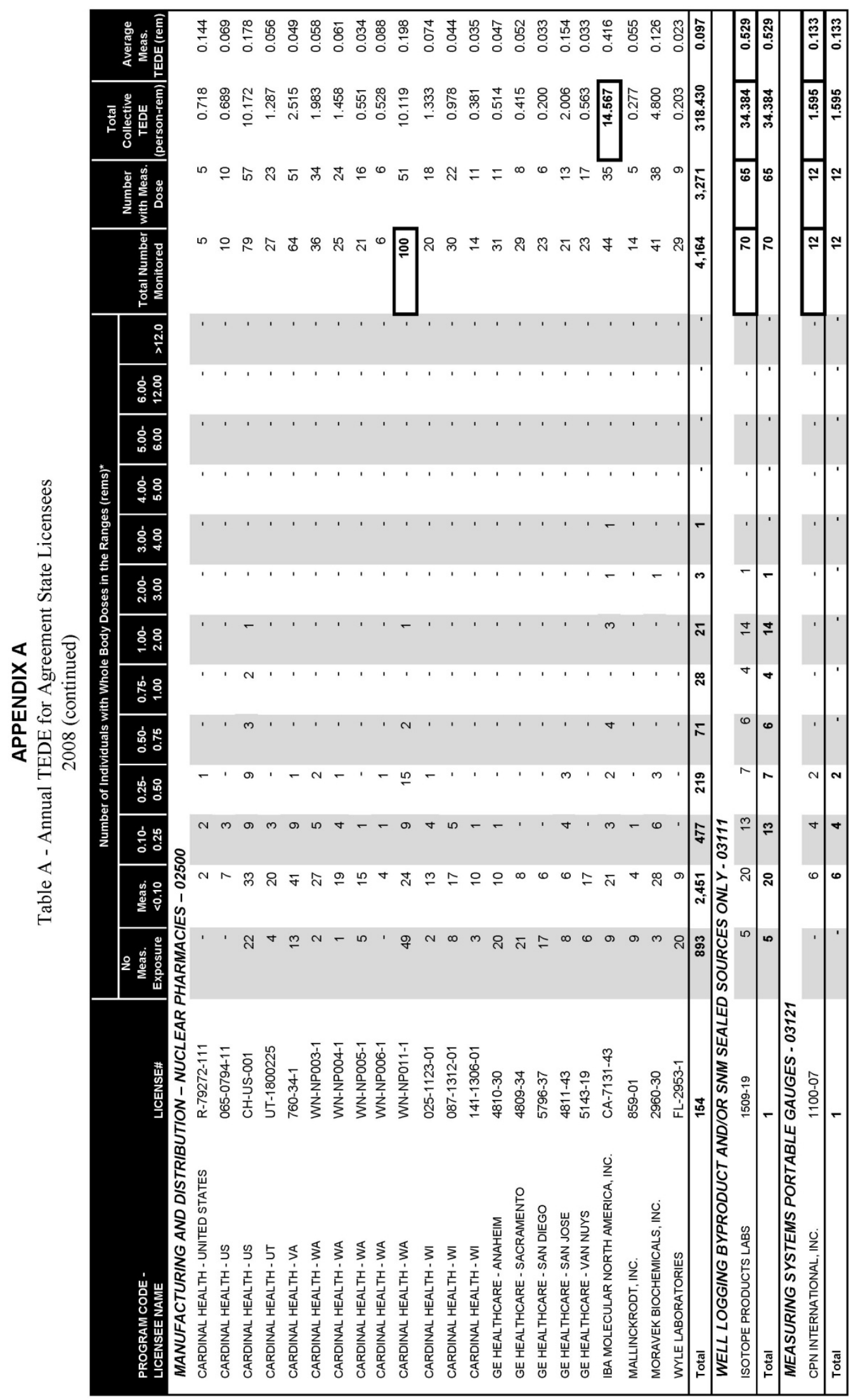




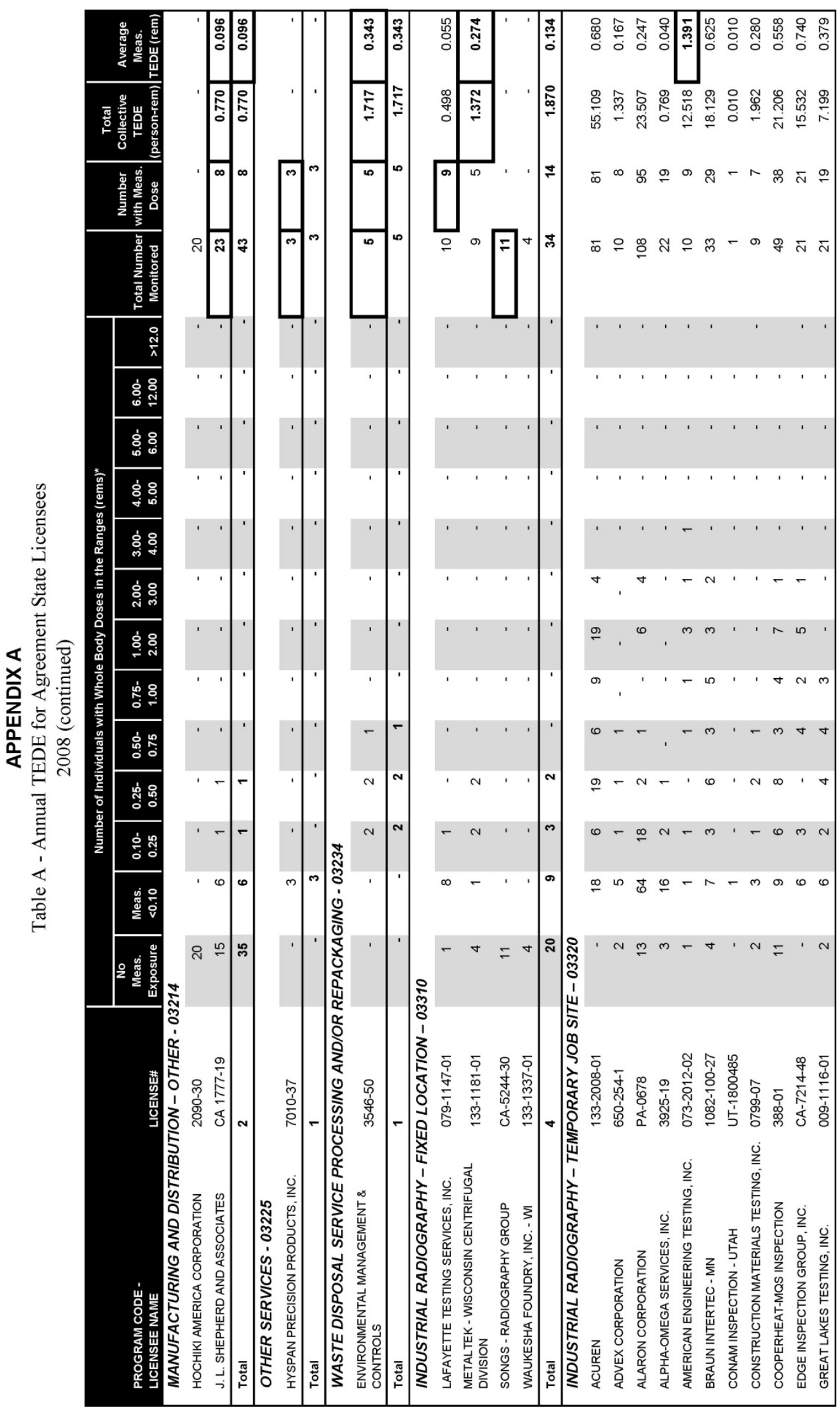




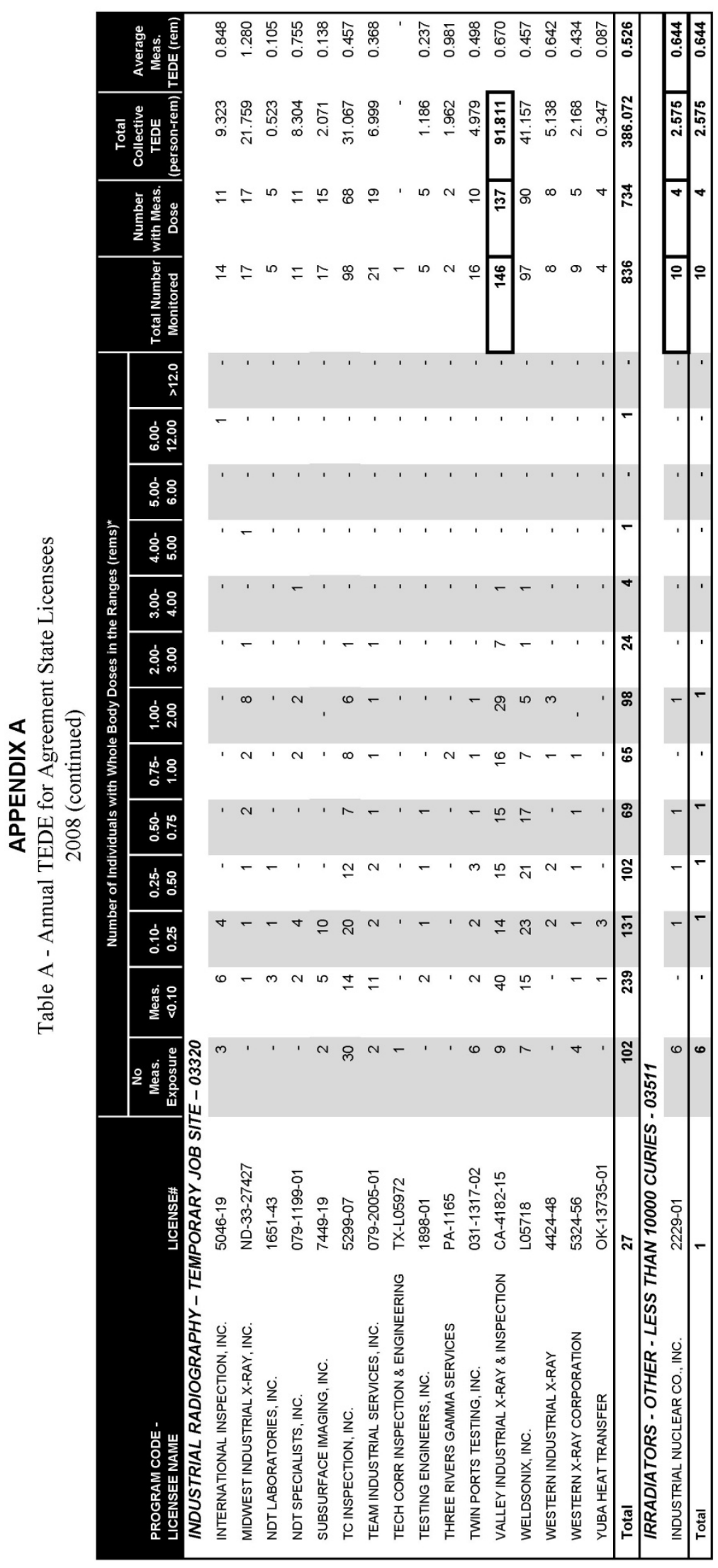




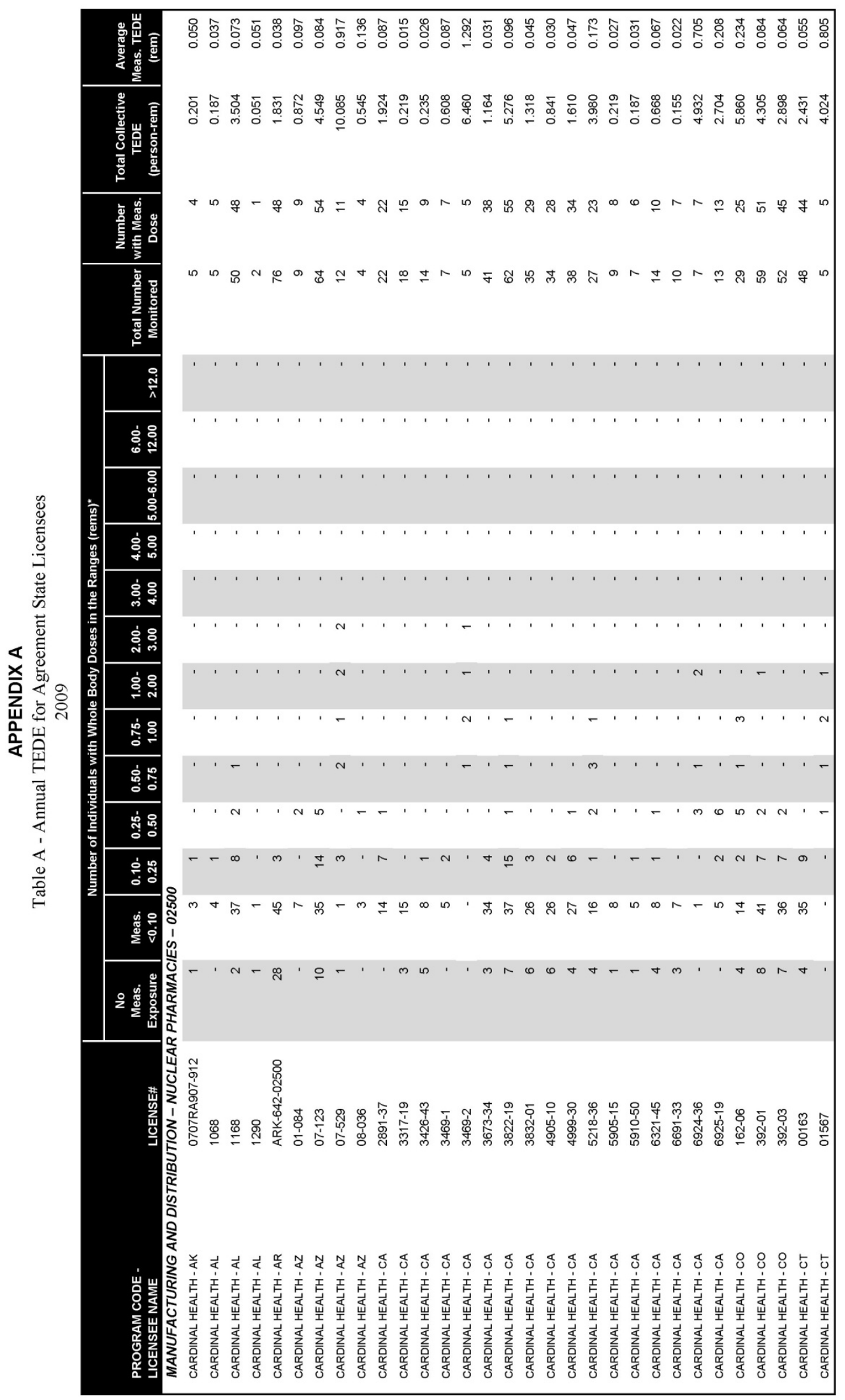




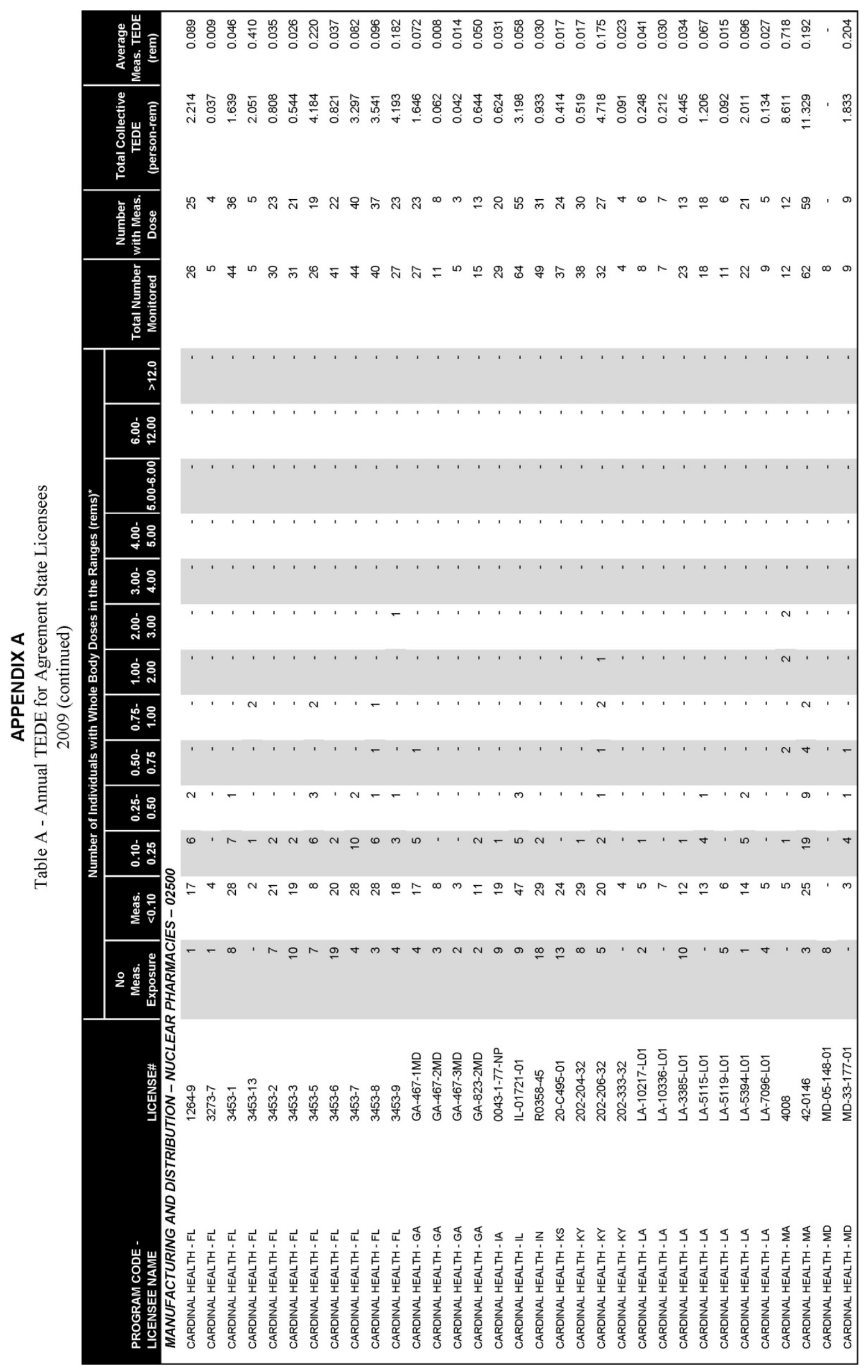




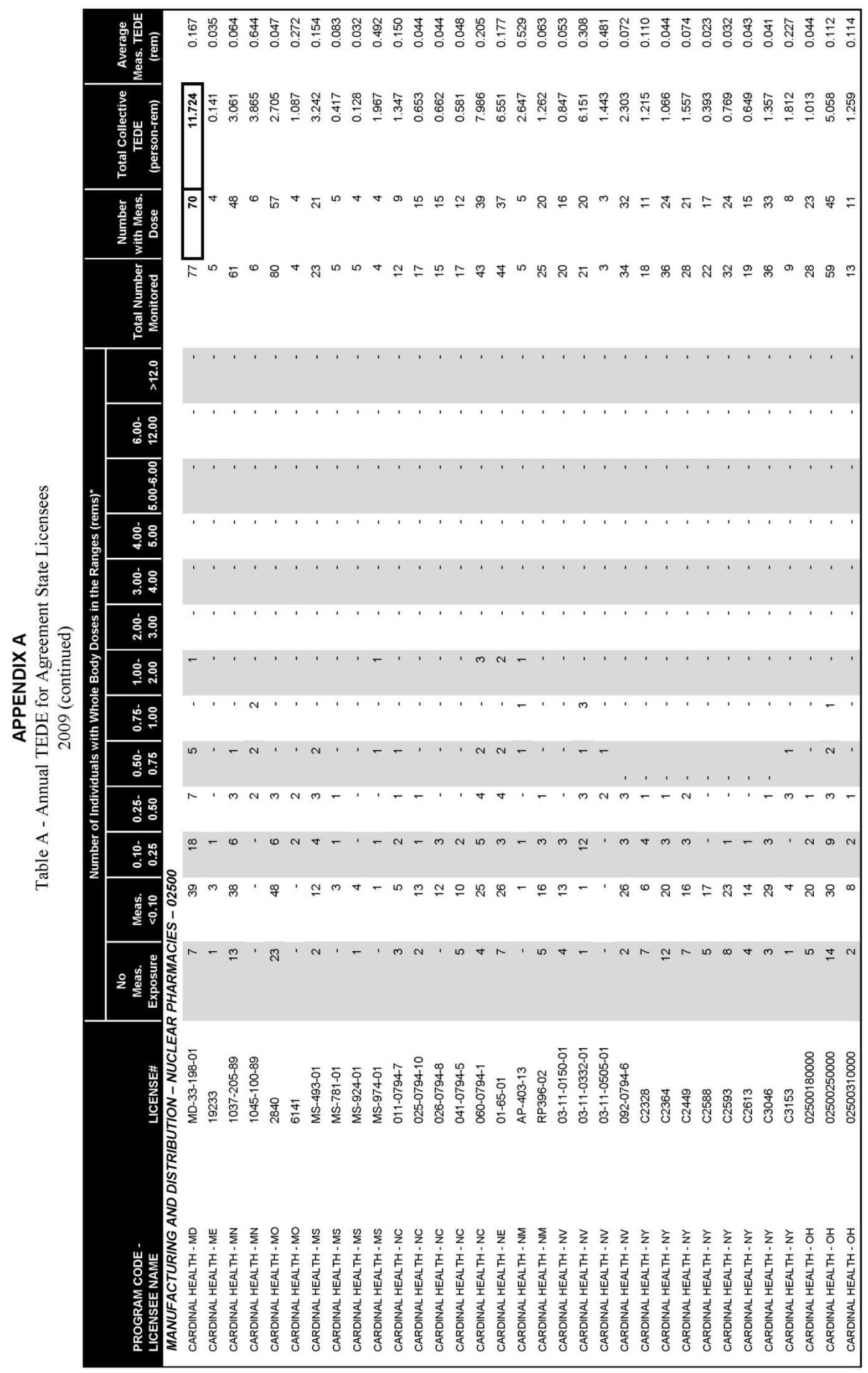




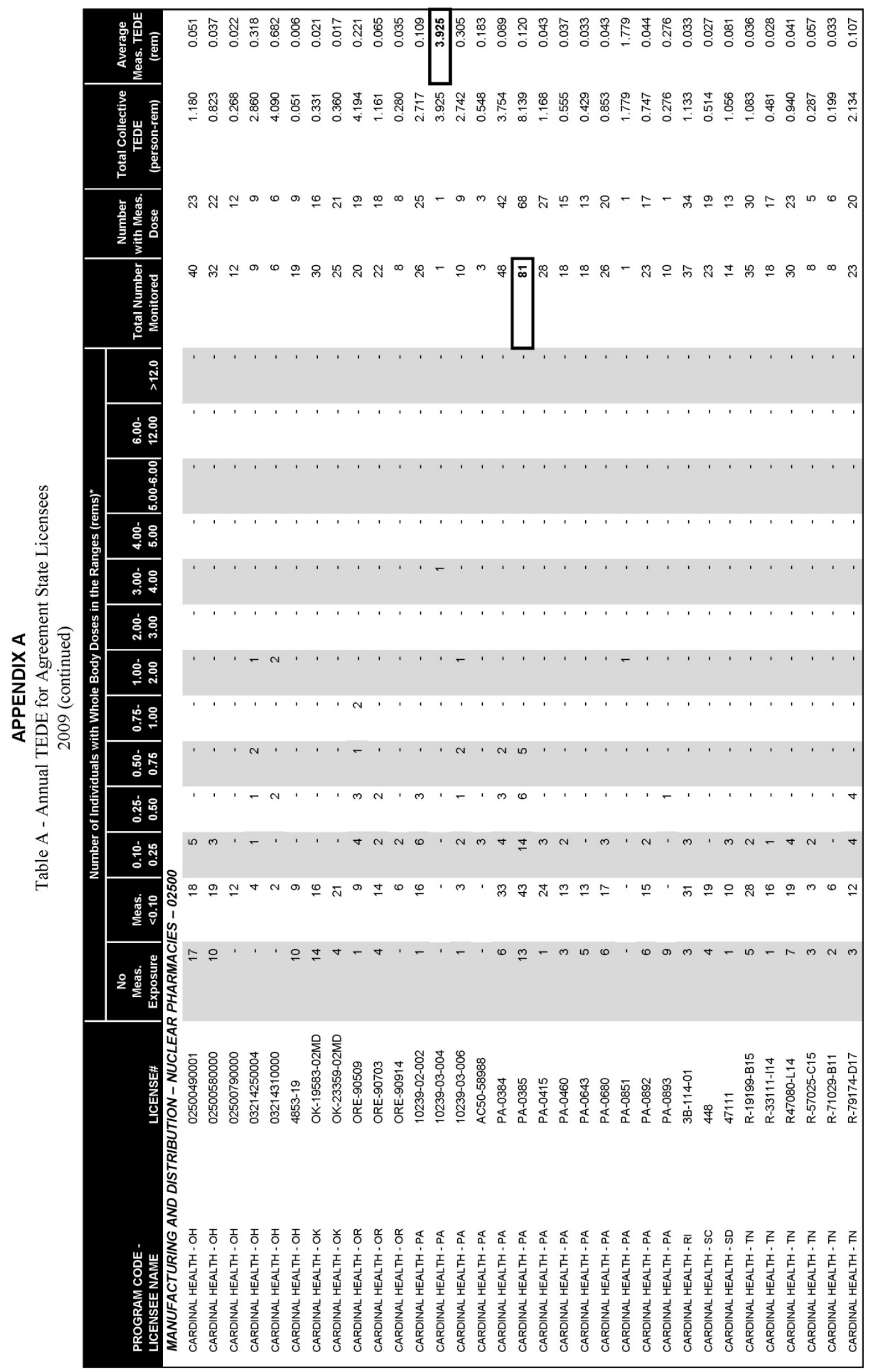




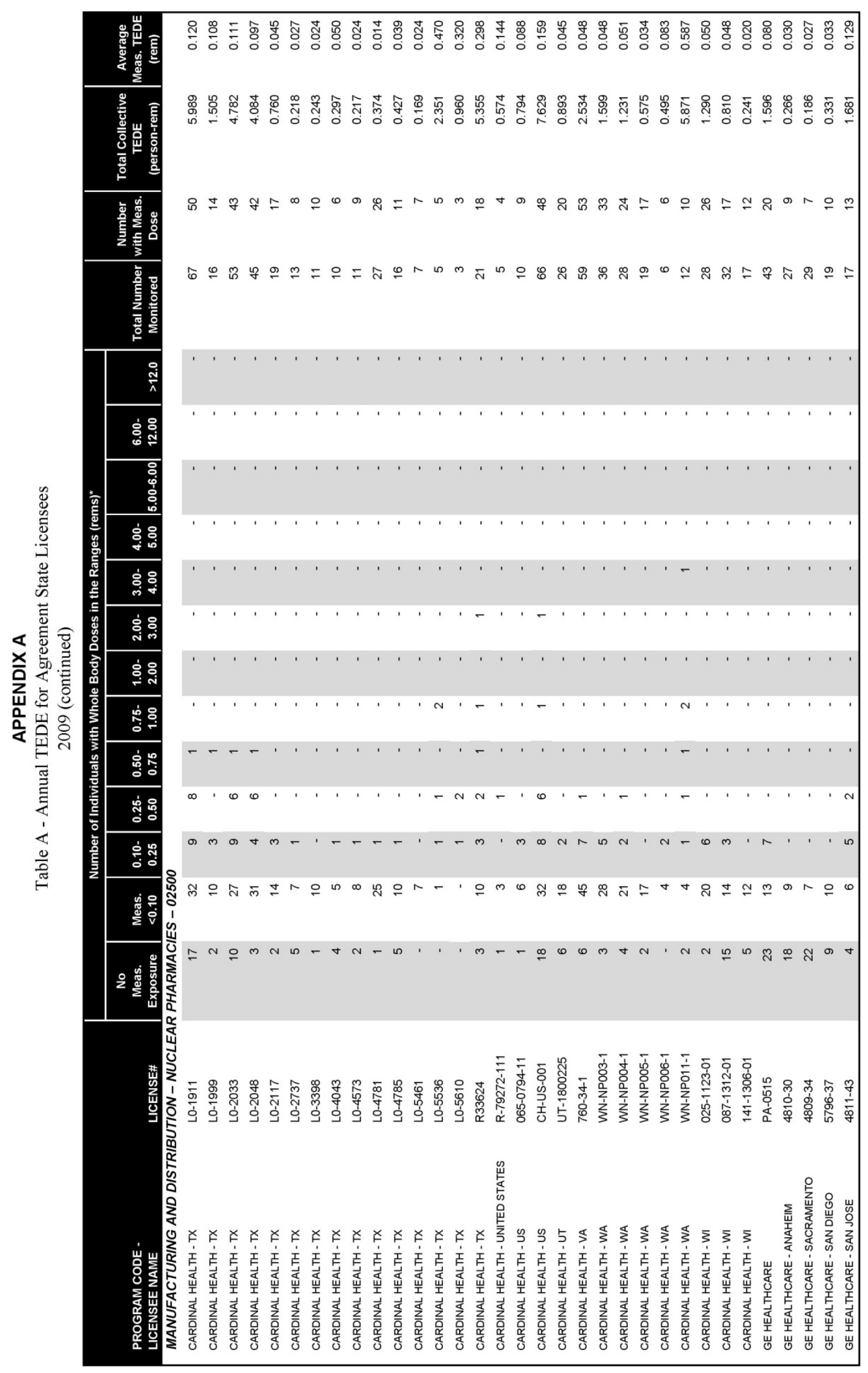




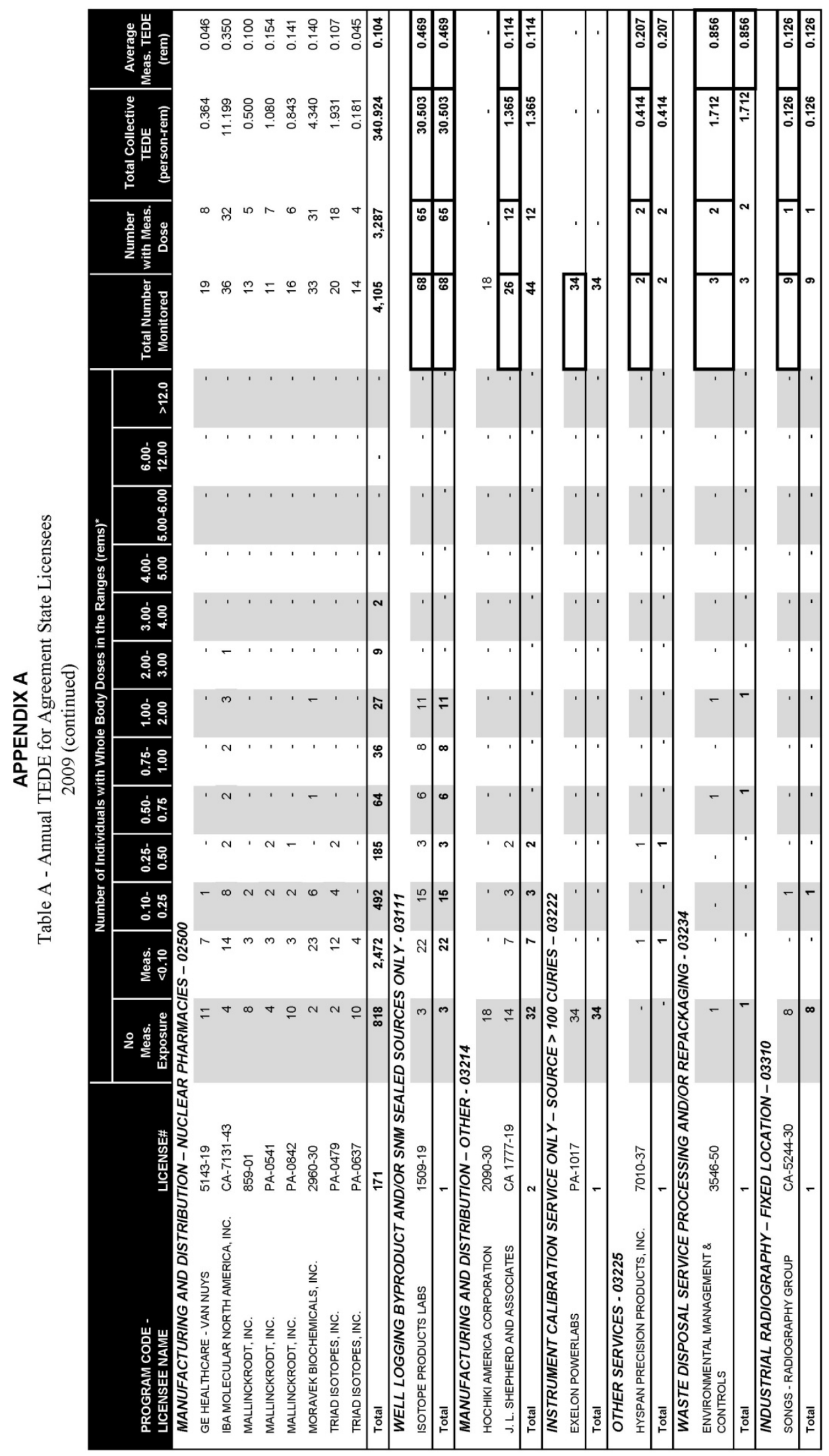




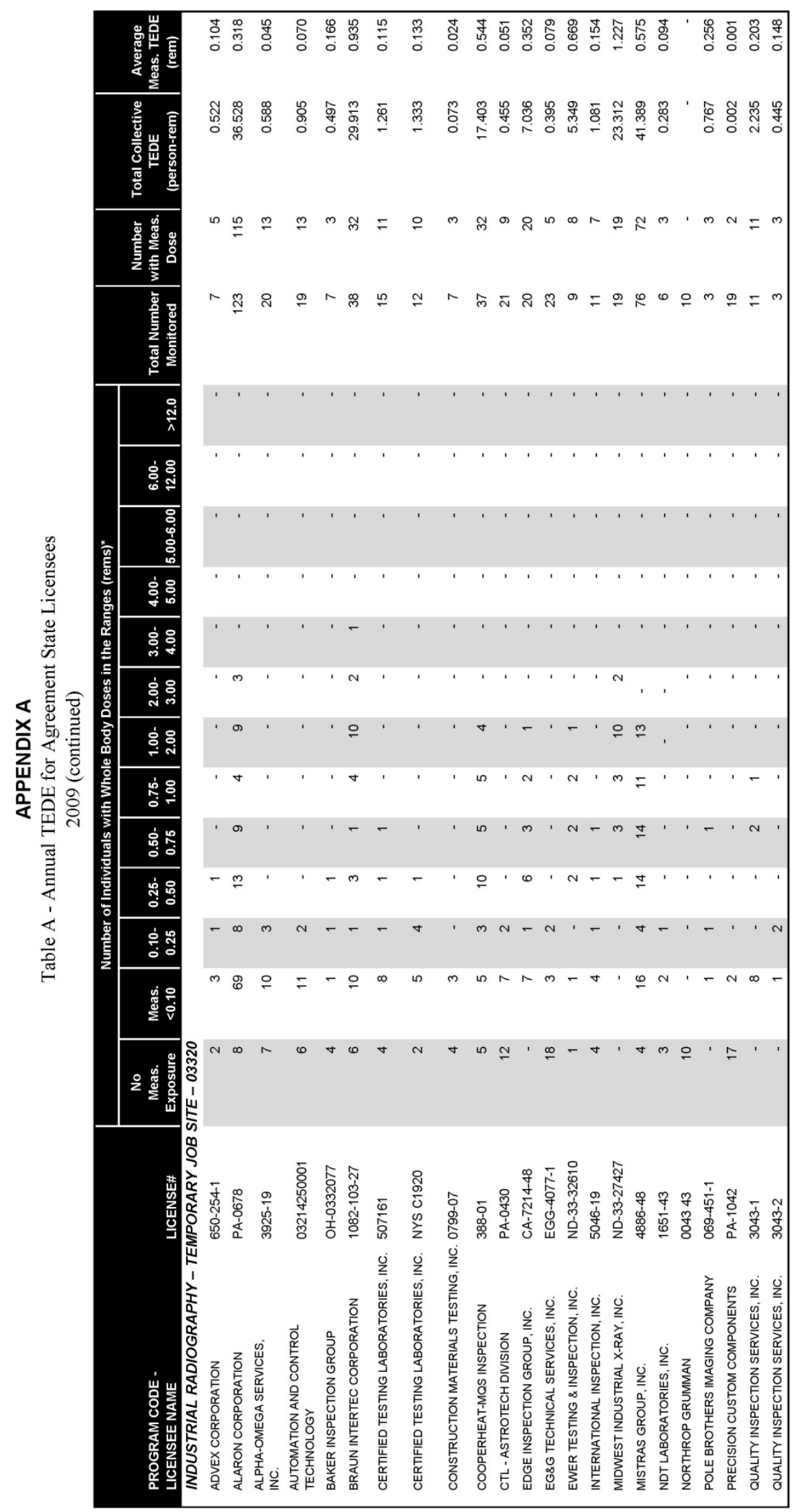




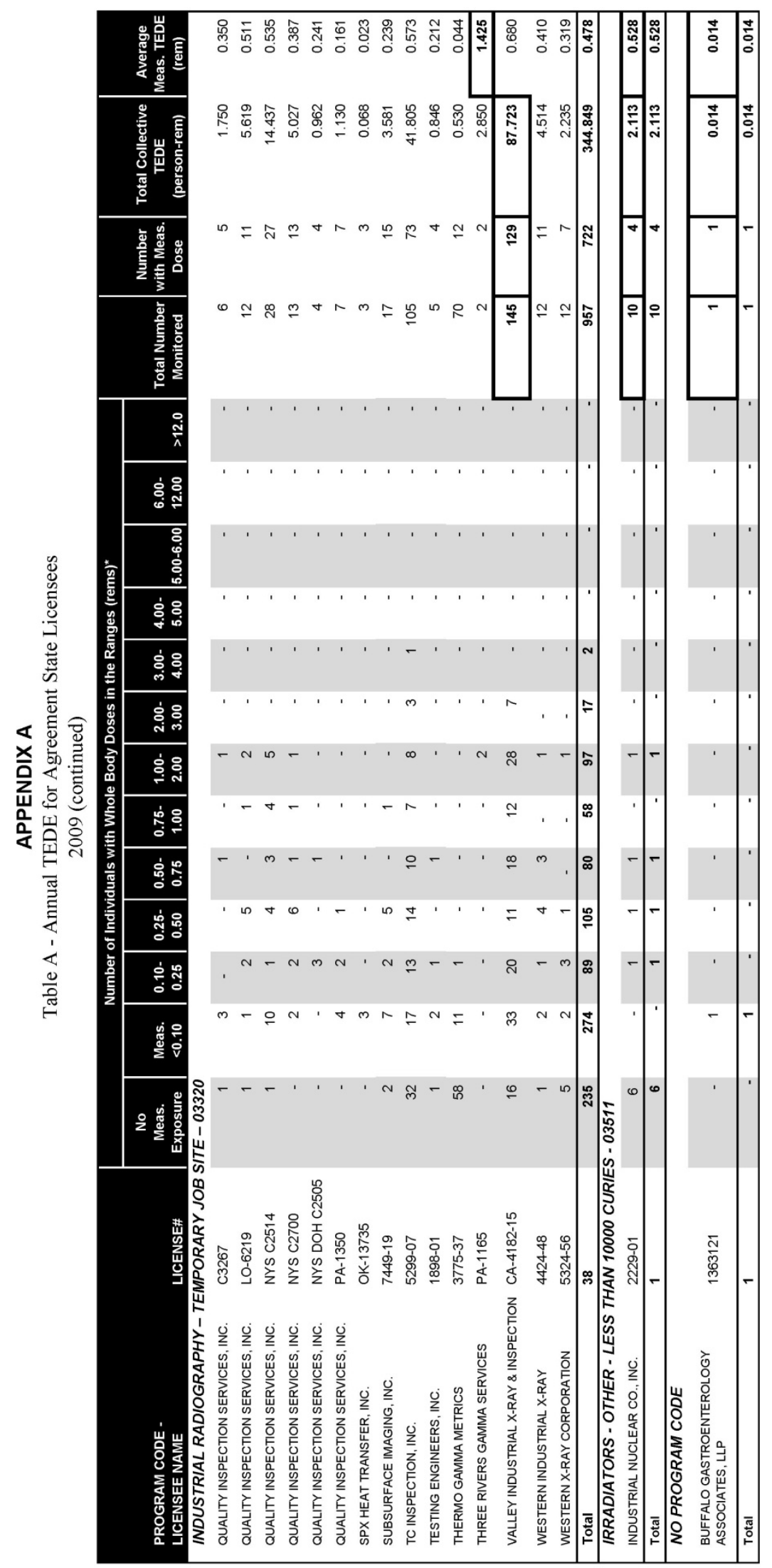




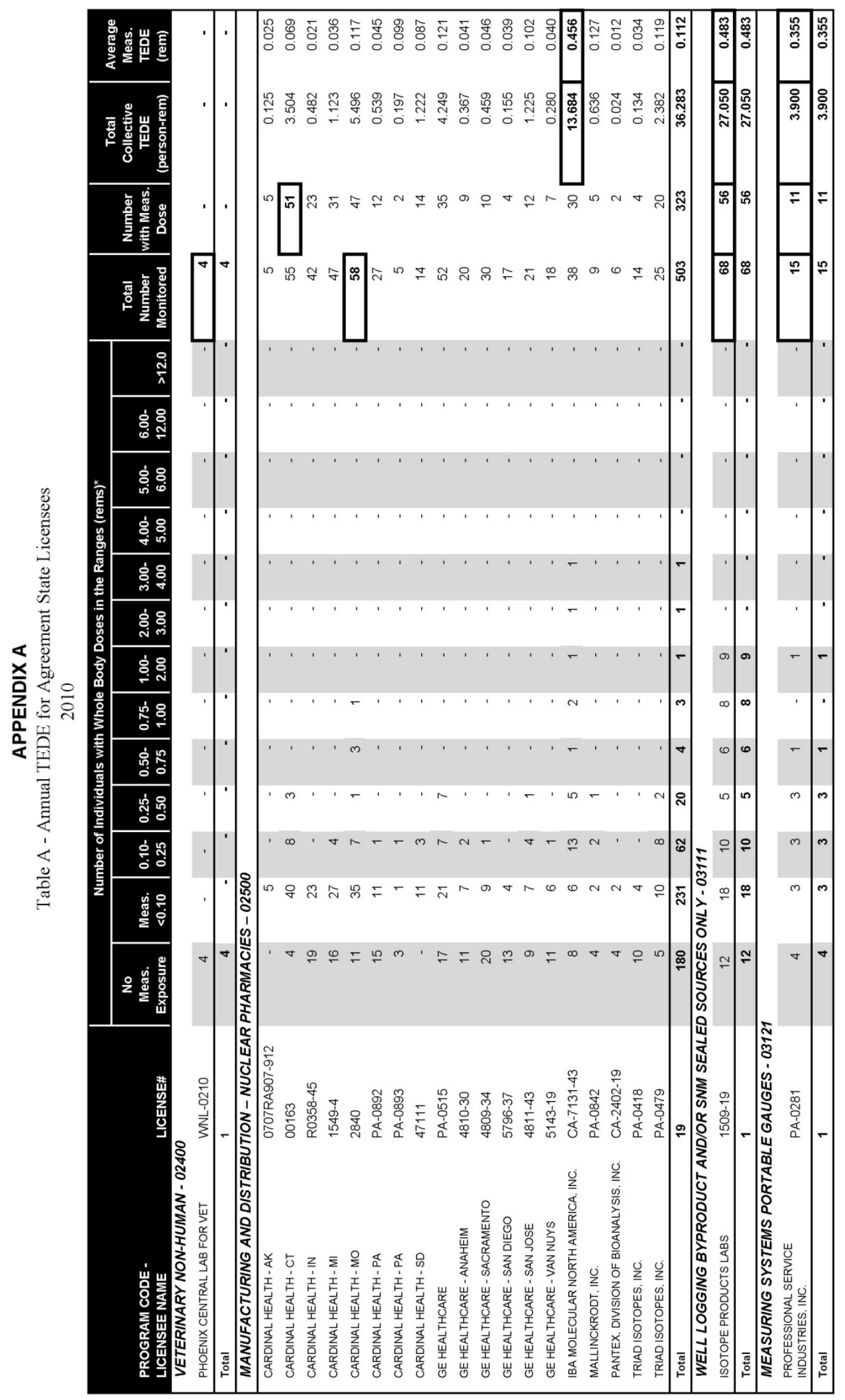




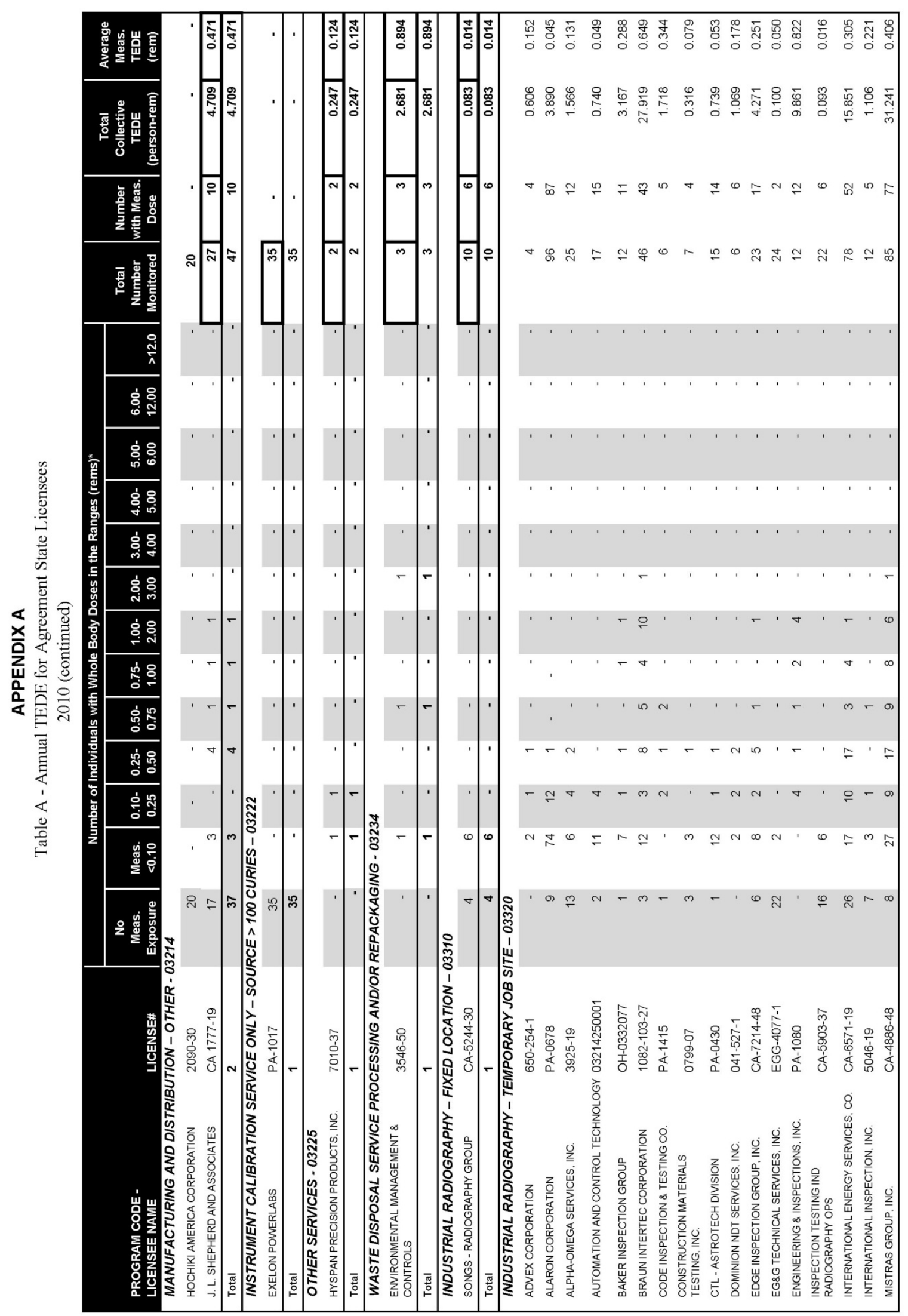




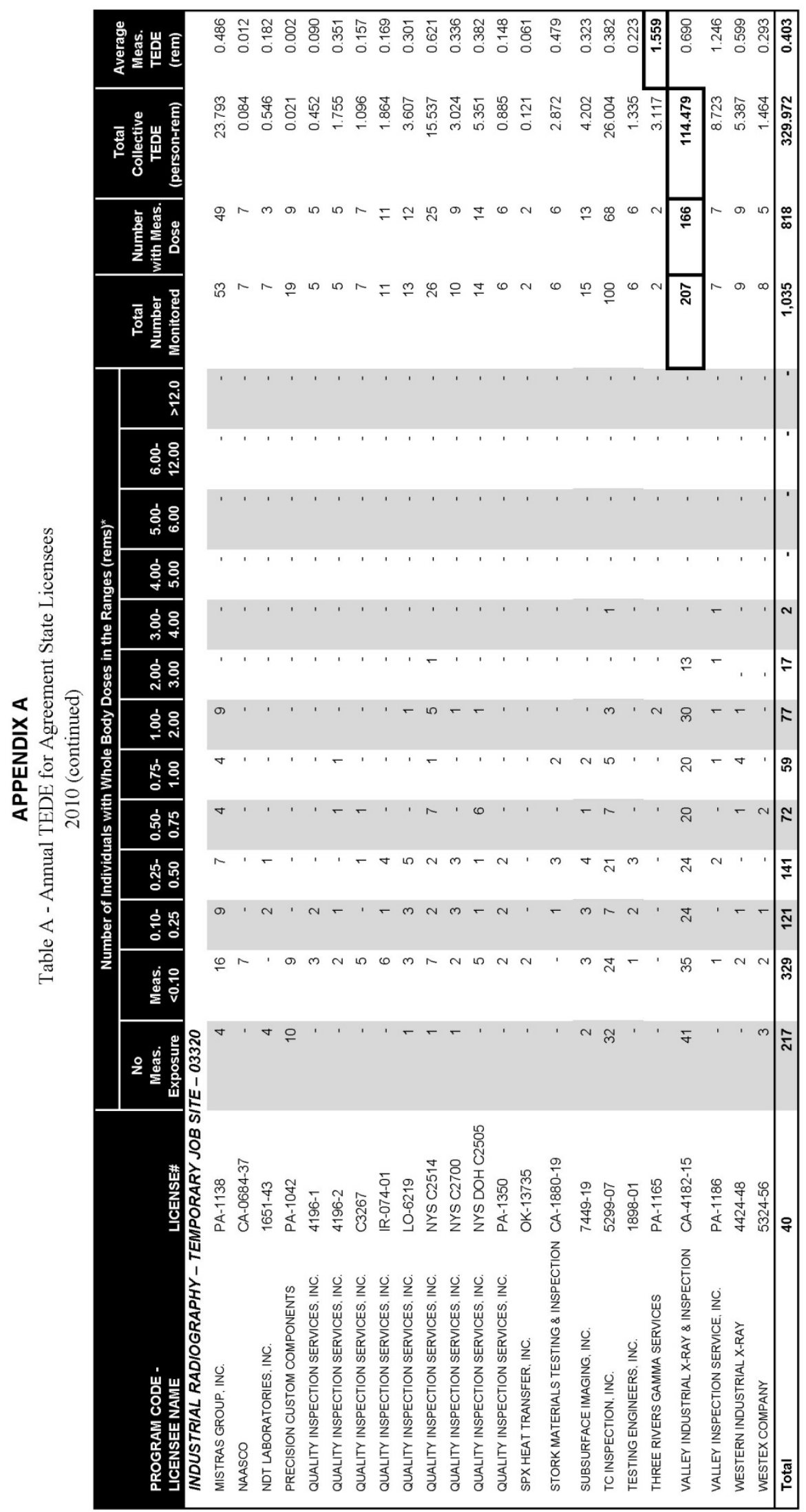

